\title{
Class IV antiarrhythmic agents: new compounds using an old strategy
}

\author{
Norbert Szentandrássy ${ }^{1,2}$, Dénes Nagy², Bence Hegyi², János Magyar ${ }^{2,3}$, Tamás Bányász², Péter P. Nánási ${ }^{1,2}$ \\ ${ }^{1}$ Department of Dental Physiology and Pharmacology, Faculty of Dentistry, University of Debrecen, Hungary \\ ${ }^{2}$ Department of Physiology, Faculty of Medicine, University of Debrecen, Hungary \\ ${ }^{3}$ Division of Sport Physiology, Department of Physiology, Faculty of Medicine, University of Debrecen, Hungary
}

Running title: calcium channel antagonists in antiarrhythmic therapy

\author{
Correspondence: \\ Norbert Szentandrássy, M.D., Ph.D. \\ Department of Physiology, University of Debrecen \\ Nagyerdei krt. 98. H-4012 Debrecen, Hungary \\ Phone: +36-52-255575 \\ FAX: +36-52-255116 \\ E-mail: szentandrassy.norbert@med.unideb.hu
}

\begin{abstract}
Cardiac arrhythmias are a major cause of morbidity and mortality in the industrialized world. Among their treatment regimens one can find the calcium channel antagonists (CCAs), the class IV agents. In the cardiovascular system Land T-type calcium channels are found on vascular smooth muscle cells and cardiac myocytes with well defined physiological roles. Inhibition of calcium channels by CCAs has widely been used in clinical practice for several decades. Cardiovascular disorders are one of the many fields of medicine in which CCAs are used for various reasons and conditions. The three main indications of them are hypertension, angina and various cardiac arrhythmias. The most important classes of CCAs are dihydropyridines, phenylalkylamines and benzothiazepines but some newer compounds do not fall into any of these major classes. Dihydropyridines are not used in the antiarrhythmic therapy but are good vasodilators and antianginal agents. In contrast, phenylalkylamines and benzothiazepines exert cardiac actions in vivo and therefore these are one choice of antiarrhythmic drugs. This review focuses on phenylalkylamines, benzothiazepines and on new drugs with potential antiarrhythmic action in the heart as well as the mechanisms how calcium channels antagonism can lead to an antiarrhythmic action.
\end{abstract}

Keywords: action potential, antiarrhythmic drugs, benzothiazepine, calcium channel, calcium channel antagonist, cardiac arrhythmia, cardiac ion currents, phenylalkylamine

\section{Introduction}

Cardiac arrhythmias are a large group of conditions in which the normal, precisely timed electrical activity of the heart is perturbed. This group includes many, greatly diverse disorders from the reduction of electrical activity in sick sinus syndrome or various forms of bradycardia through the single supraventricular or ventricular extrasystoles to the life-threatening tachyarrhythmias like ventricular fibrillation (VF). The most common form of arrhythmias is atrial fibrillation (AF) which does not usually lead to sudden cardiac death but its complications can be severe [1]. Sudden cardiac death is often a consequence of VF which occurs mostly on the ground of ischemic heart disease [2] and is a major cause of mortality in Europe and the USA [3]. In the management of cardiac arrhythmias pharmacological treatment is used beside electrical interventions as catheter ablation. In the former the arsenal of drugs keeps continuously increasing but according to the probably most commonly used classification they belong to one of the five major groups of the Vaughan Williams classification [4]. Drugs that reduce the ionic current flowing through calcium channels, the calcium channel antagonists (CCAs) fall into class IV of this classification. CCAs are being used in clinical practice for a long time now and not only in cardiovascular disorders. The three main indications of CCAs are hypertension, angina and various cardiac arrhythmias in cardiology. The most important classes of CCAs are dihydropyridines, phenylalkylamines and benzothiazepines but some newer compounds do not fall into any of these major classes.

Calcium channels are found on almost every cell in the human body and classified to various types including L-, N-, P/Q-, R-, and T-types. These channel proteins have several subunits and the $\alpha_{1}$ subunit is the pore forming one among them, whereas others $\left(\alpha_{2}, \beta, \gamma\right.$, and $\left.\delta\right)$ also have well defined roles [5]. In vascular smooth 
muscle cells (SMCs), the L-type channels $\left(\mathrm{Ca}_{\mathrm{v}} 1.2\right)$ whereas in cardiac cells in adulthood, both $\mathrm{L}-\left(\mathrm{Ca}_{\mathrm{v}} 1.2\right.$ and to a lesser extent $\left.\mathrm{Ca}_{\mathrm{v}} 1.3\right)$ and T-types $\left(\mathrm{Ca}_{\mathrm{v}} 3.1\right.$ and $\left.\mathrm{Ca}_{\mathrm{v}} 3.2\right)$ are found; the latter ones present only in nodal tissues with pacemaker activity. Their function is essential in the maintenance of vascular tone and contraction in arterioles, for the impulse generation and propagation in nodal tissues and last but not the least, for contraction of working myocardium [5]. This review focuses on the evidence of antiarrhythmic actions of some CCAs, the potential mechanisms leading to this beneficial effect, the comparison of actions of various CCAs and a structure-activity relationship of the presented CCAs.

\section{Dihydropyridines (a large class of CCAs with no antiarrhythmic activity)}

Dihydropyridines (Fig. 1.) are only mentioned very briefly for the sake of completeness as these are one of the three major classes of organic CCAs. Dihydropyridines are not used in the antiarrhythmic therapy due to their high vascular over cardiac selectivity [6]-[7]. Mechanisms of this vascular selectivity include at least two factors. One is the well known voltage- and use-dependent L-type channel inhibition [10] which taken together with the fact that SMCs are more depolarized compared to myocardium results in a higher inhibition of calcium channels in SMCs. Another mechanism is the different isoform of $\alpha_{1}$ in SMCs and myocardium and the observation that the smooth muscle isoform expressed in $\mathrm{CHO}$ cells is more sensitive to inhibition by neutral dihydropyridines but not by verapamil [9].

Dihydropyridines are good vasodilators and often used in combination with other hypertensive agents [11]. Dihydropyridines are also useful as antianginal agents [12]. The short acting dihydropyridines are more likely to cause sudden vasodilatation than those with longer onset and duration of action and therefore short acting ones more likely evoke stimulation of the sympathetic nerves leading to reflex tachycardia [13], [14]. This action is not beneficial especially in hypertensive patients with angina and ischemia where the further increase in myocardial oxygen requirement should be avoided. 
<smiles>CCOC(=O)C1=C(COCCN)NC(C)=C(C(=O)OC)C1c1ccccc1Cl</smiles>

* Amlodipine<smiles>COC(=O)C1=C(C)NC(C)=C(C(=O)O[C@H]2CCN(Cc3ccccc3)C2)C1c1cccc([N+](=O)[O-])c1</smiles>

Barnidipine

Mepirodipine<smiles></smiles>

Aranidipine<smiles>CC1=C(C(=O)OC(C)C)C(c2cccc([N+](=O)[O-])c2)C(C(=O)OC2CN(C(c3ccccc3)c3ccccc3)C2)=C(N)NC1</smiles>

* Azelnidipine<smiles>COC(=O)C1=C(C)NC(C)=C(C(=O)O[C@H]2CCCN(Cc3ccccc3)C2)C1c1cccc([N+](=O)[O-])c1</smiles>

\section{Benidipine}<smiles>CCCC(=O)OCOC(=O)C1=C(C)NC(C)=C(C(=O)OC)C1c1cccc(Cl)c1Cl</smiles>

Cilnidipine<smiles>CCOC(=O)C1=C(C)NC(C)=C(C(=O)OCC)C1c1cccc2nonc12</smiles>

Darodipine<smiles>CC1=C(C(=O)OCCN(Cc2ccccc2)c2ccccc2)C(c2cccc([N+](=O)[O-])c2)C(P2(=O)OCC(C)(C)CO2)=C(C)N1</smiles>

Efonidipine NZ-105<smiles>CCOC(=O)C1=C(C)NC(C)=C(C(=O)OC)C1c1cccc(Cl)c1Cl</smiles>

* Felodipine<smiles>COC(=O)C1=C(C)NC(C)=C(C(=O)OC(C)C)C1c1cccc2nonc12</smiles>

* Isradipine PN 200-110<smiles>CCOC(=O)C1=C(C)NC(C)=C(C(=O)OCC)C1c1ccccc1CCC(=O)OC(C)(C)C</smiles>

Lacidipine<smiles>COC(=O)C1=C(C)NC(C)=C(C(=O)OC(C)(C)CN(C)CCC(c2ccccc2)c2ccccc2)C1c1cccc([N+](=O)[O-])c1</smiles>

* Lercanidipine 


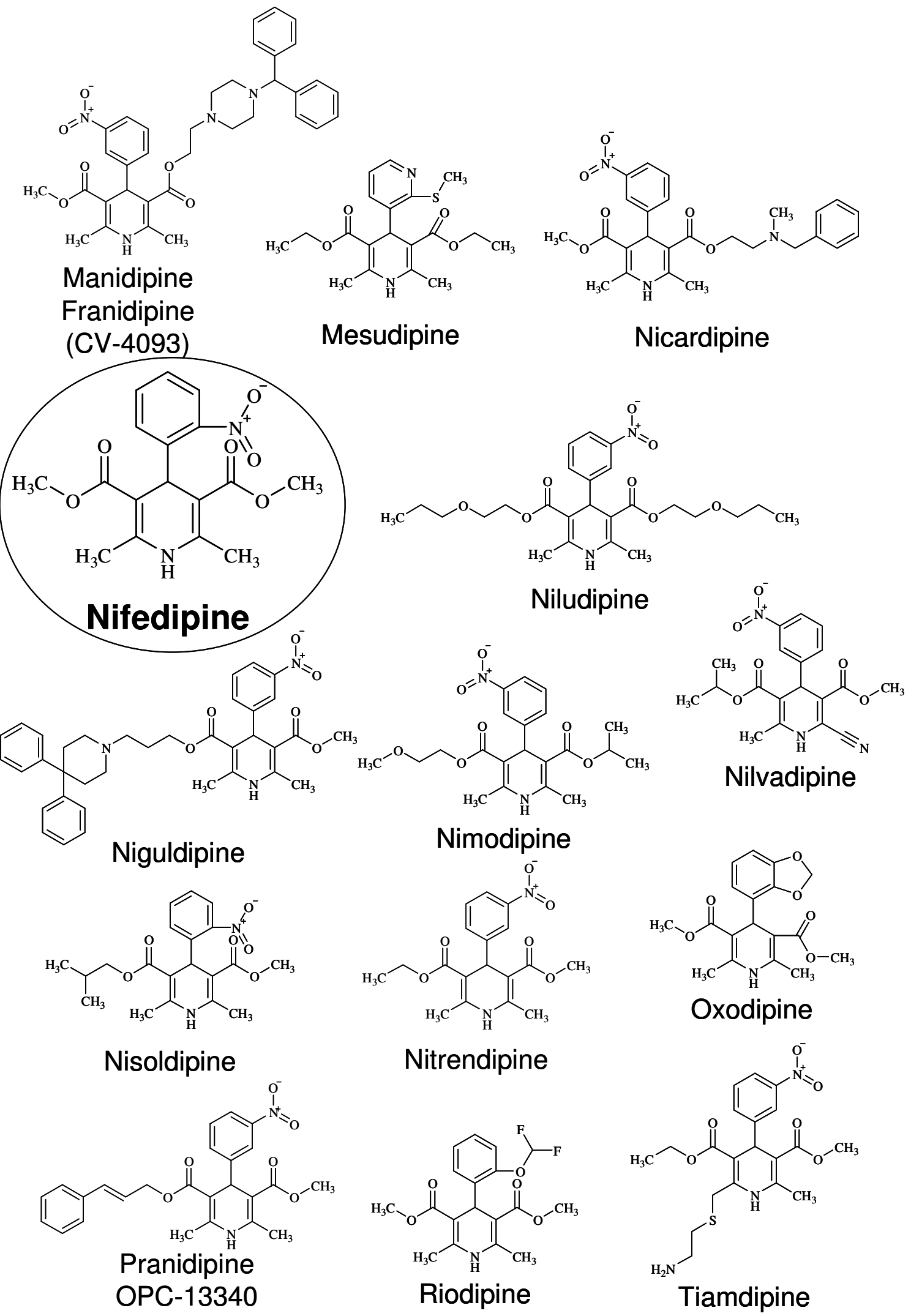

FIG. 1. Chemical structure of dihydropyridines. The first and best known one is the circled nifedipine. Those compounds marked with asterisks are the long acting ones. 


\section{The calcium channel inhibitory actions of some CCAs}

\subsection{Actions on the L-type calcium channels}

CCAs usually exert a use-dependent inhibition on L-type $\mathrm{Ca}^{2+}$ channels $\left(\mathrm{I}_{\mathrm{Ca}, \mathrm{L}}\right)$ as it was described with verapamil in rat ventricular myocytes [15]. Similar observation was made with D600 (gallopamil) in rabbit and feline ventricular muscle [16], with tiapamil (RO 11-1781) in guinea-pig urinary bladder SMCs [17] and with diltiazem in human atrial and ventricular myocardium [18] as well as in rat aorta SMCs [19]. Not only use-, but voltagedependent inhibition was observed with tiapamil in guinea-pig urinary bladder SMCs [17] and diltiazem in human atrial and ventricular myocardium [18]. It was suggested that verapamil blocked more effectively the inactivated channels [15] and also that it preferentially acted on the open state of the channels [19] similarly to diltiazem. The effectivity of phenylalkylamine and benzothiazepine type CCAs on L-type calcium current $\left(\mathrm{I}_{\mathrm{Ca}, \mathrm{L}}\right)$ is compared in Tables 1 and 2.

TABLE 1. The half-inhibitory concentrations $\left(\mathrm{IC}_{50}\right)$ of phenylalkylamine CCAs (Fig. 2.) on $\mathrm{I}_{\mathrm{Ca}, \mathrm{L}}$.

\begin{tabular}{|c|c|c|c|c|}
\hline DRUG & $\mathrm{IC}_{50}$ value & Holding potential & Species/preparation & Reference \\
\hline \multirow[t]{4}{*}{ Verapamil } & less than $100 \mathrm{nM}$ & $-40 \mathrm{mV}$ & $\begin{array}{l}\text { guinea-pig/ventricular } \\
\text { myocytes }\end{array}$ & [20] \\
\hline & $246 \mathrm{nM}$ & $-50 \mathrm{mV}$ & rat/ventricular myocytes & [21] \\
\hline & $900 \mathrm{nM}$ & $\begin{array}{l}-80 \mathrm{mV} \text {, followed } \\
\text { by a } 20 \mathrm{~ms} \text { long } \\
-40 \mathrm{mV} \text { prepulse }\end{array}$ & rat/ventricular myocytes & [15] \\
\hline & $600 \mathrm{nM}$ & $-60 \mathrm{mV}$ & rat/aorta SMCs & [19] \\
\hline \multirow[t]{3}{*}{ D600 (gallopamil) } & $1 \mu \mathrm{M}$ & $-40 \mathrm{mV}$ & guinea-pig/ventricular cells & [20] \\
\hline & less than $1 \mu \mathrm{M}$ & $-60 \mathrm{mV}$ & frog/atrial cells & [22] \\
\hline & less than $1 \mu \mathrm{M}$ & $-60 \mathrm{mV}$ & cat/ventricular muscle & [23] \\
\hline $\begin{array}{l}\text { Tiapamil } \\
(\text { RO 11-1781) }\end{array}$ & $\begin{array}{ll}\text { around } & 1 \text { and } \\
20 \mu \mathrm{M} & \end{array}$ & -45 and $-65 \mathrm{mV}$ & $\begin{array}{l}\text { guinea-pig/urinary bladder } \\
\text { SMCs }\end{array}$ & [17] \\
\hline
\end{tabular}


TABLE 2. Benzothiazepine CCA (Fig. 3.) effects on $\mathrm{I}_{\mathrm{Ca}, \mathrm{L}}$ and contractions.

\begin{tabular}{|c|c|c|c|}
\hline DRUG & $\begin{array}{c}\mathrm{IC}_{50} \text { value or percentage reduction / } \\
\text { holding potential }\end{array}$ & Species/preparation & Reference \\
\hline \multirow[t]{12}{*}{ Diltiazem } & $512 \mathrm{nM}$ in reduction of $\mathrm{I}_{\mathrm{Ca}, \mathrm{L}} /-50 \mathrm{mV}$ & rat/ventricular myocytes & [21] \\
\hline & $630 \mathrm{nM}$ in reduction of $\mathrm{I}_{\mathrm{Ca}, \mathrm{L}} /-50 \mathrm{mV}$ & guinea-pig/ventricular cells & [24] \\
\hline & $500 \mathrm{nM}$ in reduction of $\mathrm{I}_{\mathrm{Ca}, \mathrm{L}} /-40 \mathrm{mV}$ & $\begin{array}{l}\text { ferret/right ventricular } \\
\text { papillary muscles }\end{array}$ & [25] \\
\hline & $3 \mu \mathrm{M}$ in reduction of $\mathrm{I}_{\mathrm{Ca}, \mathrm{L}} /-60 \mathrm{mV}$ & rat/aorta SMCs & [19] \\
\hline & $300 \mu \mathrm{M}$ in reduction of $\mathrm{I}_{\mathrm{Ba}} /-60 \mathrm{mV}$ & rabbit/mesenteric artery SMCs & [26] \\
\hline & $694 \mathrm{nM}$ in reduction of tension & human/coronary artery & [27] \\
\hline & $277 \mathrm{nM}$ in reduction of tension & rabbit/aorta & [28] \\
\hline & $\begin{array}{l}25 \% \text { reduction of contractile force by } \\
10 \mu \mathrm{M}\end{array}$ & rabbit/atrial muscle & [29] \\
\hline & $\begin{array}{l}25 \% \text { reduction of calcium-evoked } \\
\text { contraction by } 1 \mu \mathrm{M}\end{array}$ & sheep/cerebral artery & [29] \\
\hline & $\begin{array}{l}25 \% \text { reduction of calcium-evoked } \\
\text { contraction by } 80 \mathrm{nM}\end{array}$ & $\begin{array}{l}\text { sheep/depolarized coronary } \\
\text { artery ring }\end{array}$ & [30] \\
\hline & $\begin{array}{l}120 \mathrm{nM} \text { on reduction of potassium-induced } \\
\text { contraction }\end{array}$ & rat/thoracic aorta & [31] \\
\hline & $\begin{array}{l}\text { over } 10 \mu \mathrm{M} \text { on vasodilatation of } \\
\text { phenylephrine precontracted vessels }\end{array}$ & rat/thoracic aorta & {$[31]$} \\
\hline \multirow{3}{*}{$\begin{array}{l}\text { Clentiazem } \\
\text { (TA-3090) }\end{array}$} & $30 \mu \mathrm{M}$ in reduction of $\mathrm{I}_{\mathrm{Ba}} /-60 \mathrm{mV}$ & rabbit/mesenteric artery SMCs & [26] \\
\hline & $221 \mathrm{nM}$ in reduction of tension & human/coronary artery & [27] \\
\hline & $61 \mathrm{nM}$ in reduction of tension & rabbit/aorta & {$[28]$} \\
\hline \multirow[t]{3}{*}{$\begin{array}{l}\text { Siratiazem } \\
\text { (LR-A113) }\end{array}$} & $\begin{array}{l}25 \% \text { reduction of contractile force by } \\
10 \mu \mathrm{M}\end{array}$ & rabbit/atrial muscle & [29] \\
\hline & $\begin{array}{l}25 \% \text { reduction of calcium-evoked } \\
\text { contraction by } 1 \mu \mathrm{M}\end{array}$ & sheep/cerebral artery & [29] \\
\hline & $\begin{array}{l}25 \% \text { reduction of calcium-evoked } \\
\text { contraction by } 130 \mathrm{nM}\end{array}$ & $\begin{array}{l}\text { sheep/depolarized coronary } \\
\text { artery ring }\end{array}$ & [30] \\
\hline \multirow[t]{2}{*}{ S-2150 } & $\begin{array}{l}190 \mathrm{nM} \text { on reduction of potassium-induced } \\
\text { contraction }\end{array}$ & rat/thoracic aorta & [31] \\
\hline & $\begin{array}{l}29 \mathrm{nM} \text { on vasodilatation of phenylephrine } \\
\text { precontracted vessels }\end{array}$ & rat/thoracic aorta & [31] \\
\hline
\end{tabular}

Molecules with structures different from both phenylalkylamines and benzothiazepines (and also from dihydropyridines) can also inhibit $\mathrm{I}_{\mathrm{Ca}, \mathrm{L}}$. Some of these (Fig. 4.) can show some structural similarity to one (or more) of the major groups of CCAs but some are completely different without any sign of structural similarity (Fig. 5.). The $\mathrm{IC}_{50}$ values of these substances are summarized in Table 3. On top of the concentration-dependent inhibition of $\mathrm{I}_{\mathrm{Ca}, \mathrm{L}}$ many of these drugs had additional effects on the kinetics of $\mathrm{I}_{\mathrm{Ca}, \mathrm{L}}$.

Semotiadil shifted the voltage-dependent inactivation curve to the left and accelerated the decay of the current in concentrations higher than $1 \mu \mathrm{M}$. At $1 \mu \mathrm{M}$ it also slowed the recovery from inactivation. Long-lasting inhibition of $\mathrm{I}_{\mathrm{Ca}, \mathrm{L}}$ after removal of semotiadil may be due to tight binding of semotiadil on the channel through a hydrophobic site [32]. Levosemotiadil also shifted the steady-state inactivation curve to more negative potentials [33] just as it was observed with fantofarone [34] as well as with bepridil [35]. Fantofarone blocked $\mathrm{I}_{\mathrm{Ca}, \mathrm{L}}$ in a voltage-dependent manner in rat ventricular myocytes, and evoked both tonic and use-dependent blockade of $\mathrm{I}_{\mathrm{Ca}, \mathrm{L}}$ [34]. The voltagedependent inhibition of $\mathrm{I}_{\mathrm{Ca}, \mathrm{L}}$ was detected with SR33805 [36] and bepridil [37]. Inhibition of $\mathrm{I}_{\mathrm{Ca}, \mathrm{L}}$ by $5 \mu \mathrm{M}$ AH-1058 had both tonic ( $25 \%$ reduction) and use-dependent component (further $60 \%$ reduction) [38]. Bepridil slowed the recovery from inactivation of $\mathrm{I}_{\mathrm{Ca}, \mathrm{L}}[35]$. 
TABLE 3. The inhibitory potency of other CCAs (Fig. 4 and 5.) on $\mathrm{I}_{\mathrm{Ca}, \mathrm{L}}$.

\begin{tabular}{|c|c|c|c|}
\hline DRUG & $\begin{array}{l}\mathrm{IC}_{50} \text { value / holding } \\
\text { potential }\end{array}$ & Species/preparation & Reference \\
\hline \multirow[t]{2}{*}{ Semotiadil (SD-3211) } & $\begin{array}{l}\text { between } 10 \text { and } 100 \mu \mathrm{M} / \\
-80 \mathrm{mV} \text { followed by a } 50 \\
\mathrm{~ms} \text { long }-40 \mathrm{mV} \text { prepulse }\end{array}$ & guinea-pig/ventricular cells & [39] \\
\hline & $\begin{array}{l}84,900 \text { and } 2000 \mathrm{nM} / \\
-60,-80 \text { and }-100 \mathrm{mV}\end{array}$ & rabbit/portal vein SMCs & [32] \\
\hline Levosemotiadil (SD-3212) & $1.3 \mu \mathrm{M} /-40 \mathrm{mV}$ & guinea-pig/atrial cells & [33] \\
\hline \multirow[t]{2}{*}{ Fantofarone (SR 33557) } & $\begin{array}{l}22 \mathrm{nM} \text { and } 9 \mu \mathrm{M} / \\
-50 \text { and }-80 \mathrm{mV}\end{array}$ & rat/ventricular myocytes & [34] \\
\hline & $\begin{array}{l}1.4 \text { and } 150 \mathrm{nM} / \\
-40 \text { and }-80 \mathrm{mV}\end{array}$ & $\begin{array}{l}\text { mouse/cardiac cells in primary } \\
\text { culture }\end{array}$ & [36] \\
\hline \multirow[t]{2}{*}{ SR 33805} & $\begin{array}{l}4.1 \text { and } 33 \mathrm{nM} / \\
-40 \text { and }-80 \mathrm{mV} \\
\end{array}$ & $\begin{array}{l}\text { mouse/cardiac cells in primary } \\
\text { culture }\end{array}$ & [36] \\
\hline & $24 \mathrm{nM} /-80 \mathrm{mV}$ & rat/ventricular myocytes & [40] \\
\hline BRL-32872 & $2.8 \mu \mathrm{M} /-50 \mathrm{mV}$ & guinea-pig/ventricular cells & [41] \\
\hline KT-362 & $\begin{array}{l}28.6 \% \text { reduction in } 7 \mu \mathrm{M} / \\
-40 \mathrm{mV}\end{array}$ & dog/Purkinje cells & [42] \\
\hline Monatepil (AJ-2615) & $18.7 \mathrm{nM} /-40 \mathrm{mV}$ & guinea-pig/ventricular cells & [43] \\
\hline \multirow[t]{3}{*}{ Bepridil } & $\begin{array}{l}2.6 \mu \mathrm{M} /-70 \mathrm{mV} \text { followed } \\
\text { by a }-40 \mathrm{mV} \text { prepulse }\end{array}$ & guinea-pig/ventricular cells & [44] \\
\hline & $0.5 \mu \mathrm{M} /-50 \mathrm{mV}$ & guinea-pig/ventricular cells & [35] \\
\hline & $1.55 \mu \mathrm{M} /-40 \mathrm{mV}$ & guinea-pig/atrial cells & [33] \\
\hline AH-1058 & $\begin{array}{l}0.32 \text { and } 4.91 \mu \mathrm{M} / \\
-40 \text { and }-80 \mathrm{mV}\end{array}$ & guinea-pig/ventricular cells & [45] \\
\hline
\end{tabular}

\subsection{T-type calcium channel inhibition of CCAs}

Mibefradil (Fig. 5.) is usually regarded as a selective inhibitor of the T-type calcium channels $\left(\mathrm{I}_{\mathrm{Ca}, \mathrm{T}}\right)$. Later it turned out that it is not entirely specific as $\mathrm{I}_{\mathrm{Ca}, \mathrm{L}}$ is also reduced by mibefradil. Martin et al. review the literature and list these actions of the drug. Usually the inhibitory effect of mibefradil on native $\mathrm{I}_{\mathrm{Ca}, \mathrm{T}}$ is more potent compared to that on native $\mathrm{I}_{\mathrm{Ca}, \mathrm{L}}$ by 13-70, 17 and 3 times in vascular smooth muscle, atrial myocytes and human myoblasts, respectively [46]. Mibefradil blocked 2-3 times more potently $\mathrm{I}_{\mathrm{Ca}, \mathrm{T}}$ compared to that of $\mathrm{I}_{\mathrm{Ca}, \mathrm{L}}$ in guinea-pig ventricular myocytes [47]-[49] but 30 times more potently in rat ventricular cells [50]. In contrast, in rabbit sinoatrial (SA) node cells $1 \mu \mathrm{M}$ mibefradil reduced $\mathrm{I}_{\mathrm{Ca}, \mathrm{T}}$ less than $\mathrm{I}_{\mathrm{Ca}, \mathrm{L}}$ (by 55 and $64 \%$, respectively) [51]. Regarding the mibefradil inhibition of $\mathrm{I}_{\mathrm{Ca}, \mathrm{T}}$ and $\mathrm{I}_{\mathrm{Ca}, \mathrm{L}}$ some found that only the latter one was blocked strongly in a voltage- and use-dependent manner [49]. In contrast, in rat ventricular cells both $\mathrm{I}_{\mathrm{Ca}, \mathrm{T}}$ and $\mathrm{I}_{\mathrm{Ca}, \mathrm{L}}$ was reduced by mibefradil in a voltage- and usedependent manner [50]. In canine Purkinje fibers mibefradil blocked calcium currents and in the presence of $1 \mu \mathrm{M}$ mibefradil the T/L current ratio was reduced. The steady-state activation half-potentials were shifted to the left by 40 and $10 \mathrm{mV}$ for $\mathrm{I}_{\mathrm{Ca}, \mathrm{L}}$ and $\mathrm{I}_{\mathrm{Ca}, \mathrm{T}}$, respectively [52]. Compared to other CCAs, mibefradil was less potent than verapamil in inhibiting calcium current in isolated guinea-pig myocytes [53]. The inhibitory action of mibefradil on $\mathrm{I}_{\mathrm{Ca}, \mathrm{T}}$ was approximately twice more potent compared to that of $\mathrm{I}_{\mathrm{Ca}, \mathrm{L}}[47]$.

Not only mibefradil blocks $\mathrm{I}_{\mathrm{Ca}, \mathrm{L}}$ in addition to $\mathrm{I}_{\mathrm{Ca}, \mathrm{T}}$ but other CCAs also reduce $\mathrm{I}_{\mathrm{Ca}, \mathrm{T}}$ on top of the $\mathrm{I}_{\mathrm{Ca}, \mathrm{L}}$. Verapamil block of $\mathrm{I}_{\mathrm{Ca}, \mathrm{T}}$ was observed in guinea-pig ventricular cells (10\% reduction by $1 \mu \mathrm{M}$, same extent as in $\mathrm{I}_{\mathrm{Ca}, \mathrm{L}}$ ) [47] and in rat aorta SMCs $\left(\mathrm{IC}_{50}\right.$ of $\left.30 \mu \mathrm{M}\right)$ which showed no use-dependence [19]. In contrast, stably expressed human $\mathrm{Ca}_{\mathrm{v}} 3.1 \mathrm{~T}$-type channels in human embryonic kidney (HEK) cells were blocked by verapamil in a use- and voltagedependent manner with an $\mathrm{IC}_{50}$ of $21.4 \mu \mathrm{M}$ and the drug significantly slowed the recovery from inactivation. It was suggested that verapamil achieves its inhibitory effect via occlusion of the channel pore associated with an open/inactivated conformation of the channel [54].

$10 \mu \mathrm{M}$ diltiazem (which reduced $\mathrm{I}_{\mathrm{Ca}, \mathrm{L}}$ by $18 \%$ ) had no action on T-type calcium channels in guinea-pig ventricular myocytes [47] but in rat aorta SMCs it reduced $\mathrm{I}_{\mathrm{Ca}, \mathrm{T}}$ with an $\mathrm{IC}_{50}$ of $30 \mu \mathrm{M}$, ten times less potently than $\mathrm{I}_{\mathrm{Ca}, \mathrm{L}}$. Diltiazem, similarly to verapamil, preferentially acted on the open state of the L-type calcium channel and on the resting and inactivated states of the T-type calcium channel [19]. 
Bepridil reduced $\mathrm{I}_{\mathrm{Ca}, \mathrm{T}}$ in a voltage-independent manner in guinea-pig atrial myocytes; therefore at normal diastolic potentials $(\sim-90 \mathrm{mV})$ it actually reduced $\mathrm{I}_{\mathrm{Ca}, \mathrm{T}}$ more potently than $\mathrm{I}_{\mathrm{Ca}, \mathrm{L}}$ [37]. In contrast, block of $\mathrm{Ca}_{\mathrm{v}} 3.2$ channels (underlying $\mathrm{I}_{\mathrm{Ca}, \mathrm{T}}$ ) in $\mathrm{HEK}$ cells was voltage-dependent but frequency-independent. $\mathrm{IC}_{50}$ yielded $0.4 \mu \mathrm{M}$ at $-70 \mathrm{mV}$ holding potential (26 times lower than at $-100 \mathrm{mV})$. Bepridil $(10 \mu \mathrm{M})$ shifted both steady-state activation and inactivation to more negative potentials but did not affect the recovery kinetics [55].

Within the reviewed CCAs there are some without major inhibitory action on $\mathrm{I}_{\mathrm{Ca}, \mathrm{T}}$ like D600. $1 \mu \mathrm{M}$ D600 (causing complete inhibition of $\mathrm{I}_{\mathrm{Ca}, \mathrm{L}}$ ) did not reduce $\mathrm{I}_{\mathrm{Ca}, \mathrm{T}}$ in rabbit $\mathrm{SA}$ cells [56]. In primary cultured murine cardiac cells $\mathrm{I}_{\mathrm{Ca}, \mathrm{T}}$ was not reduced by either $100 \mathrm{nM}$ fantofarone or $100 \mathrm{nM}$ SR 33805 [36].

\section{Structure-activity relationship of CCAs}

\subsection{Benzothiazepines}

Benzothiazepines are one of the three major classes of CCAs which exert a functional state-dependent inhibition of the L-type calcium channel (inactivated $>$ open $>$ closed) [57]. High affinity binding of benzothiazepines requires $\mathrm{Ca}^{2+}$ bound to the channel [57]. On the contrary, increased concentration of $\mathrm{Ca}^{2+}$ antagonize diltiazem block of the channels in both heart [58] and smooth muscle [59]. The extracellular application of benzothiazepines effectively blocks the L-type $\mathrm{Ca}^{2+}$ channel but the intracellular application does not secure the inhibitory effect. This led to the conclusion that benzothiazepine block is mediated from the extracellular side of the channel pore [60], [61]. These findings were found plausible by Monte Carlo simulation [57]. The pathway leading to the binding site of the inner pore of the channel was found to be wide enough for the molecule to "penetrate" [62]. Despite these concurrent results, the quaternary ammonium derivative of diltiazem was found to be able to inhibit the L-type channels from the intracellular side [63].

The presence of $\mathrm{Ca}^{2+}$ is an important factor in ligand-channel binding. The $\mathrm{Ca}^{2+}$ in the selectivity filter was found to bind not only to the carbonyl groups of benzothiazepine but also to the glutamates of the selectivity filter [57]. In the absence of calcium ions the amino group of benzothiazepine molecule interacts with the previously mentioned glutamates directly [57]. The interaction of the aromatic rings with the Y4i11, F3i22 and F3p49 residues is also important [57]. Substitution in position 3 of the 7 member heteroatomic ring has only moderate effect on benzothiazepine binding. However, this side group should be preferably hydrophobic to increase the inhibitory action [64]. The length of the alkyl chain between the nitrogen atoms does not influence the binding of the benzothiazepine to the channel [57]. Benzothiazepine interaction with a closed calcium channel was destabilized due to loss of contact sites at the $\mathrm{C}$ terminal of the inner helices [57]. Systematic point mutation of the amino acids in domains IIIS6 and IVS6 highlighted the essential residues for the diltiazem block, for instance I1150, I1156 and M1160 in IIIS6 as well as I1460 and M1464 in IVS6 [65].

$\mathrm{The}^{\mathrm{Ca}^{2+}}$ channel inhibitory and hypotensive effects of the derivatives of diltiazem were also investigated in several articles. Clentiazem (8-chloro-diltiazem) was also found to be able to reduce peripheral arterial resistance [66]. Assumingly, this effect mediated by the same manner as L-type $\mathrm{Ca}^{2+}$ channel inhibition by diltiazem. In S-2150 the dimethyl amino group was replaced by a complex (2-methoxyphenyl)-1-piperazinyl substituent. The nitrogen atoms in the piperazinyl ring may have the same effect as the amine nitrogen in clentiazem. The connecting ethylene chain was increased to propylene group, but this does not seem to have an effect on calcium channel inhibition (see above) [57]. The additional methoxy group probably plays a role in calcium chelating just like in the phenylalkylamines [67]. This molecule found to be less cardio-depressive than diltiazem [68] but its hypotensive effect is 4-7 times more potent than that of diltiazem [31]. This different vascular over cardiac selectivity may come from the wide spectra of the effects of benzothiazepine and derivatives, which are not just restricted to the L-type $\mathrm{Ca}^{2+}$ channel inhibition [69]. Siratiazem hardly differs from diltiazem as just one of the methyl groups was substituted to isopropyl group. This modification might mimic one of the essential parts of verapamil binding properties [70]. Semotiadil (SD-3211) and its S-enantiomer sesamodil (levosemotiadil, SD-3212) can both inhibit potassium depolarization-induced cytosolic $\mathrm{Ca}^{2+}$ increase in rat aorta [71]. We classified these two molecules as benzothiazepine-like compounds despite the smaller (only six member) heteroatomic ring containing the sulphur and nitrogen atoms. This might alter the Baeyer tension of the ring. These compounds also contain motifs similar to phenylalkylamines such as tertiary amine nitrogen and methoxy group attached to an aryl ring [67].

\subsection{Phenylalkylamines}

Articles described the mechanisms of verapamil binding to a synthetic channel peptide (SCP), which has authentic functional properties as the L-type $\mathrm{Ca}^{2+}$ channel [67]-[70]. Verapamil binds snugly to the pore of the channel in a folded conformation. Based on the Monte Carlo method with energy minimization, they showed that two important parts of the verapamil take part in the $\mathrm{Ca}^{2+}$ channel blocking action. Firstly the dimethoxy-phenyl 
groups are bound with two $\mathrm{Ca}^{2+}$ ions coordinated to the acidic residues of the channel pore [67]. That is how a ternary complex is formed involving the channel, the ions and the antagonist. The second is the isopropyl group of verapamil which interacts with the four Ile residues of the channel constituting the putative gate of the SCP [67]. Other authors claim that isopropyl group of devapamil reaches the T2p48 and F3p49 residues [72]. Another study showed that verapamil, similarly to D600, blocked L-type $\mathrm{Ca}^{2+}$ channel only if applied from the extracellular side [73]. In contrast, others found that both D600 and verapamil are able to reduce action potential duration (APD) and plateau potential of cardiac AP dose-dependently, regardless of the intra- or extracellular application in isolated guinea-pig ventricular myocytes [74]. D600 (often mentioned as gallopamil) only differs from verapamil by an addition of a methoxy group to that aryl ring which is located closer to the nitrile group. This may increase the $\mathrm{Ca}^{2+}$ chelating effect of the molecule, or the number of available sites for hydrogen bond formation [75]. Anipamil was designed to be less hydrophilic and binding studies showed that anipamil, although binds tightly to cardiac membranes, its binding to the D888 (desmethoxyverapamil) binding sites is less potent compared to verapamil [76]. The number of methoxy groups was halved on each aromatic ring, and the isopropyl group was substituted with a longer, linear dodecyl group. These changes resulted in the decrease of the inhibitory potency, but prolonged effects [76]. Tiapamil misses the isopropyl [70] and the nitrile group [77] existing in both verapamil and D600. These functional groups considered as important channel-ligand interaction sites [72]. In spite of these preconceptions, two oxygen atoms from the bulky saturated six-membered ring interact with the calcium ion in the pore [72]. Nadler and his coworkers thoroughly investigated the electrophysiological effects of BRL 32872 and its synthetic derivatives. These compounds blocked the ion channels responsible for the rapid component of the delayed rectifier potassium current $\left(\mathrm{I}_{\mathrm{Kr}}\right)$ on top of L-type calcium channels [78]. The authors stated that the hydrogen bond formation, the nitrogen substituted with aliphatic alkyl chains, but not the quaternization of nitrogen and the aromatic substitution are crucial for the inhibitory effect. The too long aliphatic nitrogen substitution decreases the activity of the molecule, which also supports the result of Dillon and his coworkers [76]. Fantofarone and SR 33805 show strong structural similarities to each other such as dimethoxy substituted aryl rings, nitrogen substituted with three aliphatic alkyl chain, isopropyl and sulfonyl groups. The role of these functional groups (except the sulphonyl group) is presumably the same as mentioned earlier in this chapter [67],[70],[78]. The sulfonyl group might participate in chelating the $\mathrm{Ca}^{2+}$ similarly to that mentioned with tiapamil [72]. SR 33805 was shown to inhibit competitively $[3 \mathrm{H}]$ fantofarone, while allosterically $[3 \mathrm{H}](+)-\mathrm{PN} 200-110,[3 \mathrm{H}](-)-\mathrm{D} 888$ and cis-(+)-[3H]diltiazem binding to cardiac sarcolemmal membranes. This suggests that, just as fantofarone, it binds to a site different from that of dihydropyridines, phenylalkylamines and benzothiazepines [79].

\subsection{Other compounds}

The structure-activity relationship of the following compounds is based on the findings described in the previous two sections.

KT-362 shows motifs from both phenylalkylamine and benzothiazepine structure elements. It "inherited" the heteroatomic ring of the benzothiazepines, however, that ring is more substituted in diltiazem. It also contains methoxy groups attached to an aryl ring, resembling phenylalkylamines [67]. The distance between the two mentioned functional groups might seem enough for the molecule to undergo the necessary conformational changes to interact with both benzothiazepine and phenylalkylamine binding sites of the channels. However, the benzothiazepine and phenylalkylamine binding sites partially overlap with each other [65].

In this review some other compounds are also mentioned which can not be categorized clearly into any of the three major classes based on their chemical structure. These contain some structural motifs which presumably have the same function as the motifs mentioned earlier related to the major classes of the $\mathrm{Ca}^{2+}$ channel blockers.

Mibefradil binds to the same binding site in cardiac membranes as verapamil and with a similar potency [80]. Mibefradil has the isopropyl group [67], the tertiary amine, and the $\mathrm{Ca}^{2+}$ chelating ester group. These functional groups might seem enough to interact with both the channel and the ion [78]. But according to our assumption, the orientation of these groups prevents the strong inhibition of the voltage-gated L-type $\mathrm{Ca}^{2+}$ channel. Monatepil has a sulphur-containing heteroatomic ring, but that contains no nitrogen. Instead, the "expected" nitrogen can be found in the amide group attached to this ring. This amide might chelate a $\mathrm{Ca}^{2+}$ ion, but not as strong as an ester group. The other parts of the molecule do not resemble any other aforementioned functional groups except the same piperazinyl ring which can be found in S-2150. Due to the above mentioned observations about the chemical structure, monatepil seems to be less potent as a $\mathrm{Ca}^{2+}$ channel inhibitor as $\mathrm{S}-2150$. Bepridil has an isobutyl ester which might take the role of the isopropyl group mentioned above, but due to the low number of hydrophilic groups, the interaction between bepridil and $\mathrm{Ca}^{2+}$ is not plausible. Owing to the lack of $\mathrm{Ca}^{2+}$ chelating activity, it cannot be an effective L-type channel inhibitor [67]. AH-1058 is quite the opposite, thanks to the adjacent methoxy and nitro groups attached to an 
aryl ring, the molecule can bind $\mathrm{Ca}^{2+}$. On the other hand, there are no molecular interaction sites binding to the channel itself. The structure of AP-792 shows absolutely no similarity to those mentioned in earlier sections.

\section{Interactions between simultaneous binding of different inhibitor classes (allosteric model)}

Nifedipine and verapamil inhibit the clentiazem binding to $\mathrm{Ca}^{2+}$ channels [81]. Binding studies showed a concentration-dependent positive allosteric interaction between $[3 \mathrm{H}](+)$-isradipine and mibefradil, but not with $[3 \mathrm{H}](+)$-isradipine and D600 enantiomers. Molecular and functional evidences point to an interaction between a dihydropyridine and mibefradil [82]. Semotiadil has a strong negative allosteric interaction with the three major classes of CCAs at their specific binding sites [83]. Based on radio ligand assays, verapamil inhibited binding of isradipine, but diltiazem stimulated the binding of isradipine in a temperature-sensitive manner [84]. Those binding residues being critical for the contact of the ligand receptor interactions are listed by Hockerman and coworkers [65]. Binding of diltiazem to L-type $\mathrm{Ca}^{2+}$ channels requires those residues overlapping with critical ones for dihydropyridine and phenylalkylamine block as well as residues unique to diltiazem. Channel-ligand interactions involve also residues which are only take part in binding one antagonist of the three major classes [65]. These facts indicate that the binding of the antagonists dynamically changes the binding regions of the L-type $\mathrm{Ca}^{2+}$ channel (mainly residues in IIIS6 and IVS6). Therefore, the binding of another class of CCA to the channel is altered. This was summarized in the allosteric model involving interactions between different binding sites [85].

\section{Potential mechanisms behind the antiarrhythmic actions of CCAs}

CCAs can induce antiarrhythmic action by several mechanisms.

1. Calcium overload occuring during cardiac ischemia [86] can lead to spontaneous $\mathrm{Ca}^{2+}$ release from the sarcoplasmic reticulum [87],[88]. This released $\mathrm{Ca}^{2+}$ is replaced by $\mathrm{Na}^{+}$by the forward mode of the $\mathrm{Na}^{+} / \mathrm{Ca}^{2+}$ exchanger leading to the depolarization of the cell membrane [89]. This depolarization is called either early or delayed afterdepolarization (EAD or DAD) depending on their timing compared to the full repolarization of the cell membrane. EADs form before, while DADs are generated after the full repolarization [90]. These afterdepolarizations are well known triggering sources of cardiac arrhythmias. Large enough afterdepolarizations occurring in the vulnerable period (when those ion channels responsible for the upstroke of the AP can be opened) can evoke a triggered AP. This AP can manifest in a simple extrasystole but can be the trigger for a much more dangerous (sometimes lethal) rhythm disorders including torsade de pointes (TdP) type VF [91].

The reduction of inward calcium currents by CCAs (due to the inhibition of both L- and T-type calcium channels) results in reduced calcium influx to cardiomyocytes, therefore leading to calcium depletion, which according to the previous fact can have antiarrhythmic effect by reducing the risk of calcium overload. Verapamil was shown to suppress spontaneous or epinephrine-induced EADs and TdP in cats [92] and it suppressed the epinephrine induced ventricular premature complexes (VPCs) and TdP in humans as well [93]. Moreover, it was suggested that semotiadil inhibits $\mathrm{Ca}^{2+}$ release from $\mathrm{Ca}^{2+}$ stores or decrease the sensitivity of the contractile elements to $\mathrm{Ca}^{2+}$ on top of the $\mathrm{I}_{\mathrm{Ca}, \mathrm{L}}$ inhibition [71].

Those CCAs, possessing large inhibitory actions on other ion channels, might have increased antiarrhythmic properties. The reduction of fast sodium current $\left(\mathrm{I}_{\mathrm{Na}}\right)$ and/or $\mathrm{Na}^{+} / \mathrm{Ca}^{2+}$ exchange current $\left(\mathrm{I}_{\mathrm{NCX}}\right)$ (as with bepridil [94]) would reduce the risk of the development of triggered AP and the generation of afterdepolarizations, respectively.

In rats with vitamin D3 induced calcium overload, fantofarone decreased the calcium content in the thoracic aorta, mesenteric artery and also in their heart [95].

2. The inhomogeneity of the repolarization times exists even in the healthy myocardium. That includes the transmural dispersion of repolarization (TDR) [96], the apico-basal gradient in repolarization [97] as well as the different repolarization times in left versus right ventricular muscle [98]. The increase of these inhomogeneities can lead to reentry arrhythmias [90]; therefore the reduction of TDR might be another important mechanism by which the antiarrhythmic action of CCAs can be mediated. This was observed in case of verapamil in a feline model of acquired long QT syndrome (LQTS) [92] as well as in patients with congenital LQTS [93]. A parallel and homogeneous prolongation in repolarization and refractoriness were thought to be essential for the antiarrhythmic effect of bepridil [99].

3. The generation and propagation of action potentials (AP) in pacemaker tissues are largely mediated by L-type calcium channels. That is the reason why CCAs with low vascular selectivity (having remarkable action on myocardium as well) are very effective in supraventricular tachyarrhythmias (AF and atrial flutter (AFL)). Namely, these CCAs effectively reduce the atrioventricular (AV) conduction leading to a negative dromotropic effect. For a recent review on AF see ref [100]. 
4. Prolongation of the recovery from inactivation of calcium channels was described with verapamil [54], bepridil [35], semotiadil and also with diltiazem [39]. This alteration of channel behavior can also contribute to the antiarrhythmic action of CCAs by increasing the refractory period (RP) of nodal tissues. This mechanism, similarly to the negative dromotropic effect of CCAs can be especially useful against supraventricular tachyarrhythmias and lead to the reduction of the ventricular rate (VR).

5. The amplitude of systolic calcium transients depends on at least two factors. One of them is the amplitude of the trigger for the calcium release from the sarcoplasmic reticulum, namely the calcium influx through mainly the L-type calcium channels of the sarcolemma. The other one is the calcium content of the intracellular calcium stores not to mention the sarcoplasmic reticulum gain which relates the amount of released calcium to the amount of the triggering calcium [101],[102]. These two factors are both reduced by CCAs, therefore it is not surprising that CCAs lead to the decrease of calcium transient amplitudes (for verapamil and mibefradil [103] for D600 [104], for SR33805 [40], for KT-362 [105] and for AH-1058 [106]). The major ATP using process in myocytes is the contractile machinery, the activity of which depends on intracellular calcium. Therefore, the previously mentioned reduction of intracellular calcium level will reduce adenosine triphosphate (ATP) consumption. Similarly, the reduction of VR will lead to an energy sparing effect and a reduction in ATP usage. Arrhythmias can develop in ischemic myocardium in which the ATP levels drop, therefore the preservation of ATP by CCAs could be another reason of their antiarrhythmic action.

Myocardial oxygen consumption can be an indirect measure of the metabolic activity of the myocardium and therefore it is likely to be directly proportional with ATP requirement. CCAs reportedly reduce cardiac oxygen consumption (for verapamil [107], for fantofarone [108], for KT-362 [42] and for bepridil [109], [110]) therefore again leading to a possible antiarrhythmic action.

The mechanism how the reduction of intracellular ATP level can lead to arrhythmias can be related to the function of ATP dependent potassium channels [111].

6. CCAs exert useful hemodynamic actions including vasodilatation leading to reduced preload and afterload, respectively. These will reduce the work of the heart, causing again a potential ATP sparing effect. Moreover, the increase in coronary flow (CF) can be found with CCAs. This effect is often not homogenous but a redistribution of the available CF can be seen. In some cases, CF of the ischemic area is increased improving the myocardial oxygen supply/oxygen requirement ratio [112] which is again beneficial.

7. Many CCAs were shown to inhibit not only calcium channels but also other ion channels. Inhibitions of $\mathrm{I}_{\mathrm{Na}}$ and $\mathrm{I}_{\mathrm{NCX}}$ have already been mentioned above to reduce the calcium overload and its arrhythmogenic consequences. Sodium channel inhibition was observed with many CCAs although in most cases only indirect, maximal rate of depolarization $\left(\mathrm{V}_{\max }\right)$ measurements are available (for verapamil [113], for diltiazem [114], for siratiazem [115], for semotiadil [116], for levosemotiadil [117], for KT-362 [118], for mibefradil [119], for AH-1058 [38] and for bepridil [33]).

Potassium channels were also reduced by some nonselective CCAs. The reduction of major repolarizing currents including transient outward potassium current $\left(\mathrm{I}_{\mathrm{to}}\right), \mathrm{I}_{\mathrm{K}}$ and inward rectifier potassium current $\left(\mathrm{I}_{\mathrm{K} 1}\right)$ would lead to the prolongation of AP thereby an increase in the RP. BRL-32872 for instance inhibits $\mathrm{I}_{\mathrm{Kr}}$ much more potently compared to $I_{C a, L}$ [41]. The increase of the RP together with the reduction of several potassium currents were observed with bepridil (see later). The prolongation of the RP induced by many CCAs on the level of nodal tissues as well as atrial and ventricular myocardium will lead to antiarrhythmic action as reentry will occur less likely.

There are several reports about the inhibition of other potassium currents by some CCAs. Some of these are mostly expressed in the atrial muscle as acetylcholine-activated potassium current $\left(\mathrm{I}_{\mathrm{K}, \mathrm{Ach}}\right)$ and the ultrarapid component of delayed rectifier potassium current ( $\mathrm{I}_{\mathrm{Kur}}$ ). The reduction of $\mathrm{I}_{\mathrm{K}, \mathrm{Ach}}$ together with the increase in atrial effective refractory period (ERP) was reported with levosemotiadil [33], [117] and also with bepridil [120],[121]. The native current of $I_{\text {Kur }}$ was blocked by verapamil in human atrial cells [122] and also by bepridil [33] and diltiazem [122] although in higher than therapeutic doses.

Bepridil blocked heterologously expressed sarcolemmal ATP dependent potassium channels, but the drug opened mitochondrial ATP dependent potassium channels which latter is believed to be cardioprotective [123]. Both levosemotiadil and semotiadil reduced ATP dependent potassium current $\left(\mathrm{I}_{\mathrm{K}, \mathrm{ATP}}\right)$ in high doses [124]. Interestingly, the infarct size reducing effect of mibefradil in isolated, Langendorff-perfused rat hearts [125] and in anesthetized pigs [126], [127] was attributed at least in part to its $I_{K, A T P}$ activating property.

Sodium activated potassium current $\left(\mathrm{I}_{\mathrm{K}, \mathrm{Na}}\right)$ was reduced by verapamil and levosemotiadil [127] as well as by bepridil, which was suggested to be responsible for the non reverse-rate dependent AP lengthening effect of bepridil [127]. 


\section{Proarrhythmic actions of CCAs}

Like other pharmacological antiarrhythmic intervention (particularly class III agents), some CCAs may also be proarrhythmic. The redistribution of $\mathrm{CF}$ is one of these unwanted actions. Verapamil caused a coronary steal from the ischemic area of the myocardium [128] thereby likely aggravated the reduction of oxygen supply, ATP production and levels. Coronary dilation itself, regardless of its position (ischemic or non-ischemic area of the myocardium), is not necessary beneficial especially if it occurs during reperfusion as it could amplify the risk of the development of reperfusion arrhythmias. Some CCAs including D600 was found to be arrhythmogenic as it induced a prolongation of the APD and provoked EADs in a special model of papillary muscles of guinea-pig hearts [129]. In Langendorff-perfused rabbit hearts D600 at higher doses when it also inhibits $\mathrm{I}_{\mathrm{Na}}$ converted ventricular tachycardia (VT) to slow VF $(11.9 \pm 2.3 \mathrm{~Hz})$ [130]. Bepridil was also reported to evoke EAD at long cycle length (CL) in canine Purkinje fibers [131] and it also increased TDR by mainly lengthening M cell APD in canine wedge preparations [132]. Moreover, in vivo animal studies reported arrhythmogenic action of bepridil during coronary occlusion (but not during reperfusion) [133], [134]. VT, prolongation of QTc interval and TdP were detected with bepridil treatment in permanent AF patients, while no ventricular arrhythmias were seen with amiodarone [134]. Anipamil was also found arrhythmogenic at least in pentobarbitone-anesthetized pigs where it increased the occurrence of VT and VF [135], [136]. In rats with healed infarcts and ventricular dysfunction, 8-week-long anipamil treatment aggravated left ventricular dilatation and remodeling, thereby reduced survival [136].

Verapamil, together with other CCAs, is on the list of drugs to avoid in the treatment of Brugada syndrome due to their potential proarrhythmic action [137], [138]. Bepridil is an exception but due to its $\mathrm{I}_{\mathrm{to}}$ and $\mathrm{I}_{\mathrm{K}, \mathrm{Ach}}$ and certainly not its calcium channel blocking action [139]. CCAs should also be avoided in the treatment of short QT syndrome as in some genetic, congenital forms of the disease (SQT4 and 5) the calcium channels are already conduct a smaller current [140], [141]. Moreover, together with other drugs, verapamil is used to model early repolarization in animal studies [142]. However, verapamil was effective but unfortunately it did not prevent sudden death [143].

\section{Additional electrophysiological effects of CCAs}

\subsection{Phenylalkylamines}

\section{Verapamil}

Verapamil (Fig. 2.) is the best known phenylalkylamine which is used in antiarrhythmic treatment even today although it is not a new compound at all. Actually, it was probably the first CCA introduced to human clinical treatment. It was considered to be a coronary vasodilator therefore its use started as an antianginal agent in 1962 in Germany [144].

The therapeutic plasma concentration of free verapamil (not bound to proteins) in humans is between 20-800 $\mathrm{nM}$ [145], although the mean myocardial to plasma concentration ratio was approximately seven suggesting accumulation of the drug in the heart [146]. Indeed, verapamil can accumulate in canine myocardium in a chamber specific manner showing greater accumulation in the ventricles compared to the atria without having left versus right-sided specific distribution [147].

Apart from the calcium channel inhibition, verapamil is likely to inhibit sodium channels as $\mathrm{V}_{\max }$, which is often used as an indirect measure of $\mathrm{I}_{\mathrm{Na}}$, was reduced by the drug in supratherapeutic concentrations $\left(\mathrm{IC}_{50}\right.$ of $\left.10 \mu \mathrm{M}\right)$ in guinea-pig [20]. In isolated canine Purkinje fibers $6 \mu \mathrm{M}$ verapamil or above decreased $\mathrm{V}_{\max }$, AP amplitude (APA) and conduction velocity [148]. The most pronounced effect on $\mathrm{V}_{\max }$ was observed in guinea-pig right ventricular muscle where $1 \mu \mathrm{M}$ evoked $42 \%$ reduction [113].

Potassium channels were also reduced by verapamil. In guinea-pig ventricular myocytes 1 and $5 \mu \mathrm{M}$ verapamil reduced $\mathrm{I}_{\mathrm{Kr}}$ by 50 and $87 \%$, respectively [149]. The slow component of the delayed rectifier potassium current $\left(\mathrm{I}_{\mathrm{Ks}}\right)$ was recuced by 18 and $40 \%$ in the presence of 1 and $5 \mu \mathrm{M}$ verapamil, respectively [149]. Verapamil exerted an inhibitory action on expressed potassium channel proteins including human ether-a-go-go (hERG) channels in the possible therapeutic level in the myocardium [150], [151] and $\mathrm{K}_{\mathrm{v}} 1.5$ (responsible for $\mathrm{I}_{\mathrm{Kur}}$ ) channels with an $\mathrm{IC}_{50}$ of $5.1 \mu \mathrm{M}$ [151].The native current of $\mathrm{I}_{\mathrm{Kur}}$ was also blocked by verapamil in human atrial cells from as low as $1 \mu \mathrm{M}$ [122]. Verapamil blocked $\mathrm{I}_{\mathrm{K}, \mathrm{Na}}$ in guinea-pig ventricular cells with an $\mathrm{IC}_{50}$ of $3.36 \mu \mathrm{M}$ [127]. Verapamil reduced the open probability of large-conductance calcium-activated potassium channels $\left(\mathrm{BK}_{\mathrm{Ca}}\right)$ in rat aortic myocytes with a dissociation constant of $4.1 \mu \mathrm{M}$. Results suggested an open channel block [152].

In guinea-pig cardiomyocytes the APD was reduced by $45 \%$ in $10 \mu \mathrm{M}$ verapamil, which also reduced the plateau of the AP [153]. In contrast, verapamil slightly increased APD in guinea-pig papillary muscle [154]. The APD increase 
by verapamil was also seen in spontaneously beating rabbit SA nodal cells together with the reduction of $\mathrm{V}_{\max }$ and APA [155].

The effects of verapamil in nodal tissues included an increase in CL, maximal diastolic potential (MDP) and APD but a reduction in both $\mathrm{V}_{\max }$ and APA on rabbit SA node tissue [156].

D600 (gallopamil)

D600 (Fig. 2.) had a peak plasma concentration of $61-77 \mathrm{ng} / \mathrm{ml}$ (equivalent to approximately $120-150 \mathrm{nM}$ ) in patients taking $50 \mathrm{mg}$ D600 three times a day for 28 days [157]. Myocardial concentrations could be even higher as, similarly to verapamil, D600 can be accumulated, at least in guinea-pig left auricles, to up to six times [158].

D600 is a methoxy derivative of verapamil which was also shown to reduce $\mathrm{I}_{\mathrm{Na}}$. In cultured chick heart cells $\mathrm{I}_{\mathrm{Na}}$ was reduced by D600 with an $\mathrm{IC}_{50}$ of $30 \mu \mathrm{M}$ [159]. $10 \mu \mathrm{M}$ D600 had no effect on $\mathrm{V}_{\max }$ in guinea-pig ventricular cells [20]. In contrast, the same study reported $50 \%$ reduction by $10 \mu \mathrm{M}$ verapamil suggesting a less potent $\mathrm{I}_{\mathrm{Na}}$ inhibition by D600.

$\mathrm{I}_{\text {to }}$ of rat ventricular cardiomyocytes was reduced with an $\mathrm{IC}_{50}$ of $3 \mu \mathrm{M}$ by D600 [160].

$\mathrm{D} 600$, at 1 and $10 \mu \mathrm{M}$, decreased the open probability of $\mathrm{BK}_{\mathrm{Ca}}$ channels by 37 and $84 \%$, respectively, in rat aortic myocytes which was more potent compared to that of verapamil [152].

\section{Tiapamil (Ro 11-1781)}

Tiapamil (Fig. 2.), similarly to verapamil, inhibited calcium-induced contractions in rat renal artery, canine coronary artery and rabbit main pulmonary artery in a dose-dependent manner [161]. Sodium channel inhibition was suggested in guinea-pig papillary muscles where tiapamil reduced $\mathrm{V}_{\max }$ at concentrations above $1 \mu \mathrm{M}$ with an $\mathrm{IC}_{50}$ value of $70 \mu \mathrm{M}$ in a use-dependent manner whereas verapamil was less potent [162] at least in that study. Similarly, tiapamil caused marked alterations of the normal sodium AP, namely the reduction of $\mathrm{V}_{\max }$ and the prolongation of plateau phase [163].

\section{Anipamil}

Only indirect effects are available suggesting the calcium channel inhibitory action of anipamil (Fig. 2.) as the drug dose-dependently reduced the contractile force of Langendorff-perfused rat hearts with an $\mathrm{IC}_{50}$ of $100 \mathrm{nM}$. Comparison to the other phenylalkylamines is difficult as rat data are not available but anipamil was slightly less potent compared to $\mathrm{D} 600$ ( $\mathrm{IC}_{50}$ of $60 \mathrm{nM}$ in guinea-pig left auricles) and its negative inotropic action was the same as that of verapamil ( $\mathrm{IC}_{50}$ of $100 \mathrm{nM}$ in isolated guinea-pig left atria). Anipamil was found to be selective to cardiac muscle and had no effect on coronary smooth muscle up to $100 \mu \mathrm{M}$ in isolated rabbit heart. In contrast, both verapamil and D600 reduced heart rate (HR) up to asystole and evoked coronary spasm together with their negative inotropic effect. The reduction in contractility was only partially reversible and long lasting (up to 12 hours) with anipamil in contrast to verapamil and D600 whose negative inotropic effect was completely reversible within 3 hours of washout [164]. 

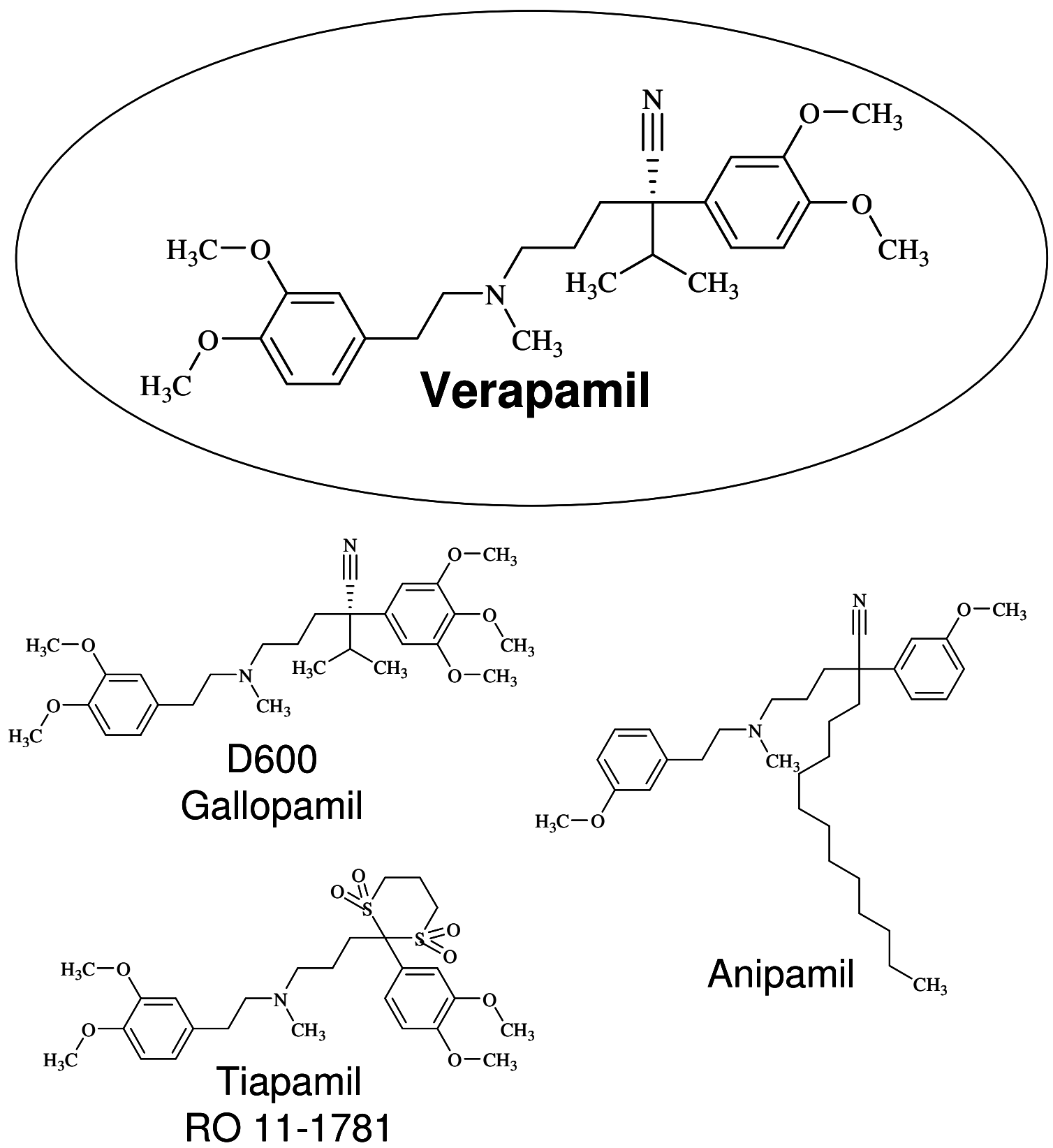

FIG. 2. Chemical structure and IUPAC name of phenylalkylamines. The first and best known one is the circled verapamil.

Verapamil, 2-(3,4-dimethoxyphenyl)-5-[2-(3,4-dimethoxyphenyl)ethyl-methylamino]-2-propan-2-ylpentanenitrile D600, 5-[2-(3,4-dimethoxyphenyl)ethyl-methylamino]-2-propan-2-yl-2-(3,4,5-trimethoxyphenyl)pentanenitrile Tiapamil, $\quad \mathrm{N}$-[2-(3,4-dimethoxyphenyl)ethyl]-3-[2-(3,4-dimethoxyphenyl)-1,1,3,3-tetraoxo-1,3-dithian-2-yl]-Nmethylpropan-1-amine Anipamil, 2-(3-methoxyphenyl)-2-[3-[2-(3-methoxyphenyl)ethyl-methylamino]propyl]tetradecanenitrile 


\subsection{Benzothiazepines}

\section{Diltiazem}

Diltiazem (Fig. 3.) is the prototype of benzothiazepine structure type CCAs.

The human therapeutic plasma concentration of diltiazem is between $100-700 \mathrm{nM}$, but after correction to protein binding it was only 10-50 $\mathrm{nM}$ [145].

Diltiazem reduced $\mathrm{I}_{\mathrm{Kur}}$ in human atrial myocytes in a dose-dependent manner with an $\mathrm{IC}_{50}$ of $11.2 \mu \mathrm{M}$, which was again less potent compared to that of verapamil $\left(\mathrm{IC}_{50}\right.$ of $\left.3.2 \mu \mathrm{M}\right)$ [122], [165].

Glibenclamide-sensitive potassium currents in Xenopus oocytes were blocked by diltiazem in a stereoselective manner with $\mathrm{IC}_{50}$ values of 4.2, 13.3, 35.8 and $75.9 \mu \mathrm{M}$ for (+)-trans, (-)-trans, (-)-cis and (+)-cis, respectively [124]. Interestingly, this order of blocking potency of the stereoisomers of diltiazem was exactly the opposite in case of $\mathrm{I}_{\mathrm{Ca}, \mathrm{L}}$ inhibition.

$9 \mu \mathrm{M} \mathrm{IC}_{50}$ value was reported for $\mathrm{I}_{\mathrm{Na}}$ inhibition in guinea-pig ventricular cells, however, L-cis diltiazem was applied instead of the racemic molecule in that study [166]. Indirect measurements about the $\mathrm{I}_{\mathrm{Na}}$ blocking action of diltiazem $\left(\mathrm{V}_{\max }\right.$ and sometimes APA determination of fast APs) are available in cat by $2.2 \mu \mathrm{M}$ [114], in guinea-pig by $22 \mu \mathrm{M}$ [167], in dogs by $11 \mu \mathrm{M}$ [168] and also in human from $30 \mu \mathrm{M}$ [169]. When compared to verapamil, diltiazem was again less potent in reducing $\mathrm{V}_{\max }$ in canine Purkinje fibers and in guinea-pig ventricular muscle as well.

Regarding the effects of diltiazem on the duration of fast APs, one can find a slight increase in guinea-pig papillary muscles [154], increased $\mathrm{APD}_{80}$ in ferret right ventricular papillary muscles [25]; no change in rabbit ventricular APD up to $10 \mu \mathrm{M}$ [170] and in feline right ventricular fibers by $2.2 \mu \mathrm{M}$ diltiazem [114]; and also reduction of APD in guinea-pigs ventricular muscle [167], in canine Purkinje fibers [171] and in human ventricular myocardium [169] by 110,1 and $10 \mu \mathrm{M}$ diltiazem, respectively. The effect of diltiazem on early repolarization duration of the fast APs corresponding to the plateau phase $\left(\mathrm{APD}_{20}\right.$ and $\left.\mathrm{APD}_{30}\right)$ is equivocal in the literature as diltiazem reduced these values and depressed the plateau potentials in ferret right ventricular papillary muscles [25], canine ventricular muscles and Purkinje fibers [168].

Comparing diltiazem to verapamil, similar effects were found on AV nodal conduction time (CT) (greater increase during tachycardia compared to that during sinus rhythm (SR)) but the tau-on was shorter for diltiazem [172]. Similar actions were detected in canine ischemia induced VF with verapamil [173], [174].

Diltiazem was less effective compared to verapamil in most of their evoked actions. This was the case in reducing $\mathrm{V}_{\max }$ in canine Purkinje fibers [148], [168] and in guinea-pig ventricular muscle [113], [167]; in reducing inotropy in dogs [175], [176] and in guinea-pig myocardial preparations [154]; in reducing chronotropy on rabbit SA node tissue [156], in anesthetized dogs [177] and in guinea-pig myocardial preparations [154]; in exerting vasorelaxing effect [154], [176]. Similar antiarrhythmic effect was observed with twice as large dose of diltiazem compared to verapamil in open-chest anesthetized dogs [178].

In contrast to the previously mentioned results, the negative chronotropic action of diltiazem was more potent than that of verapamil in anesthetized dogs [177] and in canine right atrium [175]. The vascular selectivity of verapamil was slightly lower compared to that of diltiazem [176].

\section{Siratiazem (LR-A113)}

Siratiazem (Fig. 3.) was designed to be resistant to N-demethylation and had 1.6-1.9 times longer half-life in conscious rats after both oral and intravenous administration without a major increase in its bioavailability [179]. In depolarized ovine coronary artery rings potassium-stimulated calcium uptake was also inhibited by siratiazem and diltiazem with similar potencies [30]. Siratiazem dose-dependently (1-10 $\mu \mathrm{M})$ reduced APA, $\mathrm{V}_{\max }, \mathrm{APD}_{50}$ and $\mathrm{APD}_{90}$ values of ovine Purkinje fibers without affecting resting membrane potential (RMP) [115].

\section{Clentiazem (TA-3090)}

Clentiazem (Fig. 3.) is a chloride containing diltiazem derivative having peak plasma levels of 17 and $19 \mathrm{ng} / \mathrm{ml}$ (approximately 30-33 nM) in patients with essential hypertension [180]. Clentiazem antagonized contractions of rabbit myocardium with the same potency compared to diltiazem $\left(\mathrm{IC}_{50}\right.$ values of 43 and $39 \mu \mathrm{M}$, respectively) but in a longer-lasting manner [28]. On isolated human right ventricular trabeculae clentiazem evoked negative inotropic actions with an $\mathrm{EC}_{50}$ of $8.8 \mu \mathrm{M}$ which was similar to that of diltiazem (7.2 $\left.\mu \mathrm{M} \mathrm{EC}_{50}\right)$ [27]. On isolated rabbit tissues clentiazem was more vasoselective than diltiazem [28]. Clentiazem proved to be more effective than diltiazem but less potent than verapamil in reducing the spontaneous rate of rabbit SA nodal tissue. Clentiazem reduced $\mathrm{V}_{\max }$ and APA while increased MDP and APD and the magnitude of these effects was again intermediate compared to diltiazem (being the least potent) and verapamil (being the most potent) [156]. In vitro experiment on rabbit hearts showed that, similarly to diltiazem, clentiazem (10-1000 nM) caused a dose-dependent 
increase in $\mathrm{AH}$ interval without affecting $\mathrm{HV}$ interval. In AV and SA nodal cells $1 \mu \mathrm{M}$ clentiazem reduced APA, $\mathrm{V}_{\text {max }}, \mathrm{APD}_{50}, \mathrm{APD}_{20}$ and MDP without changing $\mathrm{APD}_{90}$. In AV node the drug prolonged ERP and up to $10 \mu \mathrm{M}$ it did not change ventricular AP [170]. In dogs, sustained negative chronotropic effects were recorded in high dose and these were correlated well with myocardial clentiazem levels [181].

Similarly, clentiazem was more potent in lowering mean arterial pressure (MAP) without evoking a positive reflex chronotropic action in dogs compared to diltiazem [182]. Clentiazem increased coronary blood flow just as diltiazem [183] but its effect was more prolonged [184] and showed higher selectivity for coronary arteries [183].<smiles>COc1ccc([C@H]2Sc3ccccc3N(CCN(C)C(C)C)C(=O)[C@H]2OC(C)=O)cc1</smiles>

Siratiazem LR-A113

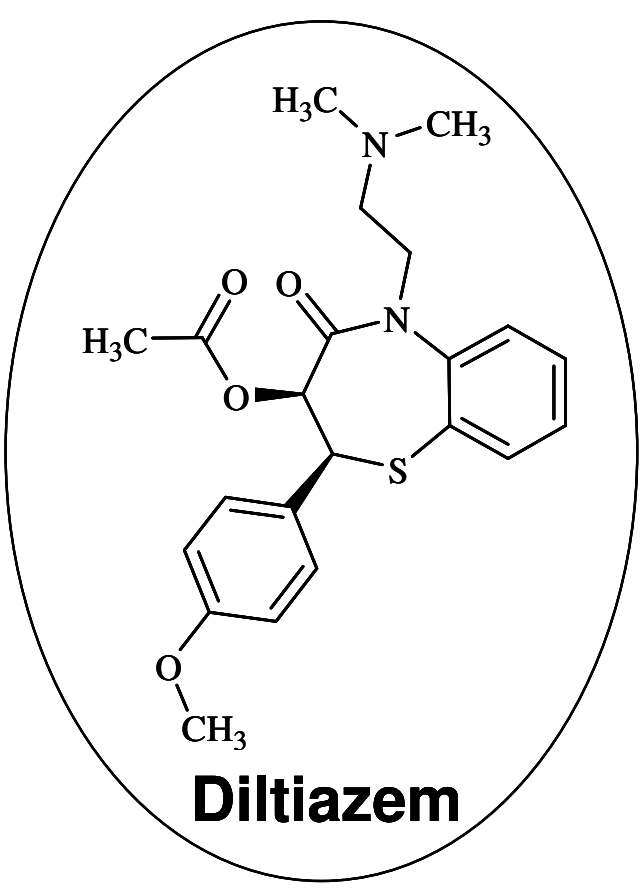

\section{Clentiazem \\ TA-3090}<smiles>COc1ccc([C@H]2Sc3cc(Cl)ccc3N(CCCN3CCN(c4ccccc4OC)CC3)C2=O)cc1</smiles>

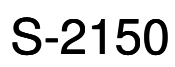

FIG. 3. Chemical structure and IUPAC name of benzothiazepines. The first and best known one is the circled diltiazem.

Diltiazem, [(2S,3S)-5-[2-(dimethylamino)ethyl]-2-(4-methoxyphenyl)-4-oxo-2,3-dihydro-1,5-benzothiazepin-3-yl] acetate Clentiazem, benzothiazepin-3-yl] acetate

[(2S,3S)-8-chloro-5-[2-(dimethylamino)ethyl]-2-(4-methoxyphenyl)-4-oxo-2,3-dihydro-1,5Siratiazem, [(2S,3S)-2-(4-methoxyphenyl)-5-[2-[methyl(propan-2-yl)amino]ethyl]-4-oxo-2,3-dihydro-1,5benzothiazepin-3-yl] acetate

S-2150, Acetic acid 8-chloro-2-(4-methoxy-phenyl)-5-\{3-[4-(2-methoxy-phenyl)-piperazin-1-yl]-propyl\}-4-oxo2,3,4,5-tetrahydro-benzo[b][1,4]thiazepin-3-yl ester 


\subsection{Other CCAs}

Semotiadil (SD-3211)

Semotiadil (Fig. 4.) blocked glibenclamide-sensitive potassium current in Xenopus oocytes more potently compared to verapamil ( $\mathrm{IC}_{50}$ values of 10 and $60 \mu \mathrm{M}$, respectively) [124].

Semotiadil, but not diltiazem, inhibited the norepinephrine-induced transient contraction, even in the absence of external $\mathrm{Ca}^{2+}$ and in nifedipine-treated muscles, suggesting an inhibition of $\mathrm{Ca}^{2+}$ release from $\mathrm{Ca}^{2+}$ stores or decrease in sensitivity of the contractile elements to $\mathrm{Ca}^{2+}$ on top of the $\mathrm{I}_{\mathrm{Ca}, \mathrm{L}}$ inhibition [71].

Semotiadil $(1-10 \mu \mathrm{M})$ reduced APD in a dose-dependent manner without affecting the RMP or $\mathrm{V}_{\max }$ in guinea-pig papillary muscles. The $\mathrm{V}_{\max }$ of slow responses was inhibited only above $1 \mu \mathrm{M}$ [116].

Semotiadil exerted potent inhibition on both depolarization-induced (evoked by $\mathrm{KCl}$ ) and ligand-induced (histamine and norepinephrine) contractions in porcine coronary arteries [6], in isolated rat aortas [71] and also in isolated canine coronary arteries [185]. The inhibition of potassium-induced contractions was usually more potent compared to both diltiazem and verapamil.

Levosemotiadil (SD-3212)

Levosemotiadil (Fig. 4.) is the stereoisomer of semotiadil with an approximate plasma level of $350 \mathrm{nM}$ [117]. Levosemotiadil inhibited $\mathrm{I}_{\mathrm{Ca}, \mathrm{L}}$ and $\mathrm{I}_{\mathrm{Na}}$ in a dose-dependent manner with $\mathrm{IC}_{50}$ values of 1.3 and $3.9 \mu \mathrm{M}$, respectively, in guinea-pig atrial cells. The steady-state inactivation curves of both currents were shifted to more negative potentials by $1 \mu \mathrm{M}$ levosemotiadil [33]. $\mathrm{V}_{\max }$ inhibition by levosemotiadil was described in guinea-pig right ventricular papillary muscles $(3 \mu \mathrm{M}$ and above in a use-dependent manner) [186], in canine tissue (0.3-3 $\mu \mathrm{M}$ in a use- and concentration-dependent manner) [117] and in rabbit papillary muscles (3-10 $\mu \mathrm{M}$ in a use- and concentration-dependent manner) [187].

Levosemotiadil blocks $\mathrm{I}_{\mathrm{K}, \mathrm{Na}}$ in guinea-pig ventricular cells with an $\mathrm{IC}_{50}$ of $0.53 \mu \mathrm{M}$ [127]. Glibenclamide-sensitive potassium channels $\left(\mathrm{I}_{\mathrm{K}, \mathrm{ATP}}\right)$ in Xenopus oocytes were blocked slightly more potently by levosemotiadil compared to semotiadil ( $\mathrm{IC}_{50}$ values of 9 and $11 \mu \mathrm{M}$, respectively) [124].

$\mathrm{I}_{\mathrm{K}, \mathrm{Ach}}$ was potently inhibited with an $\mathrm{IC}_{50}$ of approximately $0.29 \mu \mathrm{M}$. Carbachol induced AP shortening was reversed by $0.1-1 \mu \mathrm{M}$ levosemotiadil in a dose-dependent manner in guinea-pig atrial cells [33].

Levosemotiadil significantly increased APD in canine tissue (1-3 $\mu \mathrm{M})$ [117] and in rabbits (endocardial monophasic AP and in papillary muscles in the range of 3-10 $\mu \mathrm{M}$ ) [187]. The prolongation of AP did not vary with stimulation frequency and levosemotiadil did not influence APA or RMP [187]. Similarly, levosemotiadil increased right atrial ERP with the same extent regardless of the CL [117].

Levosemotiadil $(1-10 \mu \mathrm{M})$ evoked similar actions seen with semotiadil but not with diltiazem, suggesting an inhibition of $\mathrm{Ca}^{2+}$ release from $\mathrm{Ca}^{2+}$ stores or decrease in sensitivity of the contractile elements to $\mathrm{Ca}^{2+}[71]$.

\section{SR 33805}

SR 33805 (Fig. 4.) inhibited the high potassium depolarization-induced, sustained increases in intracellular calcium level and force with $\mathrm{IC}_{50}$ values of 3.2 and $49.4 \mathrm{nM}$, respectively [188]. It also sensitized myofilaments to calcium as in the medial strip of the porcine coronary artery SR33805 caused a leftward shift of both the intracellular calcium level-force and the intracellular calcium level-myosin light chain phosphorylation curves [188]. Similarly, 1$10 \mu \mathrm{M}$ SR33805 induced the sensitization of the myofilaments to calcium in ventricular myocytes from both normal [40] and from end-stage heart failure (HF) rat hearts [189] without increasing the calcium transient amplitude. SR33805-induced sensitization of myofilament activation was found to be associated with a slight increase in myosin light chain-2 phosphorylation and a more significant decrease on troponin I phosphorylation, which latter was related to inhibition of protein kinase A activity by SR33805 [189]. SR33805 reduced APD and the amplitude of the calcium transient in rat ventricular myocytes. $10 \mathrm{nM}$ SR33805 enhanced the amplitude of unloaded cell shortening and facilitated its relaxation. Moreover, it induced a significant increase in maximal calcium-activated force [40].

\section{BRL-32872}

BRL-32872 (Fig. 4.) inhibited $\mathrm{I}_{\mathrm{Kr}}$ and $\mathrm{I}_{\mathrm{Ca}, \mathrm{L}}$ with $\mathrm{IC}_{50}$ values of 0.028 and $2.8 \mu \mathrm{M}$, respectively, but had a limited effect on $\mathrm{I}_{\mathrm{K} 1}$ in isolated guinea-pig myocytes [41]. BRL-32872 evoked an unusual effect on APD. AP prolongation with 0.3-10 $\mu \mathrm{M}$ BRL-32872 had a bell-shape with the largest prolongation of $24-25 \%$ occurring at $1 \mu \mathrm{M}$ in both guinea-pig papillary muscle [41] and in canine Purkinje fibers [190]. Moreover, in guinea-pig papillary muscle the extent of prolongation did not depend on stimulation CL and no reverse-rate dependence was found [41]. 


\section{Benzothiazepine-like compounds}<smiles>COc1ccc(OCCCN(C)CCOc2ccc3c(c2)OCO3)c(C2Sc3ccccc3N(C)C2=O)c1</smiles>

Semotiadil

SD-3211

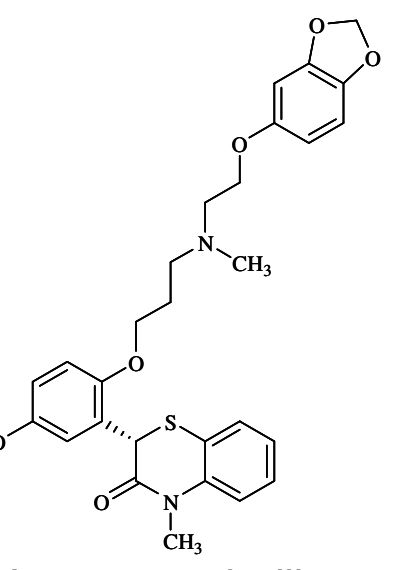

Levosemotiadil

SD-3212

\section{Mixture}

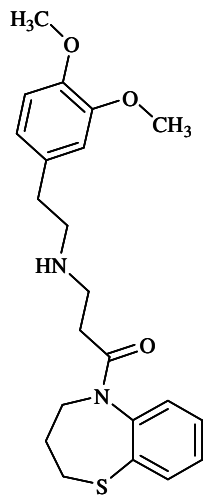

KT-362<smiles>COc1ccc(CCN(C)CCCOc2ccc(S(=O)(=O)c3c(C(C)C)cn4ccccc34)cc2)cc1OC(=O)OC(C)C(C)C</smiles>

FIG. 4. Chemical structures and IUPAC names of benzothiazepine- (above) or phenylalkylamine-like (below) compounds and one with similarity to both (up right).

Semotiadil, (2R)-2-[2-[3-[2-(1,3-benzodioxol-5-yloxy)ethyl-methylamino]propoxy]-5-methoxyphenyl]-4-methyl1,4-benzothiazin-3-one

Levosemotiadil, 2-[2-[3-[2-(1,3-benzodioxol-5-yloxy)ethyl-methylamino]propoxy]-5-methoxyphenyl]-4-methyl-1,4benzothiazin-3-one

KT-362, 1-(3,4-dihydro-2H-1,5-benzothiazepin-5-yl)-3-[2-(3,4-dimethoxyphenyl)ethylamino]propan-1-one

Fantofarone,

$\mathrm{N}$-[2-(3,4-dimethoxyphenyl)ethyl]-N-methyl-3-[4-(2-propan-2-ylindolizin-1-

yl)sulfonylphenoxy]propan-1-amine

SR 33805, [2-(3,4-Dimethoxy-phenyl)-ethyl]-\{3-[4-(3-isopropyl-1-methyl-1H-indole-2-sulfonyl)-phenoxy]-propyl\}methyl-amine

BRL 32872, N-(3,4-dimethoxyphenyl)-N-[3-[2-(3,4-dimethoxyphenyl)ethyl-methylamino]propyl]-4-nitrobenzamide

KT-362

In isolated papillary muscles of guinea-pig 3-30 $\mu \mathrm{M}$ KT-362 (Fig. 4.) caused a dose- and use-dependent decrease in $\mathrm{V}_{\max }$ without changing RMP, suggesting the inhibition of $\mathrm{I}_{\mathrm{Na}}$.

KT-362 (1-30 $\mu \mathrm{M})$ decreased both systolic and diastolic intracellular calcium concentration in a dose- and usedependent manner in cultured neonatal rat ventricular cells aggregates. $30 \mu \mathrm{M}$ KT-362 increased time to peak of the $\mathrm{Ca}^{2+}$ transient, while the half-life of the calcium transient was prolonged at $10 \mu \mathrm{M}$ and above. These effects of KT- 
$362 \mathrm{on}^{2+}$ transients could be mimicked by simultaneous application of $1 \mu \mathrm{M}$ D600 and $10 \mu \mathrm{M}$ ryanodine, suggesting that KT-362 inhibits both sarcolemmal calcium channels and calcium release channels of the sarcoplasmic reticulum [105]. Other studies also support the inhibition of calcium release channels of the endoplasmic reticulum (inositol-triphosphate receptor) by KT-362 in the micromolar range in rabbit aorta [191] and in canine femoral arteries [192].

Mibefradil (RO 40-5967)

The therapeutic plasma concentration of mibefradil (Fig. 5.) was in the range of 10-1000 ng/ml (approximately 0.02-2 $\mu \mathrm{M}$ ) [193].

Not only calcium channels were blocked by mibefradil as in CHO cells transfected with human $\mathrm{K}_{\mathrm{v}} 1.5$ mibefradil showed a dose-, use- and voltage-dependent inhibition with an $\mathrm{IC}_{50}$ of $0.78 \mu \mathrm{M}$. Recovery from inactivation was faster with mibefradil [194]. Mibefradil inhibited the expressed hERG and $\mathrm{K}_{\mathrm{v}} \mathrm{LQT} 1 / \mathrm{IsK}$ channel currents with $\mathrm{IC}_{50}$ values of 1.43 and $11.8 \mu \mathrm{M}$, respectively [150]. Mibefradil blocked the delayed rectifier potassium current, the hERG potassium current and $\mathrm{I}_{\mathrm{K} 1}$ with $\mathrm{IC}_{50}$ values of $0.3,0.7$ and $5.6 \mu \mathrm{M}$, respectively, in human myoblasts [195]. $\mathrm{Na}_{\mathrm{v}} 1.5$, the cardiac isoform of sodium channels expressed in HEK cells, was blocked by mibefradil with an $\mathrm{IC}_{50}$ value of $1 \mu \mathrm{M}$ [119] and with $\mathrm{IC}_{50}$ values of 0.5 and $2.9 \mu \mathrm{M}$ from holding potentials of -100 and $-130 \mathrm{mV}$, respectively [196]. In murine B cell lines mibefradil blocked voltage-gated potassium current and large-conductance background potassium current with $\mathrm{IC}_{50}$ values of 1.9 and $2.3 \mu \mathrm{M}$, respectively. Interestingly, calcium-activated potassium current was increased by $0.5-5 \mu \mathrm{M}$ mibefradil as the drug increased both calcium sensitivity and maximal activity of these channels. At high concentrations $(>10 \mu \mathrm{M})$, mibefradil inhibited calcium-activated potassium channel current in a voltage-dependent manner [197].

Several studies described the effects of mibefradil on APs. $100 \mathrm{nM}$ mibefradil reduced APA and AP firing rate (sometimes even stopped the activity) as well as shifted MDP to more positive potentials in rabbit SA node cells [51]. In $10 \mu \mathrm{M}$ it reduced $\mathrm{V}_{\max }$ and phase 4 slope, without affecting APD [48]. The effect of mibefradil on APD is variable. No effect was detected in human atrial myocytes in 1-10 $\mu \mathrm{M}$ [153] and in 0.1-1 $\mu \mathrm{M}$ on monophasic APDs in Langendorff-perfused rabbit heart [153]. Reduction of APD was observed in guinea-pig ventricular cells in $10 \mu \mathrm{M}$ [153]. In contrast, mibefradil (3-10 $\mu \mathrm{M})$ increased APD in canine Purkinje fibers [52]. The reduction of the plateau of the AP was described by 1 and $10 \mu \mathrm{M}$ mibefradil in isolated guinea-pig ventricular cardiomyocytes and in human atrial myocytes [153]. Same was seen in canine Purkinje fibers by doses of 3-10 $\mu$ M [52]. Indicating the inhibition of $\mathrm{I}_{\mathrm{Na}}, 10 \mu \mathrm{M}$ mibefradil reduced overshoot potential and APA in isolated guinea-pig cardiomyocytes but had no effect on the RMP [153].

\section{Bepridil (CERM-1978)}

The therapeutic plasma concentration of bepridil (Fig. 5.) is approx. $2 \mu \mathrm{M}$ [198] although the unbound concentration of bepridil is much lower, approximately $15 \mathrm{nM}$ [199]. Oral doses of 200, 300 and $600 \mathrm{mg} /$ day bepridil given to volunteers resulted in the peak plasma levels of $0.28,0.44$ and $0.97 \mu \mathrm{g} / \mathrm{ml}(0.76,1.2$ and $2.6 \mu \mathrm{M})$, respectively [200].

10-100 $\mu \mathrm{M}$ bepridil evoked calcium sensitizing action and increased force and ATPase activity in skinned porcine trabeculae [201]. In cultured neonatal rat ventricular cells $10 \mu \mathrm{M}$ bepridil sensitized myofilaments to calcium [104]. $1 \mu \mathrm{M}$ bepridil reduced oxidative phosphorylation in rabbit heart mitochondria by $50 \%$ [202].

$\mathrm{I}_{\mathrm{Na}}$ was also reduced by bepridil in neonatal rat cells with an $\mathrm{IC}_{50}$ of $30 \mu \mathrm{M}$ (much less potently compared to $\mathrm{I}_{\mathrm{Ca}, \mathrm{L}}$ inhibition). $\mathrm{I}_{\mathrm{Na}}$ steady-state inactivation was shifted to more negative potentials and recovery from inactivation was slowed down just as with $\mathrm{I}_{\mathrm{Ca}, \mathrm{L}}$ [35]. In guinea-pig ventricular cells $\mathrm{I}_{\mathrm{Na}}$ inhibition by bepridil was more potent as the $\mathrm{IC}_{50}$ was $20 \mu \mathrm{M}$ [203]. $\mathrm{I}_{\mathrm{Na}}$ in guinea-pig atrial cells was even more sensitive to bepridil ( $\mathrm{IC}_{50}$ of $4.34 \mu \mathrm{M}$ ) which is similar to that seen by levosemotiadil [33]. Interestingly, when $10 \mu \mathrm{M}$ bepridil was applied for $24 \mathrm{~h}$ on isolated neonatal rat cardiomyocytes it augmented $\mathrm{I}_{\mathrm{Na}}$ with $50 \%$ by inhibition of calmodulin action leading to a decreased degradation of the $\mathrm{Na}_{\mathrm{v}} 1.5 \alpha$ subunit while the same dose applied for 3 min reduced $\mathrm{I}_{\mathrm{Na}}$ by $20 \%$ [204].

Sodium/calcium exchange was reduced by only supratherapeutic bepridil doses $\left(\mathrm{IC}_{50}\right.$ of $\left.30 \mu \mathrm{M}\right)$ in cardiac sarcolemmal membrane vesicles and bepridil acted mode-dependently as the calcium extrusion (forward mode) was inhibited more effectively [205]. In guinea-pig ventricular cells $\mathrm{I}_{\mathrm{NCX}}$ was more sensitive to bepridil $\left(\mathrm{IC}_{50}\right.$ of $\left.8.1 \mu \mathrm{M}\right)$ [94]. 

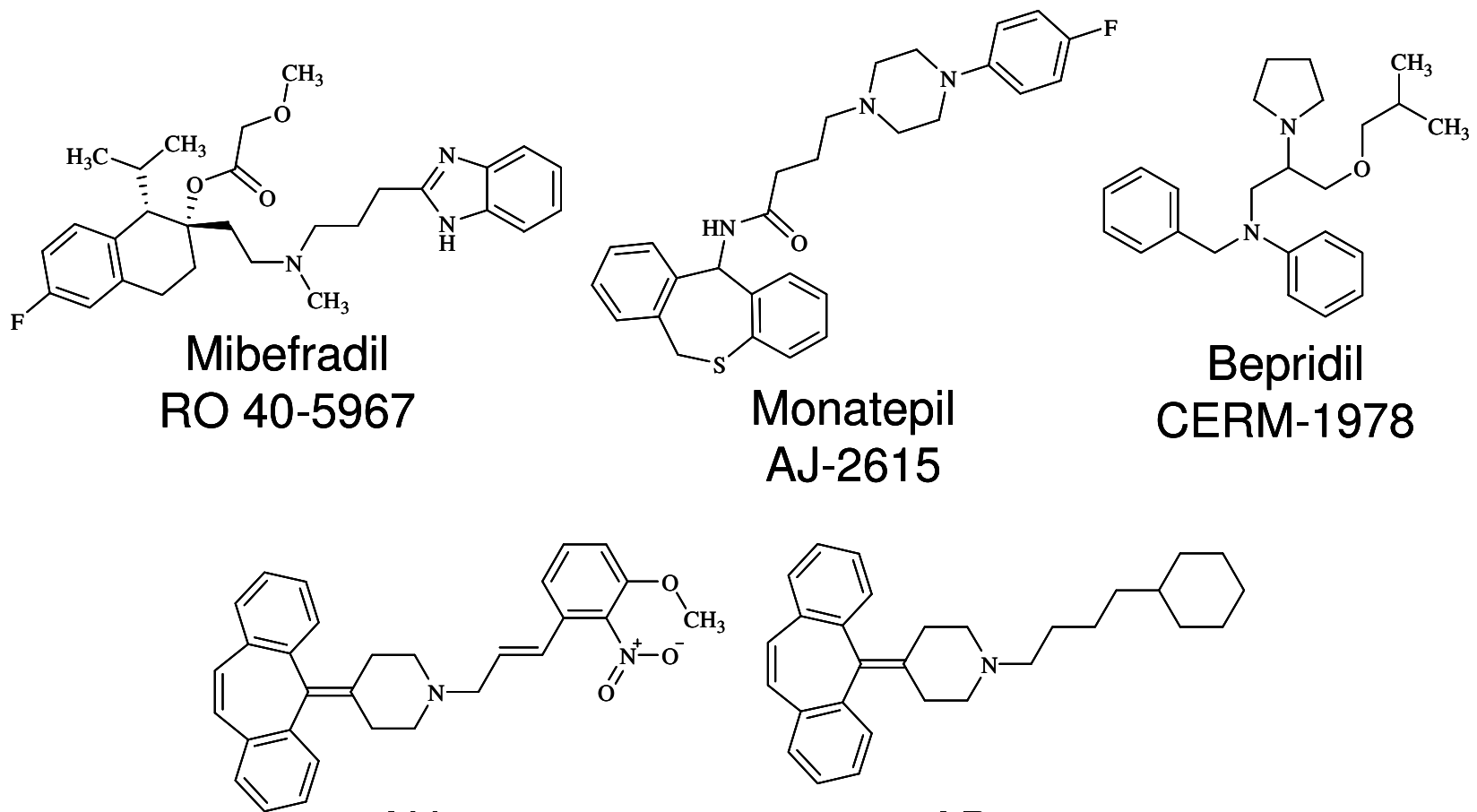

AH-1058

AP-792

FIG. 5. Chemical structures and IUPAC names of various compounds with calcium channel antagonist action. Mibefradil, [(1S,2S)-2-[2-[3-(1H-benzimidazol-2-yl)propyl-methylamino]ethyl]-6-fluoro-1-propan-2-yl-3,4-dihydro1H-naphthalen-2-yl] 2-methoxyacetate

Monatepil, N-(6,11-dihydrobenzo[c][1]benzothiepin-11-yl)-4-[4-(4-fluorophenyl)piperazin-1-yl]butanamide

Bepridil, N-benzyl-N-[3-(2-methylpropoxy)-2-pyrrolidin-1-ylpropyl]aniline

AH-1058, 4-Dibenzo[a,d]cyclohepten-5-ylidene-1-[3-(3-methoxy-2-nitro-phenyl)-allyl]-piperidine

AP-792, 1-(4-Cyclohexyl-butyl)-4-dibenzo[a,d]cyclohepten-5-ylidene-piperidine

HCN4 channels (underlying "funny" pacemaker current) expressed in HEK cells were also blocked by bepridil with an $\mathrm{IC}_{50}$ of $4.9 \mu \mathrm{M}$ whereas verapamil was much less potent inhibitor of those channels (IC $\mathrm{ID}_{50}$ of $\left.45 \mu \mathrm{M}\right)$ [206]. 10 $\mu \mathrm{M}$ bepridil reduced "funny" pacemaker current in rabbit sinus node cells [207].

Regarding potassium currents, bepridil influenced all major cardiac potassium currents. Atrial potassium currents, like the current of expressed $h_{\mathrm{v}} 1.5$ channels $\left(\mathrm{I}_{\mathrm{Kur}}\right)$ in HEK cells and $\mathrm{I}_{\mathrm{K} \text {,Ach }}$ in guinea-pig atrial cells were inhibited with $\mathrm{IC}_{50}$ values of about 7 and approximately $0.75 \mu \mathrm{M}$, respectively [33], [208]. The inhibition of $\mathrm{I}_{\mathrm{K}, \text { Ach }}$ by bepridil was less potent compared to that of levosemotiadil $\left(\mathrm{IC}_{50}\right.$ of $\left.0.3 \mu \mathrm{M}\right)$. The carbachol-induced AP shortening was reversed by levosemotiadil more potently compared to bepridil [33].

Similarly to what was observed with $\mathrm{I}_{\mathrm{Na}}$, long-term bepridil treatment $(12 \mathrm{~h}$, between $0.3-30 \mu \mathrm{M})$ increased the protein level of $\mathrm{K}_{\mathrm{v}} 1.5$ channels in a concentration-dependent manner with an $\mathrm{IC}_{50}$ of $1 \mu \mathrm{M}$ by delaying the degradation process of $\mathrm{K}_{\mathrm{v}} 1.5$ channel proteins acting at the endoplasmic reticulum as a chemical chaperone. The $\mathrm{K}_{\mathrm{v}} 1.5$ current measured as 4-AP sensitive current was increased by $3 \mu \mathrm{M}$ bepridil to $300 \%$ of control [209].

$10 \mu \mathrm{M}$ bepridil completely blocked $\mathrm{K}_{\mathrm{ir}} 6.2+\mathrm{SUR} 2 \mathrm{~A}$ channels (underlying $\mathrm{I}_{\mathrm{K}, \mathrm{ATP}}$ ) expressed in HEK 293 cells, but the drug opened mitochondrial $\mathrm{K}_{\mathrm{ATP}}$ channels thereby promoted cardioprotective action [123]. In follicle-enclosed Xenopus oocytes $\mathrm{I}_{\mathrm{K}, \mathrm{ATP}}$ was blocked by bepridil with an $\mathrm{IC}_{50}$ of $7.6 \mu \mathrm{M}$, more effectively compared to verapamil $\left(\mathrm{IC}_{50}\right.$ of $\left.60 \mu \mathrm{M}\right)$ but to the same extent as with levosemotiadil and semotiadil $\left(\mathrm{IC}_{50}\right.$ values of 9 and $11 \mu \mathrm{M}$, respectively [124]. $\mathrm{I}_{\mathrm{K}, \mathrm{Na}}$ in guinea-pig ventricular cells was reduced by bepridil with an $\mathrm{IC}_{50}$ of $0.51 \mu \mathrm{M}$, which can be the reason of the non reverse-rate dependent AP lengthening effect of the drug [127].

In guinea-pig ventricular myocytes $1-20 \mu \mathrm{M}$ bepridil increased APD due to inhibition of $\mathrm{I}_{\mathrm{K}}$ and $\mathrm{I}_{\mathrm{K} 1}$ [210] but others found that neither $I_{K}$ nor $I_{K 1}$ was sensitive to bepridil up to $100 \mu \mathrm{M}$ [35]. In sheep Purkinje fibers $I_{K}$, $I_{K 1}$ and $I_{t o}$ was reduced by bepridil to various extent. Outward $\mathrm{I}_{\mathrm{K} 1}$ was reduced by $30 \%$ in $1.8 \mu \mathrm{M}$ bepridil, $\mathrm{I}_{\mathrm{to}}$ was reduced with an $\mathrm{IC}_{50}$ of $2.5 \mu \mathrm{M}$ and $\mathrm{I}_{\mathrm{K}}$ was also reduced by $10 \mu \mathrm{M}$ [211]. In contrast, $10 \mu \mathrm{M}$ bepridil had no effect on $\mathrm{I}_{\mathrm{K}}$ in rabbit sinus node cells [207]. In HEK cells expressing KCNQ1 and KCNE1 channel proteins (underlying $\mathrm{I}_{\mathrm{Ks}}$ ) bepridil 
reduced the current with $\mathrm{IC}_{50}$ of 5.3 and $2.5 \mu \mathrm{M}$ when 250 and $1000 \mathrm{~ms}$ long depolarizing pulses were applied, respectively. This suggests a greater affinity of binding to the closed channel [212]. Others found an $\mathrm{IC}_{50}$ of $10 \mu \mathrm{M}$ for expressed $\mathrm{K}_{\mathrm{v}} \mathrm{LQT} 1 / \mathrm{IsK}$ channels mediated currents in COS cells [150]. Native $\mathrm{I}_{\mathrm{Ks}}$ in guinea-pig ventricular cells was blocked by bepridil with an $\mathrm{IC}_{50}$ of $6.2 \mu \mathrm{M}$ [213]. hERG channels expressed in HEK cells were blocked by bepridil with an $\mathrm{IC}_{50}$ of $26 \mathrm{nM}$ [44] whereas in COS cells the $\mathrm{IC}_{50}$ value was $0.55 \mu \mathrm{M}$ [150]. Native $\mathrm{I}_{\mathrm{Kr}}$ currents in guinea-pig ventricular cells were reduced with an $\mathrm{IC}_{50}$ of $13.2 \mu \mathrm{M}$ [213], less potently as expressed hERG protein. Moreover, it was suggested that bepridil can also inhibit $\mathrm{I}_{\mathrm{K}, \mathrm{Ach}}[120]$.

\section{AH-1058}

In isolated guinea-pig cardiomyocytes $\mathrm{AH}-1058$ (Fig. 5.) dose-dependently reduced the amplitude of the calcium transient [106] and $10 \mu \mathrm{M}$ AH-1058 blocked $\mathrm{I}_{\mathrm{Na}}$ by $15 \%$ without reducing $\mathrm{I}_{\mathrm{Kr}}, \mathrm{I}_{\mathrm{Ks}}$ or $\mathrm{I}_{\mathrm{K} 1}$. In coronaryperfused right ventricular guinea-pig tissue preparations $10 \mu \mathrm{M}$ AH-1058 shortened the APD with little effect on the RMP, $\mathrm{V}_{\max }$ and overshoot potential. Contractile force was reduced by 0.1-10 $\mu \mathrm{M}$ AH-1058 in a dose-dependent manner [106].

\section{Antiarrhythmic actions of certain CCAs}

Out of the compounds discussed in this review only three (verapamil, diltiazem and bepridil) have a licence for medical use according to the U.S. Food and Drug Administration and only 9 of them was tested in medical treatment in human volunteers and/or patients (see Tables 4-6 below for a summary).

\subsection{Phenylalkylamines}

Verapamil

Animal studies with verapamil

The antiarrhythmic effect of verapamil was observed in various animal models including guinea-pig [172], rabbit [214], cat [92], pig [135], [215] and dog [174], [178]. Verapamil was more useful during ischemia than reperfusion in a canine study [133].

Clinical evidence for the antiarrhythmic actions of verapamil

Verapamil was effective in various cardiac arrhythmias including AF and paroxysmal supraventricular tachycardia (PSVT). In a study of 181 patients verapamil treatment (10 mg iv. over $15-30$ seconds) significantly slowed sinus tachycardia, converted PSVT to SR and reduced VR in patients with AF and AFL very effectively [216]. It was also effective in Wolff-Parkinson-White (WPW) syndrome and AV junctional tachycardias but it was without effect in VT [217]. In acute myocardial infarction (AMI) patients with supraventricular tachyarrhythmia verapamil treatment reduced VR below 100 beats/min in every patients, but conversion to SR was achieved in only 1 out of 8 patients with AF and 7 out of 8 patients with AFL [218]. In 30 patients with PSVT, conversion to SR was achieved in 14 out of 29 patients by low-dose verapamil $(0.075 \mathrm{mg} / \mathrm{kg}$ body weight), while in 9 out of 15 high-dose verapamil $(0.15 \mathrm{mg} / \mathrm{kg}$ body weight) was required for the conversion [144].

Comparisons to $\beta$ adrenergic receptor blockers showed superiority of verapamil in restoring SR for instance in patients with PSVT compared to practolol [219]. Verapamil, unlike atenolol, did not impair exercise tolerance but reduced HR in an equally potent manner during the treatment of chronic AF in digitalized patients [220]. There is a controversy regarding the superiority of verapamil over digoxin in the treatment of chronic, persistent or permanent $\mathrm{AF}$ as two studies reported that verapamil either alone or in combination with digoxin is a better choice compared to digoxin alone [221], [222] while others reached the conclusion that verapamil is not superior to digoxin treatment [223].It seems that verapamil is at least as effective as adenosine in terminating acute episodes of PSVT but it acts more rapidly [224]. According to another study one of the first choices for short-term medications of supraventricular tachycardia (SVT) is intravenously applied verapamil especially if adenosine is contraindicated or if the PSVT terminates rapidly but is immediately recurrent [225]. Two other recent studies concluded that the two drugs have similar efficacy in treating PSVT [226], [227]. Adenosine treatment had a higher rate of minor but unpleasant adverse effects and a greater risk of relapse, while some patients treated with verapamil may develop significant hypotension. Although $80 \mathrm{mg} /$ day verapamil was effective in supraventricular tachyarrhythmias, it did not improve either exercise tolerance or cardiac output (CO) in 6 patients with chronic AF [228]. In contrast, in 18 patients with chronic AF verapamil $(240 \mathrm{mg} /$ day) proved to be effective in rate control and exerted a modest improvement in exercise tolerance [229]. The atrial ERP was reduced after AF and this reduction was prevented by verapamil but not procainamide treatment in adult patients without structural heart disease. During determinations of 
the post-AF ERP, secondary episodes of AF were unintentionally induced in $12 \%$ of verapamil patients compared to 90 and $80 \%$ of saline and procainamide patients, respectively [230]. Similarly, atrial ERP shortening induced by pacing-induced $\mathrm{AF}$ was attenuated after verapamil infusion in 60 patients and the incidence and duration of secondary AF was also reduced [231].

As mentioned above, verapamil treatment successfully converted SVTs in all 10 patients having WPW syndrome [217] or AV reentrant tachycardia [232]. In contrast, verapamil had no effect in WPW syndrome in other studies [233], [234]. Verapamil was also effective in intractable ventricular arrhythmias refractory to other treatment in cases after cardiopulmonary bypass with normal cardiac function [235] and in severe rheumatic aortic regurgitation associated with a dilated, poorly contracting left ventricle [236] as well as in patients with obstructive hypertrophic cardiomyopathy [237]. Moreover, a low number of asymptomatic patients with recurrent, sustained VT and a pattern of right bundle branch block (RBBB) without organic heart disease VT could be both induced and terminated with electrical stimulation. Verapamil terminated VT and prevented the induction of sustained VT [238]. Similarly, in 19 patients the broad complex tachycardia demonstrating RBBB was converted to SR with verapamil (5 mg intravenous boluses of verapamil up to $20 \mathrm{mg}$ or $20 \mathrm{mg}$ verapamil infused over $20 \mathrm{~min}$, titrated to effect with infusion stopped on conversion to SR) in 18 patients [239]. In 42 patients with idiopathic VT of left bundle branch block-like morphology verapamil treatment (120 mg 3 times daily) reduced VT in approximately $2 / 3$ of the patients but some patients exhibit exacerbation of the arrhythmia and verapamil should be avoided [240]. Verapamil (5 to $20 \mathrm{mg}$ intravenously over $60 \mathrm{~s}$ ) effectively terminated paroxysmal sustained monomorphic VT, repetitive non-sustained VT or premature ventricular contractions in all 7 patients [241]. On the long run (a mean 5.8 year follow up) in 37 patients with sustained left VT without apparent structural heart disease verapamil (160 to $320 \mathrm{mg} /$ day) proved to be the drug of choice for alleviating symptoms, but non pharmacologic therapy was necessary in 6 patients [242]. $5 \mathrm{mg}$ verapamil injection terminated epinephrine induced VPCs and EADs [243] as well as in 8 patients with congenital LQTS verapamil eliminated or reduced EADs, suppressed the epinephrine induced VPCs and TdP. It also shortened AP and decreased TDR [93]. 6 patients with molecularly defined catecholaminergic polymorphic VT, all carrying a cardiac ryanodine receptor (RyR2) mutation and on $\beta$ adrenergic receptor blocker therapy, received intravenous injection of $0.2 \mathrm{mg} / \mathrm{kg}$ verapamil and this reduced the number of isolated and successive premature ventricular complexes during exercise by $76 \%$ and delayed the appearance of premature ventricular complexes [244]. In a small study done on 5 patients with either catecholaminergic polymorphic VT or polymorphic VT addition of verapamil to the $\beta$ adrenergic receptor blockers reduced the number of ventricular ectopic beats during the whole exercise test as well as the ratio of ventricular ectopic to sinus beats in one patient [245]. Ischemia-induced arrhythmias were also effectively reduced by verapamil. In 31 patients (6 premature ventricular contractions, 19 accelerated idioventricular rhythms, $3 \mathrm{VTs}, 2 \mathrm{VFs}$ and $1 \mathrm{TdP}$ all with a diagnosis of AMI after mechanical revascularization therapy within $6 \mathrm{~h}$ of onset of symptoms) intracoronary verapamil $(0.25$ to $1.0 \mathrm{mg})$ was effective in rapidly terminating all reperfusioninduced arrhythmias except for VFs. The intracoronary use of verapamil was without major complications and resumptions of arrhythmias [246].

Right ventricular outflow tract tachycardia as well as idiopathic verapamil sensitive ventricular tachycardia can both be treated with verapamil [247], [248]. In the former case verapamil works by reducing $\mathrm{Ca}^{2+}$ overload [249] while it slows down conduction and prevents re-entry in the latter [250].

D600 (gallopamil)

Animal studies with D600

In open-chest anesthetized dogs D600 significantly elevated myocardial blood flow in the non-ischemic area, but did not influence blood flow in the ischemic region [251] in contrast to the effect of verapamil, which either increased CF to the ischemic area [112] or caused a coronary steal from the ischemic area of the myocardium [128]. Ischemia and reperfusion-induced arrhythmias were reduced by D600 in rats [252], dogs [253] and guinea-pigs [254].

D600, in a dose reducing the contractile force by $50 \%$, induced a further prolongation of the APD and provoked EADs thus it had arrhythmogenic action in a special model of papillary muscles of guinea-pig hearts [129]. In Langendorff-perfused rabbit hearts $0.5 \mathrm{mg} / \mathrm{l}$ D600 infused during fast VF (dominant frequency, $19.1 \pm 1.8 \mathrm{~Hz}$ ) consistently converted fast VF to VT. However, increasing D600, in a higher dose of 2.5 or $5.0 \mathrm{mg} / \mathrm{l}$, converted VT to slow VF $(11.9 \pm 2.3 \mathrm{~Hz})$. D600 in the lower dose inhibited calcium current and mediated antiarrhythmic action. On the contrary, higher doses of D600 (evoking $\mathrm{I}_{\mathrm{Na}}$ inhibition) can be arrhythmogenic [130].

In cats with left ventricular hypertrophy D600 prolonged sinus CL and AV CT but it did not protect against ventricular arrhythmia [255].

In open-chest anesthetized dogs with $20 \mathrm{~min}$ transient coronary artery occlusion D600 $(0.13 \mathrm{mg} / \mathrm{kg}$ iv), similarly to verapamil $(0.25 \mathrm{mg} / \mathrm{kg}$ iv $)$ both given $5 \mathrm{~min}$ prior the ischemia reduced the epicardial conduction delay 
of the ischemic area and almost completely suppressed ventricular arrhythmias and VF. Delayed ventricular reperfusion arrhythmias were also significantly reduced by both drugs [178]. In dogs 3-7 days after ligation of the left anterior descending coronary artery (LAD) D600 and verapamil $(0.2-0.5 \mathrm{mg} / \mathrm{kg}$ iv) improved the conduction in reentrant pathways with abolition of both spontaneous and premature depolarizations evoked reentrant ventricular arrhythmias [256]. It seems that lower D600 doses were required to induce antiarrhythmic action in dogs therefore, D600 is likely to be more effective in the prevention of cardiac arrhythmias compared to verapamil. On the other hand it must be highlighted that D600 was arrhythmogenic at least in guinea-pigs and rabbits under certain conditions.

Clinical evidence for the antiarrhythmic actions of D600

Regarding human data, D600 significantly prolonged CT and the ERP of the AV node just as did verapamil [257]. Similarly, in 13 patients with normal SR intravenous administration of D600 increased AV CT. Second degree AV block occurred at lower stimulation rates in all patients during atrial stimulation but D600 had no effect on the impulse propagation in atrial tissue and within the His-Purkinje system [258]. In $10 \mathrm{AF}$ patients, $100 \mathrm{mg}$ orally given D600 decreased the HR for 10 hours. In 5 patients a regularization of the ventricular response was observed without bradycardia. Oral administration of 3 times $50 \mathrm{mg}$ D600 daily decreased HR after a treatment period of 1 week to about $79 \%$ of control [259]. D600, just as verapamil, evoked bradycardia or SA and AV nodal conduction disturbances. Gastrointestinal side effects were stomach problems after D600 and constipation after verapamil [260]. In 36 healthy men plasma digoxin concentration was increased by $16 \%$ after $50 \mathrm{mg}$ D600 three times a day and by $70 \%$ after 80 or $120 \mathrm{mg}$ verapamil [261]. Slow-release formulations of D600 (100 $\mathrm{mg}$ twice a day) and verapamil (120 mg twice a day) reduced peak HRs recorded during a 6-min walking test to a similar extent in 18 patients with permanent AF receiving oral digoxin without organic heart disease. D600 appeared to be less effective at controlling VR both at resting and during exercise [262].

Tiapamil (Ro 11-1781)

Animal studies with tiapamil

The antiarrhythmic actions of tiapamil were documented in open-chest pigs with LAD ligation. Tiapamil (6 $\mathrm{mg} / \mathrm{kg}$ intravenously) decreased the incidence of VF by $60 \%$, maintained left ventricular maximal rate of pressure rise $\left(\mathrm{dP}_{\mathrm{dt}} \mathrm{dmax}_{\max }\right)$ after ligation and increased blood flow in the peripheral ischemic zone as well as in the peri-ischemic and non-ischemic zones [215]. In the same model verapamil in ten times lower dose fully prevented the occurrence of VF but left ventricular $\mathrm{dP} / \mathrm{dt}_{\max }$ was reduced to $50 \%$ without changing blood flow in the peripheral, peri-ischemic, or non-ischemic zones.

Tiapamil reduced the incidence of ventricular ectopic beats (VEBs) both during LAD occlusion and reperfusion in a canine model [263]. Furthermore, tiapamil $(4.75 \mathrm{mg} / \mathrm{kg})$ reduced myocardial infarct size which effect was lost with $11.25 \mathrm{mg} / \mathrm{kg}$ tiapamil probably due to marked hypotension and varying degrees of heart block [263]. In other studies tiapamil possessed again antiarrhythmic actions both during ischemia and reperfusion [264] but in others it proved effective against VF only during sympathetic stimulation and myocardial ischemia but not during reperfusion [173], [265].

In anesthetized open-chest dogs, intravenous tiapamil increased CF and decreased coronary vascular resistance, HR, blood pressure (BP) and total peripheral resistance. Tiapamil, in contrast to verapamil, did not depress myocardial contractility over a rather wide dose range and was more effective in increasing CF. Tiapamil dilated small but not large coronary arteries and raised $\mathrm{pO}_{2}$ relatively more in the subendocardial than in the subepicardial layers of the myocardium [266].

Compared to verapamil, tiapamil was 33 and 18 times less potent in reducing the contractility of rabbit left atrium and right ventricular papillary, respectively [267]. Both tiapamil and verapamil decreased HR and increased $\mathrm{CF}$ in isolated cat hearts. The vascular selectivity of tiapamil was higher compared to verapamil [161].

Clinical evidence for the antiarrhythmic actions of tiapamil

In patients with AFL, AF or PSVT $1 \mathrm{mg} / \mathrm{kg}$ intravenous tiapamil produced a marked decrease in VR and conversion to SR was achieved in some cases [268]. Tiapamil was also effective in patients with chronic AF. AV CT was increased and the frequency of atrial ectopic beats was reduced. Moreover, ectopic beats were reduced by $30-$ $50 \%$ in 6 out of 20 cases in patients with ventricular premature beats previously not responding to antiarrhythmic therapy [269]. In a small study tiapamil effectively restored SR and prevented tachycardias in patients with recurrent PSVT except in those with retrograde conduction involving an accessory pathway [270]. Tiapamil was also without effect in WPW syndrome patients on anterograde or retrograde RPs of the accessory pathway or on that of the 
ventricle [271]. Tiapamil (3 times $200 \mathrm{mg}$ per os daily) had positive effects in supraventricular and ventricular extrasystoles in 23 patients with extrasystoles of different origin [272].

Ischemia related arrhythmias were also effectively reduced by tiapamil as in patients with coronary disease and AF it decreased the VR by $54 \%$, although SR was not restored. The median frequency of VPC decreased just as the median ectopic/sinus beat ratio. Hypotension and bradycardia were observed in 5 out of 20 patients [273]. Similar results were reported in another article but tiapamil was effective both against supraventricular premature complexes and VPCs in contrast to other CCAs [274]. In AMI patients, tiapamil effectively reduced the number of premature ventricular contractions [275], supraventricular extra beats [276] and HR to less than 90 beats/min, which latter effect was also seen in reoccurring tachyarrhythmias during successive tiapamil administrations [277]. $1 \mathrm{mg} / \mathrm{kg}$ intravenous tiapamil significantly reduced the number of exercise-induced extrasystoles in patients 3-6 weeks after AMI [278]. Tiapamil was effectively used in 32 surgical patients in the treatment of intra- and postoperative cardiac arrhythmias such as AF, supraventricular paroxysmal tachycardia and VEBs. Small doses of 0.3-0.5 mg/kg were only effective in patients with tachycardic AF. The effective dose was between 1 and $1.5 \mathrm{mg} / \mathrm{kg}$ in most other arrhythmias [279].

Anipamil

Animal studies with anipamil

There are several animal studies showing the antiarrhythmic action of anipamil in rats [280]-[282] and also in pigs [283]. Anipamil had a stronger antiarrhythmic than hypotensive effect compared to verapamil in rats [280]. Anipamil pretreatment proved to be protective against LAD ligation induced functional (monitored by ECG signs) and biochemical (creatine kinase loss) damage in rats. In reperfusion experiments $(0.5 \mathrm{or} 1 \mathrm{mg} / \mathrm{kg}$ iv. anipamil injection $30 \mathrm{~min}$ before $5 \mathrm{~min}$ ischemia) the incidence of VT and VF was markedly reduced and completely prevented by the smaller and the higher anipamil dose, respectively [281]. $2.5 \mathrm{mg} / \mathrm{kg}$ anipamil did not produce any class I or III effects tested with recording epicardial APs but depressed early plateau phase in rats [282].

On the contrary, two studies reported harmful anipamil actions. In pentobarbitone-anesthetized pigs, intravenous anipamil exerted arrhythmogenic action as it increased the occurrence of VT and VF. On the contrary, verapamil, in a dose which produced similar hemodynamic effects than those of anipamil, reduced the occurrence of VT and VF [135], [136]. 8-week-long anipamil treatment aggravated left ventricular dilatation and remodeling, thereby reduced survival in rats with healed infarcts and ventricular dysfunction [136].

There is no information about the anipamil plasma levels in humans but in rabbits long-term (17 weeks) application of daily doses of 1 and $10 \mathrm{mg} / \mathrm{kg}$ led to plasma levels of 0.23 and $202 \mathrm{ng} / \mathrm{ml}$ (approximately 0.44 and 388 $\mathrm{nM}$ ), respectively [284], [285]. There are no human data about the antiarrhythmic actions of anipamil only the systolic and diastolic BP reducing [285] and anti ischemic effects of the drug were documented [286].

TABLE 4. Human studies describing the pro- and antiarrhythmic actions of phenylalkylamines.

\begin{tabular}{|c|c|c|c|}
\hline DRUG / dose & $\begin{array}{l}\text { Proarrhythmic } \\
\text { action }\end{array}$ & Antiarrhythmic action & Reference \\
\hline $\begin{array}{l}\text { Verapamil / } 3 \times 120 \\
\text { mg daily for at least } 5 \\
\text { half-lives to load }\end{array}$ & $\begin{array}{l}\text { exacerbation of } \\
\text { the arrhythmia } \\
\text { in idiopathic VT } \\
\text { of left bundle } \\
\text { branch block- } \\
\text { like morphology }\end{array}$ & & [240] \\
\hline $\begin{array}{llll}\text { Verapamil / } & 10 & \mathrm{mg} \\
\text { intravenously } & & \\
\end{array}$ & $\begin{array}{lr}\text { increased ST- } \\
\text { segment } \\
\text { elevation and } \\
\text { programmed } \\
\text { stimulation } \\
\text { induced } \\
\text { ventricular } \\
\text { fibrillation } & \\
\text { shorter } & \text { F-F } \\
\text { intervals } \\
\text { Brugada } \\
\text { syndrome }\end{array}$ & & [138] \\
\hline
\end{tabular}




\begin{tabular}{|c|c|c|}
\hline $\begin{array}{l}\text { Verapamil / } 10 \mathrm{mg} \\
\text { intravenously over } 15- \\
30 \text { seconds }\end{array}$ & $\begin{array}{l}\text { slowed sinus tachycardia, converted PSVT to SR and } \\
\text { reduced VR in AF and AFL patients }\end{array}$ & [216] \\
\hline $\begin{array}{l}\text { Verapamil / } 0.075- \\
0.15 \mathrm{mg} / \mathrm{kg}\end{array}$ & $\begin{array}{l}\text { conversion to SR was achieved in } 48-60 \% \text { of PSVT } \\
\text { patients }\end{array}$ & [144] \\
\hline $\begin{array}{lll}\text { Verapamil / } 10 & \mathrm{mg} \\
\text { intravenously }\end{array}$ & $\begin{array}{l}\text { successfully converted SVTs in WPW syndrome } \\
\text { or was without effect in WPW syndrome }\end{array}$ & $\begin{array}{l}{[217]} \\
{[233]} \\
{[234]}\end{array}$ \\
\hline $\begin{array}{l}\text { Verapamil / } 2.5-5 \mathrm{mg} \\
\text { intravenously }\end{array}$ & $\begin{array}{l}\text { was effective in ventricular arrhythmias refractory to } \\
\text { other treatment in several conditions }\end{array}$ & $\begin{array}{l}{[235]} \\
{[236]} \\
{[237]}\end{array}$ \\
\hline $\begin{array}{l}\text { Verapamil / } 5 \mathrm{mg} \\
\text { intravenous } \\
\text { up to } 20 \mathrm{mg}\end{array}$ & $\begin{array}{l}\text { broad complex tachycardia demonstrating RBBB was } \\
\text { converted to SR }\end{array}$ & [239] \\
\hline $\begin{array}{l}\text { Verapamil / } 3 \times 120 \\
\text { mg daily for at least } 5 \\
\text { half-lives to load }\end{array}$ & $\begin{array}{l}\text { reduced VT in approximately } 2 / 3 \text { of the patients in } \\
\text { idiopathic VT of left bundle branch block-like } \\
\text { morphology }\end{array}$ & [240] \\
\hline $\begin{array}{l}\text { Verapamil } \quad / \quad 5-20 \\
\mathrm{mg} / \mathrm{min} \text { intravenously }\end{array}$ & $\begin{array}{l}\text { terminated paroxysmal sustained monomorphic VT, } \\
\text { repetitive non-sustained VT or premature ventricular } \\
\text { contractions }\end{array}$ & {$[241]$} \\
\hline $\begin{array}{l}\text { Verapamil / } 0.2 \mathrm{mg} / \mathrm{kg} \\
\text { intravenously }\end{array}$ & $\begin{array}{l}\text { reduced the number of premature ventricular complexes } \\
\text { in catecholaminergic polymorphic VT carrying a } \\
\text { cardiac ryanodine receptor mutation }\end{array}$ & [244] \\
\hline $\begin{array}{l}\text { Verapamil / } 0.25-1.0 \\
\text { mg intracoronary }\end{array}$ & $\begin{array}{l}\text { terminated all reperfusion-induced arrhythmias except } \\
\text { for VFs and reduced various ischemia-induced } \\
\text { arrhythmias }\end{array}$ & [246] \\
\hline $\begin{array}{l}\text { Verapamil / up to } 20 \\
\mathrm{mg} \text { in } 1 \text { } \mathrm{mg} / \mathrm{min} \\
\text { increments, } \\
\text { intravenously, titrated } \\
\text { to effect }\end{array}$ & $\begin{array}{l}\text { in supraventricular tachyarrhythmia VR was reduced } \\
\text { below } 100 \text { beats/min in patients within } 72 \text { hours with of } \\
\text { AMI, conversion to SR was done in most patients with } \\
\text { AFL }\end{array}$ & [218] \\
\hline $\begin{array}{l}\text { Verapamil / } 240 \mathrm{mg} \\
\text { SR tablet daily }\end{array}$ & $\begin{array}{lllll}\text { right ventricular outflow tract tachycardia } & \text { was } \\
\text { terminated }\end{array}$ & [247] \\
\hline D600/ $100 \mathrm{mg}$ per os & decreased the HR for 10 hours in $\mathrm{AF}$ & [259] \\
\hline $\begin{array}{l}\text { Tiapamil / } 1 \mathrm{mg} / \mathrm{kg} \\
\text { intravenously }\end{array}$ & $\begin{array}{l}\text { reduced VR and rhythm was converted to SR in some } \\
\text { cases in AFL, AF or PSVT patients }\end{array}$ & [268] \\
\hline $\begin{array}{l}\text { Tiapamil } / 1 \mathrm{mg} / \mathrm{kg} \text { or } \\
50 \mu \mathrm{g} / \mathrm{kg} / \mathrm{min} \text { for } 4 \mathrm{~h} \\
\text { intravenously }\end{array}$ & $\begin{array}{l}\text { ectopic beats were reduced in patients with atrial and } \\
\text { ventricular premature beats, AV CT was increased in } \\
\text { chronic AF }\end{array}$ & [269] \\
\hline $\begin{array}{l}\text { Tiapamil / a bolus of } 2 \\
\mathrm{mg} / \mathrm{kg} \text { intravenously, } \\
1 \mathrm{x} 1.2-1.5 \mathrm{~g} \text { daily }\end{array}$ & $\begin{array}{l}\text { restored SR and prevented tachycardias in patients with } \\
\text { recurrent PSVT having no accessory pathway }\end{array}$ & [270] \\
\hline $\begin{array}{l}\text { Tiapamil / } 3 \text { x } 200 \mathrm{mg} \\
\text { daily per os }\end{array}$ & $\begin{array}{l}\text { positive effects in supraventricular and ventricular } \\
\text { extrasystoles }\end{array}$ & {$[272]$} \\
\hline $\begin{array}{l}\text { Tiapamil } / 1 \mathrm{mg} / \mathrm{kg} \\
\text { then } 50 \mu \mathrm{gg} / \mathrm{kg} / \mathrm{min} \text { for } \\
4 \mathrm{~h} \text { intravenously }\end{array}$ & $\begin{array}{l}\text { reduced ischemia related arrhythmias, decreased the VR } \\
\text { in patients with AF }\end{array}$ & [273] \\
\hline $\begin{array}{l}\text { Tiapamil / } 1 \mathrm{mg} / \mathrm{kg} \\
\text { then } 25 \quad \mu \mathrm{g} / \mathrm{kg} / \mathrm{min} \\
\text { intravenously }\end{array}$ & $\begin{array}{l}\text { reduced the number of premature ventricular } \\
\text { contractions, supraventricular extra beats, HR to less } \\
\text { than } 90 \text { beats/min and exercise-induced extrasystoles in } \\
\text { patients with or after AMI }\end{array}$ & $\begin{array}{l}{[275]} \\
{[276]} \\
{[277]} \\
{[278]}\end{array}$ \\
\hline $\begin{array}{l}\text { Tiapamil } / 1-1.5 \\
\mathrm{mg} / \mathrm{kg} \text { intravenously }\end{array}$ & $\begin{array}{l}\text { reduced intra- and postoperative cardiac arrhythmias } \\
\text { such as AF, supraventricular paroxysmal tachycardia } \\
\text { and in VEBs }\end{array}$ & [279] \\
\hline
\end{tabular}




\subsection{Benzothiazepines}

Diltiazem

Animal studies with diltiazem

Antiarrhythmic actions of diltiazem on both ischemia- and reperfusion-induced arrhythmias were described in rats [287], [288]. The antiarrhythmic actions were attributed to its negative chronotropic [287] or its energysparing properties [288]. The protective effects of diltiazem against VF were observed in canine ischemia models [173], [174], [178] but the drug proved to be ineffective in preventing tachycardia induced atrial remodeling compared to placebo [289].

The cardiac selectivity of diltiazem was described in rabbit [28], in dog [176] and also in human preparation [27]. The $\mathrm{EC}_{50}$ values for vasorelaxation and negative inotropy were $277 \mathrm{nM}$ and $39 \mu \mathrm{M}$, respectively, in rabbit tissues [28] while 0.69 and $7.2 \mu \mathrm{M}$ in human coronary artery and right ventricular trabeculae [27]. The smallest cardiac selectivity was seen in canine tissue as blood flow rate was doubled by $21 \mu \mathrm{g}$ while $110 \mu \mathrm{g}$ caused a $50 \%$ reduction in force of contraction [176].

Clinical evidence for the antiarrhythmic actions of diltiazem

Diltiazem and digoxin had additive depressant effects on SA and AV node function (increased sinus CL, AH CT, AV node functional and effective RPs) as well as on atrial function (reduced atrial RP) without significant adverse effects in patients without conduction disorders [290].

Intravenous diltiazem effectively and safely reduced HR in patients with AF or AFL. Hypotension was the most common side effect, occurring in $13 \%$ of patients. Symptomatic hypotension was present in $3.6 \%$ of patients, and responded to normal saline solution in all cases [291]. Similar beneficial actions were seen in another, placebo controlled study involving 113 AF or AFL patients without severe HF [292] as well as in 37 AF or AFL patients with moderate to severe congestive HF [293]. Intravenous diltiazem proved to be more effective and faster acting (in 5 min) than intravenous digoxin (acting only in 3 hours) or the combination of the two drugs in AF and AFL patients [294]. Moreover, in a study involving 180 patients with rapid AF, low-dose diltiazem $(\leq 0.2 \mathrm{mg} / \mathrm{kg}$ as a starting intravenous bolus) proved to be as effective as the standard dose of $0.25 \mathrm{mg} / \mathrm{kg}$ (according to the 2006 guidelines developed by the American College of Cardiology/American Heart Association/European Society of Cardiology for the management of patients with $\mathrm{AF}$ ) in adequate rate control but the complication of hypotension was seen significantly less frequently 18 vs. $35 \%$ in low and standard doses, respectively [295].

Oral diltiazem treatment also effectively lowered VR in patients with AF [296] and also reduced the maximal and submaximal HRs during exercise without affecting oxygen uptake, minute ventilation, respiratory exchange ratio or $\mathrm{BP}$ [297]. The effects of diltiazem on exercise tolerance are controversial in chronic AF as one study found a modest improvement similarly to that observed with verapamil [229] while another found no benefit in terms of improving either exercise tolerance or $\mathrm{CO}$ with either diltiazem or verapamil [228]. When compared to other drugs in controlling the VR at rest and during exercise in patients with chronic AF, diltiazem ( $240 \mathrm{mg}$ daily) proved to be least effective compared to atenolol treatment but it more effectively reduced HR during exercise compared to digoxin [298]. In chronic AF patients $240 \mathrm{mg} /$ day diltiazem combined with digoxin is an effective and safe regimen and enhances digoxin-mediated control of HR both at rest and during exercise [299], [300]. The same combined treatment alleviated the symptoms in $69 \%$ of the patients without changing the digoxin serum level [300] and was superior for control of 24-hour mean HR as compared to each drug used separately [301]. Slow-release formulation of diltiazem (120 mg twice a day) similarly to D600 (100 mg twice a day) and verapamil (120 mg twice a day) reduced peak HRs recorded during a 6-min walking test to similar extent in 18 permanent AF patients without organic heart disease but receiving oral digoxin [262].

Intravenous diltiazem effectively converted VT to SR (in $87 \%$ of SVT patients) or slowed HR to 100 beats/min or even below (in $82 \%$ of patients) [302]. Similar results were found in patients with inducible sustained SVT but diltiazem had no effect on the electrophysiological properties of accessory AV connections and was safe and very effective for acute tachycardia termination when the AV node was part of the reentrant circuit [303]. In another study involving 87 patients ( 25 with AV nodal reentry tachycardia, 60 with AV reentry associated with an accessory AV connection, and 2 with AT) the time to conversion was 3 minutes in diltiazem responding patients and the most frequent adverse response to diltiazem was hypotension in $11 \%$ of patients [304].

The incidence of postoperative AF in 60 patients, monitored continuously for 8 days after coronary bypass grafting with extracorporal circulation, was lower by diltiazem (10\% of patients) compared to the standard prophylactic regimen of an oral beta blocker (23.3\% of patients) [305]. CCAs, especially diltiazem were found to be beneficial after non-cardiac surgery in reducing the relative risk of myocardial ischemia and SVT [306]. Moreover, diltiazem, similarly to verapamil, effectively converted broad complex tachycardia demonstrating RBBB to SR [239]. 
Siratiazem (LR-A113)

Animal studies with siratiazem

Siratiazem evoked an antiarrhythmic action in a rat ischemia-reperfusion model as $2 \mathrm{mg} / \mathrm{kg}$ siratiazem reduced the incidence of VF on reperfusion. It also caused a reduction of HR and MAP [115]. The antiarrhythmic effect of siratiazem was similar to diltiazem, but less potent compared to that of verapamil in rats and guinea-pigs when studied with calcium, aconitine- and ouabain-induced arrhythmias [307].

Clentiazem (TA-3090)

Animal studies with clentiazem

Clentiazem treatment did not change transmural collateral flow measured $15 \mathrm{~min}$ after occlusion and the area at risk in an ischemic canine model. Infarct size was reduced by clentiazem only in those animals having a collateral flow greater than $0.02 \mathrm{ml} / \mathrm{min} / \mathrm{g}$, but not in those with lesser collateral flow [308].

In a hamster chronic HF model, clentiazem reduced inotropy with an $\mathrm{EC}_{50}$ of $734 \mathrm{nM}$, similarly to that observed in normal hearts $(677 \mathrm{nM})$. The coronary circulation was enhanced by clentiazem in both normal and failing hearts, although less pronounced action was detected in the latter $\left(\mathrm{EC}_{50}\right.$ values were 56 and $15 \mathrm{nM}$, respectively) [309].

Clinical evidence for the antiarrhythmic actions of clentiazem

In 11 patients with PSVT, clentiazem $(0.1 \mathrm{mg} / \mathrm{kg}$ intravenously for 3 minutes $)$ terminated programmed electrical stimulation-induced SVT at high right atrium in 9 out of 11 cases, while diltiazem $(0.2 \mathrm{mg} / \mathrm{kg}) \mathrm{was}$ more effective as it terminated 4 out of 4 cases [310]. In patients with stable angina, as low as $40 \mathrm{mg} /$ day clentiazem reduced the HR and increased exercise duration after 4 hours of medication. After 12 hours only 80 and $120 \mathrm{mg} / \mathrm{day}$ doses had antianginal action. The most frequently reported treatment-related adverse events with clentiazem were asthenia, headache (both $7.9 \%$ ), first-degree AV block and dizziness (both $4.4 \%$ ) [311].

S-2150

Animal studies with S-2150

S-2150 (Fig. 3.) applied to anesthetized rats $(30-60 \mathrm{mg} / \mathrm{kg}$ per os or $5 \mathrm{mg} / \mathrm{kg}$ intravenous pretreatment) reduced the myocardial infarct size just as diltiazem $(5 \mathrm{mg} / \mathrm{kg})$ and verapamil $(3 \mathrm{mg} / \mathrm{kg})$ [68]. The incidence of VT and fibrillation, induced by 4 min occlusion followed by reperfusion of the coronary artery, was reduced almost to zero by $60 \mathrm{mg} / \mathrm{kg} \mathrm{S}-2150$. Moreover, S-2150 also decreased cardiac mechanical function and increased CF [68]. Compared to diltiazem, S-2150 was less cardiodepressive but exerted stronger vasodilatation [68]. Similarly, in anesthetized open-chest dogs, S-2150 decreased myocardial work to a greater extent compared to diltiazem while caused a comparable hypotensive effect. S-2150 more promptly improved the local myocardial stunning caused by ischemia and reperfusion and unlike with diltiazem, this effect did not accompany the energy-sparing action in ischemic/reperfused myocardium. These results suggest that S-2150 is a favorable hypotensive agent for hypertensive patients with ischemic heart disease [312].

TABLE 5. Human studies describing the pro- and antiarrhythmic actions of benzothiazepines.

\begin{tabular}{|l|l|l|c|}
\hline \multicolumn{1}{|c|}{ DRUG / dose } & Proarrhythmic action & \multicolumn{1}{|c|}{ Antiarrhythmic action } & Reference \\
\hline $\begin{array}{l}\text { Diltiazem / 50 mg infused } \\
\text { over 20 min, titrated to } \\
\text { effect }\end{array}$ & & $\begin{array}{l}\text { broad complex tachycardia demonstrating } \\
\text { RBBB was converted to SR }\end{array}$ & {$[239]$} \\
\hline $\begin{array}{l}\text { Diltiazem / intravenously } \\
\begin{array}{l}0.25 \text { or } 0.35 \mathrm{mg} / \mathrm{kg} / \text { over 2 } \\
\text { minutes }\end{array}\end{array}$ & $\begin{array}{l}\text { reduced HR in patients with AF or AFL } \\
\text { regardless the presence of absence of } \\
\text { congestive HF }\end{array}$ & {$[292]$} \\
\hline $\begin{array}{l}\text { Diltiazem / once } 120 \mathrm{mg} \\
\text { or 3x80 mg daily per os }\end{array}$ & lowered VR in patients with AF \\
\hline Diltiazem / 4x60 mg per os & $\begin{array}{l}\text { reduced the maximal and submaximal HRs } \\
\text { during exercise }\end{array}$ & {$[297]$} \\
\hline $\begin{array}{l}\text { Diltiazem / bolus of either } \\
\begin{array}{l}150 \text { or } 300 \mu \mathrm{g} / \mathrm{kg} \text { over 2 } \\
\text { minutes intravenously }\end{array}\end{array}$ & $\begin{array}{l}\text { converted VT to SR, reduced HR to 100 } \\
\text { beats/min }\end{array}$ & {$[302]$} \\
\hline $\begin{array}{l}\text { Diltiazem / continuous } \\
\text { infusion of for 24 h } \\
\text { (minimum dose, } 0.1\end{array}$ & $\begin{array}{l}\text { reduced the incidence of AF after coronary } \\
\text { bypass grafting }\end{array}$ & {$[305]$} \\
\hline
\end{tabular}




\begin{tabular}{|c|c|c|c|}
\hline $\mathrm{mg} / \mathrm{kg} / \mathrm{h})$ & & & \\
\hline $\begin{array}{lrr}\begin{array}{l}\text { Diltiazem } \\
\text { intravenously }\end{array} & 0.2 \text { for } \quad 3 \\
\text { minutes } & & \end{array}$ & & 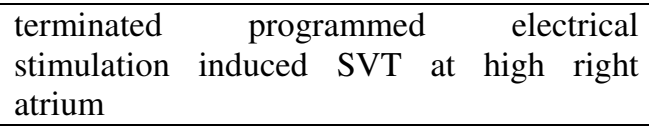 & {$[310]$} \\
\hline $\begin{array}{l}\text { Clentiazem (TA-3090) / } \\
0.1 \mathrm{mg} / \mathrm{kg} \text { intravenously } \\
\text { for } 3 \text { minutes }\end{array}$ & & $\begin{array}{l}\text { terminated programmed } \\
\text { stimulation induced SVT at high right } \\
\text { atrium }\end{array}$ & [310] \\
\hline $\begin{array}{l}\text { Clentiazem / } 80 \text { and } 120 \\
\mathrm{mg} / \text { day }\end{array}$ & & $\begin{array}{l}\text { antianginal action in patients with stable } \\
\text { angina }\end{array}$ & [311] \\
\hline $\begin{array}{l}\text { Clentiazem / } 80 \text { and } 120 \\
\mathrm{mg} / \text { day }\end{array}$ & $\begin{array}{l}\text { induced first-degree } \\
\text { AV block as a side- } \\
\text { effect in patients with } \\
\text { stable angina }\end{array}$ & & [311] \\
\hline
\end{tabular}

\subsection{Other CCAs}

Semotiadil (SD-3211)

Animal studies with semotiadil

The tau-on of negative dromotropic action was shorter for diltiazem and longer with verapamil compared to that of semotiadil in isolated guinea-pig hearts. During AFL semotiadil has a verapamil type of action on ventricular $\mathrm{CL}$, whereas the disadvantageous prolongation of maximal ventricular CL as well as the dispersion of ventricular CL with semotiadil was only about half of those found with verapamil [172].

Comparing the vascular over cardiac selectivity of semotiadil with that of diltiazem and verapamil semotiadil was more vasoselective than the other two in guinea-pigs [6]; than diltiazem in isolated perfused rat hearts [313] and in anesthetized open-chest dogs [314].

Semotiadil produced antiarrhythmic actions in anesthetized rats as the number of total ventricular premature beats occurring during ischemia as well as the incidence of reperfusion-induced VF were reduced very effectively by the drug $\left(\mathrm{EC}_{50}\right.$ values of 11 and $372 \mathrm{nM}$, respectively) [315]. On the contrary, semotiadil $(1 \mathrm{mg} / \mathrm{kg})$ exerted no antiarrhythmic action in a canine model [316].

Levosemotiadil (SD-3212)

Animal studies with levosemotiadil

There are much more data about the antiarrhythmic actions of levosemotiadil compared to semotiadil. In anesthetized rats, levosemotiadil reduced the number of total ventricular premature beats during the ligation period with an $\mathrm{EC}_{50}$ of $39 \mathrm{nM}$ (4 times less potently than semotiadil) and reduced the incidence of reperfusion-induced VF with an $\mathrm{EC}_{50}$ of $32 \mathrm{nM}$ (11 times more effectively than semotiadil) [315]. Levosemotiadil (3 $\mathrm{mg} / \mathrm{kg}$ ) had more potent antiarrhythmic properties compared to semotiadil $(1 \mathrm{mg} / \mathrm{kg})$ as it reduced the ratio of ectopic beats in a canine model [316]. Levosemotiadil suppressed adrenaline-induced arrhythmia in dogs and showed some antiarrhythmic effect on arrhythmias induced by either digitalis or 48 hour long coronary ligation [317]. Levosemotiadil (in $1.9 \mathrm{mg} / \mathrm{kg}$ mean dose and a plasma level of $187 \mathrm{ng} / \mathrm{ml}$, approx. $350 \mathrm{nM}$ ) terminated AFL after significant increase in AFL CL in a canine model [117]. Levosemotiadil (30 mg/kg/daily per os for 7 days) prevented VF in $64 \%$ of conscious dogs at high risk for VF. HR responses to myocardial ischemia and to graded doses of isoproterenol were blunted by levosemotiadil, which had approximately half the $\beta$-blocking activity of propranolol. The combination of $\mathrm{I}_{\mathrm{Na}}$ and $\mathrm{I}_{\mathrm{Ca}, \mathrm{L}}$ channel and partial $\beta$-adrenergic blockades was equally effective in preventing VF as propranolol (73\%) [318]. Due to these effects the antiarrhythmic properties of levosemotiadil in ventricular arrhythmias are more pronounced compared to semotiadil.

\section{Fantofarone (SR 33557)}

Animal studies with fantofarone

Contractile responses were more potently antagonized by fantofarone (Fig. 4.) compared to verapamil and diltiazem aortic strips and portal veins of the rat [319]. The negative inotropic action of fantofarone was smaller and bigger than that of verapamil and diltiazem, respectively, on rabbit left atria. Fantofarone was particularly selective for vascular smooth muscle and devoid of any potent negative inotropic actions [319].

The negative chronotropic effects were greater with fantofarone than with verapamil or diltiazem on spontaneous right atrial rate of rabbit atrium [319]. 
Direct antiarrhythmic action of fantofarone is not documented but, in a dose of $100 \mathrm{mg} / \mathrm{kg}$, it decreased the calcium content in rat hearts where calcium overload was induced by vitamin D3 [95]. Fantofarone, at concentrations which cause minimal alterations to normal function, can significantly improve functional recovery following an ischemic insult in the rat heart [320]. In isovolumic perfused rat heart, 20 min pretreatment of $1 \mu \mathrm{M}$ fantofarone significantly improved the recovery of mechanical performance, metabolic activity and cytosolic $\mathrm{pH}$ after 18 min of ischemia. Fantofarone treatment was even more beneficial during the reperfusion period. Higher recoveries of left ventricular pressure and rate pressure product, low end diastolic pressure, significant and complete recovery of ATP and phosphocreatine pool and a fast return of cytosolic $\mathrm{pH}$ to normal value were detected [321]. In anesthetized dogs $25 \mu \mathrm{g} / \mathrm{kg}$ intravenous fantofarone induced a decrease in myocardial oxygen consumption during periods of normal but not of elevated HR. In double dose, a decrease in myocardial oxygen consumption was maintained during pacing-induced elevated HR [108].

Human data on hemodynamic effects of fantofarone

In 6 healthy volunteers a single oral administration of 100 and $300 \mathrm{mg}$ fantofarone resulted in peak plasma concentrations of its active metabolite SR 33671 of 16 and $63 \mathrm{ng} / \mathrm{ml}$, respectively [322].

Fantofarone was examined on human volunteers where 100 and $300 \mathrm{mg}$ per os did not change systemic hemodynamics, although arterial pressure and $\mathrm{CO}$ tended to decrease slightly after $300 \mathrm{mg}$ [323]. In contrast, at the regional level, fantofarone produced strong vasodilatation of arterioles and, as a consequence, significantly increased brachial and carotid blood flow. The blood flow was preferentially increased in the brachial arterioles resulting in a redistribution of $\mathrm{CO}$ towards the musculocutaneous tissues. Fantofarone caused a marked and long-lasting decrease in HR, but it did not affect the auriculo-ventricular CT [323]. These effects were largely mediated by its active metabolite SR 33671 [322]. The effects of fantofarone (5 mg iv. in $10 \mathrm{~min}$ ) were tested in both before and during right atrial pacing (100 beats/min) in 9 patients with coronary artery disease and normal systolic left ventricular function. Without atrial pacing, fantofarone decreased $\mathrm{HR}, \mathrm{MAP}$, left ventricular $\mathrm{dP} / \mathrm{dt}_{\max }$ and rate-pressure product; increased stroke volume index but had no effect on cardiac index, filling pressures or systemic vascular resistance. During the pacing phase, none of the hemodynamic parameters differed from baseline including especially $\mathrm{dP} / \mathrm{dt}_{\max }$. Fantofarone has negative chronotropic action but shows no direct negative inotropic effect in patients with normal systolic left ventricular function [324]. Fantofarone, in doses of 100-150 mg twice daily, was effective and safe in the treatment of patients with chronic, stable angina pectoris as the drug prolonged exercise time without any effect on systolic BP both at rest and during exercise. Sinus bradycardia occurred in approximately $10 \%$ of the patients [325].

SR 33805

Animal studies with SR 33805

In isolated rabbit atrial preparations, SR 33805 exerted weaker negative chronotropic and inotropic response ( $\mathrm{EC}_{50}$ values of 6 and $12 \mu \mathrm{M}$, respectively) compared to fantofarone, verapamil and diltiazem. In superfused rat aortic strips and in femoral, renal and basilar arteries, SR 33805 reduced potassium-induced contractile responses ( $\mathrm{IC}_{50}$ approximately $40 \mathrm{nM}$ ) to a similar extent to those seen with fantofarone, verapamil and diltiazem. Moreover, unlike other CCAs, SR 33805 also reduced serotonin-induced contractions $\left(\mathrm{IC}_{50}\right.$ approximately $\left.250 \mathrm{nM}\right)$. SR 33805 is a potent CCA highly selective for vascular smooth muscle and devoid of any potent negative inotropic actions [79].

Beneficial actions of SR 33805 include the reduction of calcium overload induced with vitamin D3 and its deleterious consequences (lesions appearing in the tissue adjacent to the arteries) of rat hearts (per os $30 \mathrm{mg} / \mathrm{kg}$ ) [95], the restoration of myocardial infarction-altered cell shortening without affecting the calcium transient amplitude in cardiomyocytes isolated from rat with end-stage HF and the improvement of end-systolic strain and fractional shortening of hearts with myocardial infarction in vivo (a single intra-peritoneal bolus of $20 \mathrm{mg} / \mathrm{kg}$ ) [189]. SR 33805 was more effective in reducing calcium overload compared to fantofarone and verapamil [95].

BRL-32872

Animal studies with BRL-32872

Proarrhythmic actions of BRL-32872 were rare as in guinea-pig papillary muscle $1 \mu \mathrm{M}$ produced EADs in only one experiment (out of 35) which was suppressed at $3 \mu \mathrm{M}$ [41] and in canine Purkinje fibers EADs were never detected [190].

BRL-32872 can be very useful in antiarrhythmic treatment due to the lack of reverse frequency-dependent effect on APD and the relative absence of EADs. The ability of BRL-32872 to antagonize EADs produced by E-4031 in guinea-pig papillary muscle [41] or by clofilium in canine Purkinje fibers [190] adds to its antiarrhythmic potential. Moreover, BRL-32872 limited the increase in APD heterogeneity between ventricular muscle and Purkinje 
preparations which might also represent the basis for its antiarrhythmic action [190]. 0.1-1 $\mu$ M BRL-32872, similarly to flecainide and dofetilide, significantly lengthened $\mathrm{CL}$ of AF, prolonged ERPs and reduced AF inducibility in a model of acute stretch-related AF in isolated rabbit hearts, [326][327].

In vivo experiments also support the antiarrhythmic actions of BRL-32872. The incidence of VF was reduced to 13 and $0 \%$ by 0.3 and $1.0 \mathrm{mg} / \mathrm{kg}$ intravenously given BRL-32872, respectively, compared to $66 \%$ observed without the drug in minipigs with 20-min LAD occlusion. The antifibrillatory effects of BRL-32872 and dofetilide were associated with a prolongation of QT interval on ECG. The protective effect of BRL-32872 was greater compared to dofetilide during early reperfusion and this was most likely due to its calcium channel blocking activity [327]. This was confirmed as BRL-32872 was more potent than E-4031 in reducing the severity of arrhythmias whereas verapamil was without effect in a canine model. Combination of E-4031 with verapamil provided a similar degree of protection to that observed with BRL-32872 [328]. Similarly, in anesthetized rabbits sensitized to develop TdP, BRL-32872 (10 $\mu \mathrm{g} / \mathrm{kg} / \mathrm{min})$ prolonged QT interval without inducing TdP. Classical class III antiarrhythmic agents including E-4031 and dofetilide increased QT interval and induced TdP in 50-90\% of the rabbits. The addition of verapamil reduced the incidence of TdP induced by E-4031 [328].

KT-362

Animal studies with KT-362

Antiarrhythmic actions of KT-362 were detected in anesthetized dogs subjected to a 15-min or 90-min LAD occlusion followed by 3 hours of reperfusion. KT-362 treatment $(0.3 \mathrm{mg} / \mathrm{kg} / \mathrm{min}$ intravenously started $10-15 \mathrm{~min}$ before and continued throughout the occlusion) reduced the incidence of reperfusion-induced VF and markedly improved myocardial segment shortening of the ischemic-reperfused region. Moreover, myocardial infarct size was reduced by KT-362 [329][330].

KT-362 (10 mg/kg intravenously) suppressed coronary ligation arrhythmia and induced a transient hypotension in a canine model. Oral administration of 70-100 mg/kg was also effective on $24 \mathrm{hr}$ coronary ligation arrhythmia but it produced no prominent hypotension. KT-362 was more effective against digitalis- and adrenaline-induced arrhythmias as the required doses were only 3 and $1 \mathrm{mg} / \mathrm{kg}$, respectively [331].

There are several studies where a comparison of KT-362 with other CCAs is made. Verapamil, but not KT-362, significantly increased $\mathrm{CF}$ in guinea-pig hearts. $\mathrm{EC}_{50}$ values for negative inotropy, chronotropy and dromotropy were about 25, 3 and 3 times lower for verapamil compared to those with KT-362 [42]. Verapamil was again more potent than KT-362 in anesthetized dogs as prolongation of PQ interval on the electrocardiogram was observed with 0.1 $\mathrm{mg} / \mathrm{kg}$ verapamil but KT-362 even at $10 \mathrm{mg} / \mathrm{kg}$ evoked no negative dromotropic action [332][333]. In anesthetized ischemic dogs KT-362 $(0.3 \mathrm{mg} / \mathrm{kg} / \mathrm{min}$ intravenously started $10-15 \mathrm{~min}$ before and continued throughout the occlusion) but not diltiazem (15 and $30 \mu \mathrm{g} / \mathrm{kg} / \mathrm{min}$ ) produced a significant decrease in $\mathrm{HR}$ and $\mathrm{dP} / \mathrm{dt}_{\max }$ [333]. In rabbit aorta in the absence of extracellular calcium, responses to norepinephrine and methoxamine were inhibited by KT-362 (1-100 $\mu \mathrm{M})$ but not by verapamil or diltiazem (10 $\mu \mathrm{M}$ each) [191].

Mibefradil (RO 40-5967)

Animal studies with mibefradil

Mibefradil evoked antiarrhythmic action in Langendorff-perfused rat hearts. VF occurring during 30 min regional ischemia was abolished by $600 \mathrm{nM}$ mibefradil but reperfusion-induced VF incidence was not changed [334]. Similar results were found in open chest pigs where the low (clinically relevant) dose of mibefradil prevented the fall of the VF threshold, without depressing contractility during the ischemic period. The double mibefradil dose was antiarrhythmic during ischemia and during reperfusion, at the cost of depressed contractile activity [335], [336]. In dogs with healed infarctions, mibefradil $(125-1000 \mu \mathrm{g} / \mathrm{kg})$ prevented programmed electrical stimulation evoked arrhythmias during ischemia [174]. Rapid atrial pacing (400 bpm) for 7 days decreased atrial ERP and increased ERP heterogeneity, AF duration, and AF inducibility by single extrastimuli in dogs. Mibefradil treatment (100 $\mathrm{mg}$ /day throughout the 7 days of pacing but not that of acute administration) strongly attenuated tachypacing induced changes in ERP, AF duration and inducibility [289][336].

The cardiac selectivity of mibefradil was described in many species. $\mathrm{EC}_{50}$ of negative inotropy was 12 times higher than the one which doubled CF in guinea-pig whole hearts [49]. Mibefradil increased CF with an $\mathrm{EC}_{50}$ of $54 \mathrm{nM}$ and reduced contractility of myocardium and aorta with $\mathrm{EC}_{50}$ values of $14 \mu \mathrm{M}$ and $275 \mathrm{nM}$, respectively [337]. In human small arteries, the potassium contractures and isoprenaline-stimulated right atrial contractions were inhibited with $\mathrm{IC}_{50}$ values of $603 \mathrm{nM}$ and $24.5 \mu \mathrm{M}$, respectively, indicating a high (41) vascular selectivity of mibefradil [8]. 300 and $600 \mathrm{nM}$ mibefradil showed a marked vascular selectivity in Langendorff-perfused rat hearts [334]. In open chest pigs, the low (clinically relevant) dose of mibefradil increased left ventricular blood flow without depressing contractility [335][336]. 
Comparing the extent of the effects of mibefradil with other CCAs in guinea-pig ventricular cells, the negative inotropic action of mibefradil was more potent than that of diltiazem ( $\mathrm{EC}_{50}$ values of 6.3 and $31.6 \mu \mathrm{M}$, respectively) [338]. On the contrary, in conscious normotensive rats, intravenous mibefradil possessed the smallest negative inotropic action compared to both verapamil and diltiazem [339]. In isovolumically beating perfused control and early phase HF rabbit hearts, mibefradil did not exert negative inotropic action up to $10 \mu \mathrm{M}$ whereas both verapamil and diltiazem had a more potent effect in reducing contractility. Moreover, the negative inotropic actions of verapamil and diltiazem, but not that of mibefradil, were larger in HF than in control hearts [340]. In dogs with chronic HF intravenous mibefradil, but not diltiazem, caused significant improvement in contractility [341]. Verapamil was more potent in reducing the diastolic relaxation and developed pressure in Langendorff-perfused rat hearts [334].

Clinical evidence for the antiarrhythmic actions of mibefradil

In mild to moderate hypertension patients, after 4 weeks of per os mibefradil treatment the BP reduction as well as the prolongation of $\mathrm{PQ}$ interval was proportional with the measured plasma levels and only the highest dose (150 mg daily) was associated with cardiac complications related to AV block and bradycardia [193]. Acute effects of intravenous mibefradil ( $15 \mathrm{mg}$ in $15 \mathrm{~min}$ followed by $25 \mathrm{mg}$ in $60 \mathrm{~min}$ or $35 \mathrm{mg}$ in $15 \mathrm{~min}$ followed by $45 \mathrm{mg}$ in $60 \mathrm{~min}$ ) tested on 71 patients included a reduction in sinus node recovery time, an increase of AH interval in the higher dose, and an increase of AV nodal refractoriness with both doses [342]. Sinus node automaticity was suppressed and HR was lowered comparatively more than its negative dromotropic effect on the AV node by a single dose of $100 \mathrm{mg}$ mibefradil after 90 minutes [343]. In patients with higher than $40 \% \mathrm{EF}$, the plasma level of $800 \mathrm{ng} / \mathrm{ml}$ achieved by intravenous administration, which is equivalent with an oral dose of $100 \mathrm{mg}$ mibefradil, reduced MAP, total peripheral resistance and left ventricular end diastolic pressure; had no effect on HR but increased EF (from 52 to $58 \%$ ). In patients with low EF (less than $40 \%$ ) the same dose of mibefradil reduced HR but exerted a negative inotropic action. On the contrary, the $50 \%$ reduced dose not only reduced HR but also improved EF. It seems therefore, that high plasma concentrations of mibefradil might produce myocardial depression in patients with HF [344]. In 309 patients with coronary artery disease, stable angina pectoris and positive exercise tests, mibefradil (in 100 and $150 \mathrm{mg} /$ day doses) proved to be more effective as an anti ischemic drug compared to both amlodipine (10 mg/day) and placebo [345]. The Mach-1 study, done on 2590 congestive HF patients with a follow up of up to 3 years, showed that adjunct mibefradil treatment $(50-\mathrm{mg} / \mathrm{day}$ for 1 month followed by $100 \mathrm{mg} / \mathrm{day}$ for up to 3 years) did not have a beneficial effect on total mortality and cardiovascular morbidity/mortality. Moreover, mibefradil increased risk of mortality by $14 \%$ in the first 3 months which was not significant. Patients co-medicated with mibefradil and antiarrhythmics (class I or III), including amiodarone, had a significantly increased risk of death [346]. Mibefradil caused TdP [347] and sinus arrest [348] and interfered with the metabolism of many drugs as it is degraded by the cytochrome P450 pathway [349]. Due to the disappointing results of the Mach-1 study and the abovementioned severe side effects mibefradil was withdrawn from the market [350]. This happened only after the limited selectivity of the drug on T-type calcium channels has been discovered.

Monatepil (AJ-2615)

Animal studies with monatepil

Monatepil (Fig. 5.) was shown to possess $\alpha_{1}$-adrenoceptor blocking activity [351], which could contribute to its hypotensive effect by $20-35 \%$ [352].

Monatepil exerted antiarrhythmic action in rats as ventricular arrhythmias induced by adrenaline, as well as AT induced by aconitine was suppressed by intravenously applied monatepil $(0.1-3.0 \mathrm{mg} / \mathrm{kg})$ [353]. The antianginal effect of $0.1 \mathrm{mg} / \mathrm{kg}$ intravenous monatepil was more potent than that of diltiazem $(0.3 \mathrm{mg} / \mathrm{kg})$ in anesthetized rats [353].

Similarly, monatepil was more effective in inhibiting the potassium-induced contractile response and calcium influx in rat aorta (3 and 10 times more potent than verapamil and diltiazem, respectively) [351]. The antianginal effect of $0.1 \mathrm{mg} / \mathrm{kg}$ intravenous monatepil was more potent than that of diltiazem $(0.3 \mathrm{mg} / \mathrm{kg})$ in anesthetized rats [353]. The effects of monatepil on cardiac function and myocardial oxygen supply and demand were comparable with those of diltiazem, but the negative chronotropic and negative dromotropic effects of monatepil were less potent, therefore monatepil is a safer drug in the treatment of hypertension than diltiazem [354]. Indeed, in various hypertensive models of dogs and rats monatepil evoked an antihypertensive effect which developed more slowly and lasted longer compared to diltiazem [355]. Moreover, monatepil exerted comparable or more potent antiarrhythmic action than diltiazem or verapamil in rats but its proarrhythmic activity was less potent than that of the other two [353]. 
In a human study monatepil reduced both systolic and diastolic pressure without affecting the HR. In this regard it was similar to nitrendipine but monatepil had additional favorable effects on carbohydrate and lipid metabolism [356].

Human data on hemodynamic effects of monatepil

In patients with essential hypertension monatepil decreased BP to similar extent when applied alone or combined with ACE inhibitors. When monatepil was combined with $\beta$-blockers, the rate of responders and the reduction in both systolic and diastolic BP was lower compared to the other two groups [357].

Bepridil (CERM-1978)

Animal studies with bepridil

The antiarrhythmic actions of bepridil were described in ouabain-intoxicated canine Purkinje fibers [358], in rats [359], in anesthetized guinea-pigs [360] and also in isolated rabbit hearts [361].

Intravenous bepridil increased right atrial ERP and prevented VT in 33 and $50 \%$ of chronically infarcted dogs in 5 and $10 \mathrm{mg} / \mathrm{kg}$, respectively [362]. $5 \mathrm{mg} / \mathrm{kg}$ bepridil reduced myocardial oxygen consumption, HR, the number of VEBs and also abolished VF [109]. Similarly, in anesthetized rats, the number of total ventricular premature beats during coronary ligation and the incidence of reperfusion-induced VF were reduced with $\mathrm{EC}_{50}$ values of 229 and 676 $\mathrm{nM}$, respectively [315]. Bepridil suppressed the aconitine-induced dysrhythmias in anesthetized cats (in $5 \mathrm{mg} / \mathrm{kg}$ given intravenously) [363] but not in mice (in $20-100 \mathrm{mg} / \mathrm{kg}$ given intraperitoneally) [359]. Bepridil proved to be beneficial in AF in dogs as $4 \mathrm{mg} / \mathrm{kg}$ intravenous bepridil increased sinus CL, prevented the development of AF and reduced the shortening of monophasic $\mathrm{APD}_{90}$ probably due to the inhibition of $\mathrm{I}_{\mathrm{KAch}}[120]$. Another study showed that bepridil (10 mg/kg/day) reversed the electrophysiological consequences of atrial remodeling (shortening of atrial ERP) to some extent. L-type calcium channel downregulation (at least on mRNA level) and ERP was also reversed and the latter positively correlated with $\alpha_{1 \mathrm{C}} \mathrm{mRNA}$ expression [364]. Moreover, $1.8 \mathrm{mg} / \mathrm{kg}$ bepridil was protective against programmed electrical stimulation-induced VT. A correlation was found between the effective antiarrhythmic dose of bepridil and percentage changes in both the ERP for the first extrastimulus and QT, suggesting that a parallel and homogeneous prolongation in repolarization and refractoriness is essential for the antiarrhythmic effect of bepridil [99]. In $15 \mathrm{dogs}, 4-8$ days after myocardial infarction, $5 \mathrm{mg} / \mathrm{kg}$ intravenous bepridil prevented or significantly slowed sustained VT in 11/12 experiments. Bepridil prolonged the ERP of infarcted myocardium to a greater extent (15\%) compared to normal tissue $(9 \%)$ [365].

On the contrary, bepridil in the same dose $(5 \mathrm{mg} / \mathrm{kg})$ administered to dogs during coronary occlusion proved to be arrhythmogenic but it must be noted that bepridil administration during the reperfusion period absolutely prevented VF [133]. In canine Purkinje fibers, $1-10 \mu \mathrm{M}$ bepridil evoked EAD at long CL but the triggered activity was rare [131]. Finally in a canine model no antiarrhythmic action of bepridil (1-6 mg/kg) was found [316].

Comparing the extent of the effects of bepridil to other CCAs it seems that bepridil is not the most potent CCA. Bepridil exerted less potent negative dromotropic action compared to verapamil [116] and also to diltiazem [177]. The negative inotropic action compared to both verapamil and diltiazem [175][366] was also weaker just as its negative chronotropic action compared to the two drugs [175], as well as its antiarrhythmic action compared to both semotiadil and levosemotiadil [315]. Similarly, the action of bepridil was at least 10 times less potent on HR and the AV nodal conduction compared to verapamil in Langendorff-perfused rabbit hearts [367]. The increase of CF by bepridil was smaller than that seen with diltiazem but comparable to that of verapamil [366].

In rabbit aorta SMCs only bepridil reduced both the potassium- and norepinephrine-induced contractions whereas diltiazem and verapamil inhibited only the depolarization-induced ones, and bepridil was one of the most vascular selective CCAs [366]. Unlike verapamil and diltiazem, which had no effect on ventricular level, bepridil caused a small increase in QRS and a bigger increase in RP and $\mathrm{QT}_{\mathrm{c}}[177]$.

Clinical evidence for the antiarrhythmic actions of bepridil

Many human studies described the antiarrhythmic properties of bepridil. In 20 patients bepridil appeared beneficial in suppressing AFL, atrial and ventricular extrasystoles [368].

Regarding ventricular arrhythmias bepridil was effective in non-responding VT in the dose of a single $800 \mathrm{mg}$ followed by $500-600 \mathrm{mg}$ as it prevented VT initiation in $66 \%$ of the cases and caused side effects (paralytic ileus) in only 1 patient. Three patients remained symptom-free over a follow-up of 4 to 13 months [369]. Bepridil prevented VT induction in $47 \%$ of patients with symptomatic VT [370]. AV reentrant tachycardia was terminated in $30 \%$ of the 20 patients by $2 \mathrm{mg} / \mathrm{kg}$ intravenous bepridil [232]. In the presence of $3 \mathrm{mg} / \mathrm{kg}$ bepridil, VT was still inducible in 19 patients out of 21 versus 20 out of 21 in the absence of bepridil indicating its limited potency to suppress VT [371]. On the contrary, intravenous bepridil $(2 \mathrm{mg} / \mathrm{kg})$ prevented the induction of sustained VT in $21 \%$ of 38 
patients. $900 \mathrm{mg} /$ day bepridil was more effective as it prevented the induction of sustained VT in $50 \%$ of patients. The response to intravenous bepridil did not predict the response to oral bepridil. The response to any form of bepridil treatment was not related to the plasma level of bepridil but was rather related to a higher left ventricular EF. In conclusion, that study suggested that oral bepridil at the dose of $600 \mathrm{mg} /$ day may be useful in patients with recurrent VT [372]. During a mean follow-up of $52 \pm 44$ months, bepridil (mean dose of $156 \mathrm{mg} /$ day) completely suppressed ventricular tachyarrhythmias in $38 \%$ of the patients and decreased the frequency of ventricular tachyarrhythmia recurrences by more than $75 \%$ in $30 \%$ of the patients [373]. In a study on 8 men with idiopathic $\mathrm{VF}$, bepridil (200 mg/day) effectively reduced the frequency of VF episodes in association with prolongation of QT intervals at slower HRs [374]. In 21 patients with frequent VPCs, $900 \mathrm{mg}$ bepridil for 2 days as loading followed by 12 days of $400 \mathrm{mg}$ daily, reduced VPC frequency more than $70 \%$ in $48 \%$ of the patients. In $50 \%$ of the patients at least a $95 \%$ reduction in frequency of non-sustained VT was observed. Gastrointestinal and central nervous system side effects were considered to be mild and occurred in $62 \%$ of the patients. Bepridil had moderate antiarrhythmic efficacy in patients with ventricular arrhythmias [375].

$\mathrm{AF}$ was usually more sensitive to bepridil and a correlation was found between the efficacy of bepridil in AF and its plasma concentration measured just before the intake of the next oral dose. The target value to obtain clinical benefit was approximately $300 \mathrm{ng} / \mathrm{ml}$ [376]. 100-200 mg/day bepridil successfully converted AF to SR in $58 \%$ of the patients within 6 month (2.1 in average) and maintained that for 18 months in $81 \%$ of these patients [377]. Similarly, $53 \%$ of the 60 patients with long-lasting persistent AF were converted to SR by bepridil (100-200 mg/day for 8 weeks). Comparing these responders and non-responders revealed that the only difference was that the prolongation of fibrillation CL became significantly larger in responders suggesting that repetitive evaluation of fibrillation CL can be a feasible index to predict the efficacy of bepridil therapy [378]. Another study showed the same results (conversion in $50 \%$ of the patients by $200 \mathrm{mg} / \mathrm{day}$ bepridil) and reached the same conclusion regarding responders [379]. When bepridil was compared to other antiarrhythmic drugs, some studies found bepridil to be superior for instance over amiodarone in patients with persistent $\mathrm{AF}$ as the conversion to SR was achieved in $35 \%$ of patients with amiodarone ( $400 \mathrm{mg} /$ day for 7 days followed by $200 \mathrm{mg} /$ day) and in $85 \%$ of bepridil receiving patients (150 $\mathrm{mg} /$ day for 2 weeks followed by 100 or $200 \mathrm{mg} /$ day according to the age, gender, body weight, renal function and QT interval of the patients). The time elapsed till conversion was significantly shorter with bepridil (2.3 months) compared to amiodarone (3.2 months). Moreover, bepridil was also more effective in maintaining SR after conversion (50\% of patients in the amiodarone group and $75 \%$ of bepridil patients) [380]. Similarly, in patients with AF longer than 3 months, bepridil (200-600 mg/day for 3 weeks) seemed to be more effective in conversion of the AF to SR compared to amiodarone but unfortunately also more arrhythmogenic (VT, prolongation of $\mathrm{QT}_{\mathrm{c}}$ interval and TdP) than amiodarone with which no ventricular arrhythmias were seen [134]. Comparing bepridil to class IC drugs, their effectivity was similar (71\%) in the prevention of paroxysmal AF [381]. Bepridil (200 mg/day) proved to be more effective in reverting AF to SR alone or in combination with aprindine than electrical cardioversion [382]. Combination of bepridil with other antiarrhythmic drugs was studied as well. For instance, when 50-200 mg/day bepridil was added to a class I antiarrhythmic drug the frequency of symptomatic AF episodes was reduced to less than $10 \%$ in $78 \%$ of the patients and SR was restored within 3 months and maintained during the follow-up in $74 \%$ of patients with persistent AF. During a mean follow-up period of $27 \pm 22$ months, no potential complications occurred in any of the patients [383]. Again, combined therapy of bepridil (200 mg/day) and a class IC antiarrhythmic drug was more efficient for pharmacological cardioversion of refractory long-lasting persistent AF than bepridil alone [384]. Adding $\beta$-blocker (metoprolol or bisoprolol) to bepridil medication decreased the $\mathrm{QT}_{\mathrm{c}}$ interval (to a level which was still longer compared to that with bepridil alone) and significantly decreased both the $\mathrm{QT}_{\mathrm{c}}$ dispersion and TDR induced by bepridil [385].

As seen before, bepridil is more effective in atrial than in ventricular arrhythmias but sometimes arrhythmogenic effects were also reported as severe adverse effects. In a large trial involving 459 patients with AF or AFL, $4 \%$ of the patients receiving 100-200 mg bepridil daily had adverse effects during an average follow-up of 20 months. Marked QT prolongation occurred in 13, bradycardia in 6 and dizziness and general fatigue in 1 patient each. TdP occurred in 4 of 13 patients usually triggered by hypokalemia and sudden decrease in HR. Therefore careful observation of serum potassium concentration and the ECG should always be done during bepridil administration, particularly in elderly patients [386]. A trial involving 90 patients demonstrated that bepridil dose-dependently reduced AF and converted it to SR. Unfortunately the AF reoccurrence was high (75 and $91 \%$ with 200 and 100 $\mathrm{mg}$ /day dose, respectively) and adverse effects (VT, QT prolongation, sinus bradycardia) were frequent (approximately $10 \%$ ) indicating that the balance between benefits and risks of the drug should be individualized [387]. In 284 paroxysmal or persistent AF patients, the clinical outcome did not improve with bepridil during a median follow-up of 17 month and the probability of progression to permanent $\mathrm{AF}$ was $23.5 \%$ at 5 years. $\mathrm{QT}_{\mathrm{c}}$ 
interval prolongation was observed when plasma concentrations of bepridil were higher than $800 \mathrm{ng} / \mathrm{ml}$ and TdP occurred in two patients without structural heart disease taking $200 \mathrm{mg}$ daily [388].

AH-1058

Animal studies with AH-1058

AH-1058 exerted antiarrhythmic action in several species. For instance in the ouabain-induced arrhythmia model of the guinea-pig, pretreatment with AH-1058 (0.1-0.3 mg/kg, intravenously) delayed the appearance of VPC and VF in contrast to verapamil (1 mg/kg, intravenously) which failed to affect these arrhythmias [38]. In rat hearts subjected to 5-min coronary occlusion followed by 10 - $\mathrm{min}$ reperfusion, AH-1058 (both at 0.1-0.3 $\mathrm{mg} / \mathrm{kg}$, intravenously and 2-4 mg/kg per os) inhibited the incidence of both VT and VF. In contrast, even in a higher dose (1 $\mathrm{mg} / \mathrm{kg}$, intravenously) the aconitine-induced arrhythmias were not affected in rats [38]. AH-1058 $(100 \mu \mathrm{g} / \mathrm{kg}$, intravenously) effectively suppressed epinephrine-, digitalis- as well as two-stage coronary ligation-induced ventricular arrhythmias in dogs and exerted weak hypotensive effects. In contrast, verapamil suppressed only the epinephrine-induced ventricular arrhythmia and produced severe hypotension. These results indicate that AH-1058 may possess a more selective inhibitory action on calcium channels in the heart than on those located in the vessels. The antiarrhythmic actions of either intravenously or orally administered AH-1058 did not correlate with drug plasma concentrations and were slower in onset and longer lasting than those of verapamil [389].

AP-792

Animal studies with AP-792

AP-792 (Fig. 5.) proved to possess antiarrhythmic properties using the epinephrine-, digitalis- and twostage coronary ligation-induced canine ventricular arrhythmia models as intravenous administration of AP-792 (0.3 or $1.0 \mathrm{mg} / \mathrm{kg}$ ) effectively suppressed each of the ventricular arrhythmias and its antiarrhythmic action was slow in onset and long-lasting [390]. 
TABLE 6. Human studies describing the pro- and antiarrhythmic actions of other CCAs.

\begin{tabular}{|c|c|c|c|}
\hline DRUG / dose & Proarrhythmic action & Antiarrhythmic action & Reference \\
\hline $\begin{array}{l}\text { Mibefradil (RO 40- } \\
5967) / 150 \mathrm{mg} \text { daily } \\
\text { per os }\end{array}$ & 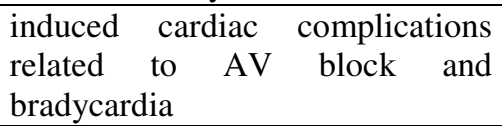 & & [193] \\
\hline $\begin{array}{l}\text { Mibefradil / applied as } \\
\text { co-medication }\end{array}$ & caused TdP & & [347] \\
\hline $\begin{array}{l}\text { Bepridil / } 200-600 \\
\mathrm{mg} / \text { day for } 3 \text { weeks }\end{array}$ & $\begin{array}{l}\text { in persistent AF patients VT, } \\
\text { prolongation of QTc interval and } \\
\text { TdP was observed }\end{array}$ & & [134] \\
\hline $\begin{array}{l}\text { Bepridil / } 200-600 \\
\mathrm{mg} / \text { day for } 3 \text { weeks }\end{array}$ & $\begin{array}{l}\text { in patients with persistent } \mathrm{AF} \text {, } \\
\text { induced VT, prolongation of QTc } \\
\text { interval and TdP more often } \\
\text { compared to amiodarone }\end{array}$ & & [134] \\
\hline $\begin{array}{l}\text { Bepridil / } 100-200 \\
\mathrm{mg} / \text { day }\end{array}$ & $\begin{array}{l}\text { induced QT prolongation, } \\
\text { bradycardia, TdP usually triggered } \\
\text { by hypokalemia, sudden decrease } \\
\text { in HR in patients with AF or AFL }\end{array}$ & & [386] \\
\hline $\begin{array}{l}\text { Bepridil / plasma level } \\
\text { of approximately } 300 \\
\mathrm{ng} / \mathrm{ml}\end{array}$ & & suppressed AF & [376] \\
\hline $\begin{array}{lll}\begin{array}{l}\text { Bepridil } \\
\text { mg/day }\end{array} & 100-200 \\
\end{array}$ & & $\begin{array}{l}\text { successfully converted AF to SR in } \\
\text { about half of the patients }\end{array}$ & $\begin{array}{l}{[377]} \\
{[378]}\end{array}$ \\
\hline $\begin{array}{l}\text { Bepridil } / 150 \mathrm{mg} / \text { day } \\
\text { for } 2 \text { weeks followed } \\
\text { by } 100 \text { or } 200 \mathrm{mg} / \text { day }\end{array}$ & & $\begin{array}{l}\text { converted AF to SR in shorter time } \\
\text { and maintained SR for a longer period } \\
\text { compared to amiodarone }\end{array}$ & [380] \\
\hline $\begin{array}{l}\text { Bepridil / applied as } \\
\text { co-medication with } \\
\text { various antiarrhythmic } \\
\text { drugs }\end{array}$ & & $\begin{array}{l}\text { prevented paroxysmal } \mathrm{AF} \text {, converted } \\
\mathrm{AF} \text { to } \mathrm{SR} \text { in persistent } \mathrm{AF}\end{array}$ & $\begin{array}{l}{[381]} \\
{[382]} \\
{[383]}\end{array}$ \\
\hline $\begin{array}{l}\text { Bepridil / a single } \\
\text { dose of } 800 \mathrm{mg} \\
\text { followed by } 500-600 \\
\mathrm{mg}\end{array}$ & & $\begin{array}{l}\text { prevented VT initiation in non- } \\
\text { responding VT patients }\end{array}$ & [369] \\
\hline $\begin{array}{l}\text { Bepridil / } 2 \mathrm{mg} / \mathrm{kg} \\
\text { intravenously }\end{array}$ & & $\begin{array}{l}\text { terminated } \mathrm{AV} \text { reentrant tachycardia } \\
\text { in a third of patients }\end{array}$ & [232] \\
\hline Bepridil / 900 mg/day & & $\begin{array}{l}\text { prevented the induction of sustained } \\
\text { VT in } 50 \% \text { of patients }\end{array}$ & [372] \\
\hline $\begin{array}{l}\text { Bepridil / mean dose } \\
\text { of } 156 \mathrm{mg} / \text { day }\end{array}$ & & $\begin{array}{l}\text { suppressed ventricular } \\
\text { tachyarrhythmias and decreased the } \\
\text { frequency of ventricular } \\
\text { tachyarrhythmia recurrences in } 30 \% \\
\text { of the patients }\end{array}$ & [373] \\
\hline Bepridil / 200 mg/day & & $\begin{array}{l}\text { reduced the frequency of VF episodes } \\
\text { in idiopathic VF }\end{array}$ & [374] \\
\hline $\begin{array}{l}\text { Bepridil / } 900 \mathrm{mg} \text { for } \\
2 \text { days followed by } \\
400 \mathrm{mg} / \text { day }\end{array}$ & & $\begin{array}{l}\text { moderate antiarrhythmic efficacy in } \\
\text { patients with ventricular arrhythmias }\end{array}$ & [375] \\
\hline
\end{tabular}

\section{Concluding remarks}

As was shown in this review, class IV agents, acting through several mechanisms, provide antiarrhythmic action against mainly supraventricular tachyarrhythmias. These drugs, especially the compounds of phenylalkylamine group, are unfortunately not entirely devoid of proarrhythmic side effects. These side effects could 
probably be minimized with inhibition of other ion channels making these compounds to be able to target multiple sites. This clearly could be observed with BRL-32872 or AH-1058. Other compounds like monatepil (AJ-2615) can have a potentially useful side effect (lowering blood pressure) due to the blockade of alpha-1 adrenergic receptors.

Nowadays the discovery of new pharmacological targets to treat cardiac arrhythmias is a rapidly growing area of research. Relatively new targets include for instance gap junction proteins or ion channels like $\mathrm{I}_{\mathrm{KAch}}$, $\mathrm{I}_{\mathrm{Kur}}$, which chennels can not be found on the entire myocardium. But the successful application of amiodarone and bepridil in the antiarrhythmic therapy reminds us that a compound with multiple target sites is probably as good as, if not better, than a very selective ion channel blocker.

Another conclusion based on this review can be that mother compounds like verapamil and diltiazem in the group of phenylalkylamines and benzothiazepines, respectively, are still very much used in the medical practice. This is the case regardless the existence of numerous newer derivatives. These newer compounds can actually be more selective to inhibit the L-type calcium channels but their other effects make them less likely to have an advantage over the mother compound. This highlights the long and cumbersome process of drug design.

CCAs are still in use for antiarrhythmic therapy but their indication is very narrow. These drugs are not the first choice to be given in most cases but both verapamil and diltiazem are recommended for both acute and long-term rate control of $\mathrm{AF}$ as well as in $\mathrm{AF}$ associated with hyperthyroidism when beta-blocker is contraindicated. The application of these non-dihydropyridine compounds should also be considered in AF with pulmonary disease and acute coronary syndrome.

\section{LIST OF ABBREVIATIONS}

AF: atrial fibrillation

AFL: atrial flutter

AMI: acute myocardial infarction

AP: action potential

APA: action potential amplitude

APD: action potential duration

ATP: adenosine triphosphate

$\mathrm{AV}$ : atrioventricular

$\mathrm{BK}_{\mathrm{Ca}}$ : large-conductance calcium-activated potassium channel

BP: blood pressure

CCA: calcium channel antagonist

CF: coronary flow

CL: cycle length

CO: cardiac output

$\mathrm{CT}$ : conduction time

$\mathrm{dP} / \mathrm{dt}_{\max }$ : maximal rate of pressure rise

EAD: early afterdepolarization

$\mathrm{EC}_{50}$ : half-effective concentration

ERP: effective refractory period

HEK: human embryonic kidney

hERG: human ether-a-go-go

HF: heart failure

HR: heart rate

$\mathrm{IC}_{50}$ : half-inhibitory concentration

$\mathrm{I}_{\mathrm{Ca}, \mathrm{L}}$ : L-type calcium current

$\mathrm{I}_{\mathrm{Ca}, \mathrm{T}}$ : T-type calcium current

$\mathrm{I}_{\mathrm{K} 1}$ : inward rectifier potassium current

$\mathrm{I}_{\mathrm{K}, \mathrm{Ach}}$ : acetylcholine-activated potassium current

$\mathrm{I}_{\mathrm{K}, \mathrm{ATP}}$ : ATP dependent potassium current

$\mathrm{I}_{\mathrm{K}, \mathrm{Na}}$ : sodium activated potassium current

$\mathrm{I}_{\mathrm{Kr}}$ : rapid component of delayed rectifier potassium current

$\mathrm{I}_{\mathrm{Ks}}$ : slow component of delayed rectifier potassium current

$\mathrm{I}_{\text {Kur }}$ : ultrarapid component of delayed rectifier potassium current

$\mathrm{I}_{\mathrm{Na}}$ : sodium current

$\mathrm{I}_{\mathrm{NCX}}: \mathrm{Na}^{+} / \mathrm{Ca}^{2+}$ exchange current 
$\mathrm{I}_{\mathrm{to}}$ : transient outward potassium current

LAD: left anterior descending coronary artery

LQTS: long QT syndrome

MAP: mean arterial pressure

MDP: maximal diastolic potential

PSVT: paroxysmal supraventricular tachycardia

RBBB: right bundle branch block

RMP: resting membrane potential

RP: refractory period

SA: sinoatrial

SMC: smooth muscle cell

SR: sinus rhythm

SVT: supraventricular tachycardia

TdP: torsade de pointes

TDR: transmural dispersion of repolarization

VEB: ventricular ectopic beat

VF: ventricular fibrillation

$\mathrm{V}_{\text {max }}$ : maximal rate of depolarization

VPC: ventricular premature complex

VR: ventricular rate

VT: ventricular tachycardia

WPW: Wolff-Parkinson-White

\section{ACKNOWLEDGEMENTS}

Financial support was provided by grants from the Hungarian Research Fund (OTKA-K100151, OTKA-PD101171, OTKA-K101196, OTKA-K109736, and OTKA-NK104331). This publication was also supported by the TÁMOP4.2.2.A-11/1/KONV-2012-0045 project, which is co-financed by the European Union and the European Social Fund. This research was supported by the European Union and the State of Hungary, co-financed by the European Social Fund in the framework of TÁMOP 4.2.4. A/2-11-1-2012-0001 'National Excellence Program'.

\section{REFERENCES}

[1] Garg A, Akoum N. Atrial fibrillation and heart failure: beyond the heart rate. Curr Opin Cardiol 2013; 28: 332-6.

[2] Huikuri HV, Castellanos A, Myerburg RJ. Sudden death due to cardiac arrhythmias. N Engl J Med 2001; 345 : 1473-82.

[3] Fishman GI, Chugh SS, Dimarco JP, et al. Sudden cardiac death prediction and prevention: report from a National Heart, Lung, and Blood Institute and Heart Rhythm Society Workshop. Circulation 2010; 122: 233548.

[4] Vaughan Williams EM. A classification of antiarrhythmic actions reassessed after a decade of new drugs. J Clin Pharmacol 1984; 24: 129-47.

[5] Catterall WA. Voltage-gated calcium channels. Cold Spring Harb Perspect Biol 2011; 3: a003947.

[6] Nishimura K, Miyawaki N, Yamauchi H, Iso T. Tissue selectivity of the novel calcium antagonist sesamodil fumarate in isolated smooth muscles and cardiac muscles. Arzneimittelforschung 1990; 40: 244-8.

[7] Sun J, Triggle DJ. Calcium channel antagonists: cardiovascular selectivity of action. J Pharmacol Exp Ther 1995; 274: 419-26.

[8] Sarsero D, Fujiwara T, Molenaar P, Angus JA. Human vascular to cardiac tissue selectivity of L- and T-type calcium channel antagonists. Br J Pharmacol 1998; 125: 109-19.

[9] Morel N, Buryi V, Feron O, Gomez JP, Christen MO, Godfraind T. The action of calcium channel blockers on recombinant L-type calcium channel alpha1-subunits. Br J Pharmacol 1998; 125: 1005-12.

[10] Charnet P, Ouadid H, Richard S, Nargeot J. Electrophysiological analysis of the action of nifedipine and nicardipine on myocardial fibers. Fundam Clin Pharmacol 1987; 1: 413-31.

[11] Derosa G, Maffioli P. Nifedipine and telmisartan for the treatment of hypertension: the TALENT study. Expert Rev Cardiovasc Ther 2011; 9: 1499-503.

[12] Lundy A, Lutfi N, Beckey C. Review of nifedipine GITS in the treatment of high risk patients with coronary artery disease and hypertension. Vasc Health Risk Manag 2009; 5: 429-40. 
[13] Castaneda MP, Walsh CA, Woroniecki RP, Del Rio M, Flynn JT. Ventricular arrhythmia following shortacting nifedipine administration. Pediatr Nephrol 2005; 20: 1000-2.

[14] Takahashi T, Tomoike H, Muramatsu K, et al. Effects of a new calcium antagonist, CD-832, on coronary and systemic hemodynamics in conscious dogs. J Cardiovasc Pharmacol 1994; 24: 8-12.

[15] Nawrath H, Klein G, Rupp J, Wegener JW, Shainberg A. Open state block by fendiline of L-type Ca++ channels in ventricular myocytes from rat heart. J Pharmacol Exp Ther 1998; 285: 546-52.

[16] Trautwein W, Pelzer D, McDonald TF. Interval- and voltage-dependent effects of the calcium channelblocking agents D600 and AQA 39 on mammalian ventricular muscle. Circ Res 1983; 52: I60-8.

[17] Klöckner U, Isenberg G. Tiapamil reduces the calcium inward current of isolated smooth muscle cells. Dependence on holding potential and pulse frequency. Eur J Pharmacol 1986; 127: 165-71.

[18] Sutton MS, Morad M. Mechanisms of action of diltiazem in isolated human atrial and ventricular myocardium. J Mol Cell Cardiol 1987; 19: 497-508.

[19] Kuga T, Sadoshima J, Tomoike H, Kanaide H, Akaike N, Nakamura M. Actions of Ca2+ antagonists on two types of Ca2+ channels in rat aorta smooth muscle cells in primary culture. Circ Res 1990; 67: 469-80.

[20] Noguchi K, Masumiya H, Takahashi K, et al. Comparative effects of gallopamil and verapamil on the mechanical and electrophysiological parameters of isolated guinea-pig myocardium. Can J Physiol Pharmacol 1997; 75: 1316-21.

[21] Zahradníková A, Minarovic I, Zahradník I. Competitive and cooperative effects of Bay K8644 on the L-type calcium channel current inhibition by calcium channel antagonists. J Pharmacol Exp Ther 2007; 322: 638-45.

[22] Hume JR. Comparative interactions of organic $\mathrm{Ca}++$ channel antagonists with myocardial $\mathrm{Ca}++$ and $\mathrm{K}+$ channels. J Pharmacol Exp Ther 1985; 234: 134-40.

[23] Nawrath H, Eick RE, McDonald TF, Trautwein W. On the mechanism underlying the action of D-600 on slow inward current and tension in mammalian myocardium. Circ Res 1977; 40: 408-14.

[24] Kurokawa J, Adachi-Akahane S, Nagao T. 1,5-benzothiazepine binding domain is located on the extracellular side of the cardiac L-type Ca2+ channel. Mol Pharmacol 1997; 51: 262-8.

[25] Kanaya S, Katzung BG. Effects of diltiazem on transmembrane potential and current of right ventricular papillary muscle of ferrets. J Pharmacol Exp Ther 1984; 228: 245-51.

[26] Xiong Z, Sakai T, Inoue Y, Kitamura K, Kuriyama H. Inhibitory actions of diltiazem and its derivative, TA3090 on the Ba-current recorded from smooth muscle cells of the rabbit mesenteric artery. Naunyn Schmiedebergs Arch Pharmacol 1990; 341: 373-80.

[27] Narita H, Zera PH, Ginsburg R. Mechanism of action of clentiazem on human coronary artery and myocardium. Cardiovasc Drugs Ther 1990; 4: 1097-104.

[28] Narita H, Ginsburg R. In-vitro study of the effect of clentiazem on rabbit aorta and on myocardium. Cardiovasc Drugs Ther 1990; 4: 723-30.

[29] Panesar MS, Hagerty MJ, Kane KA, Wadsworth RM. Comparison of the effects of diltiazem and its analogue siratiazem on contractility in arteries, ileum and cardiac muscle. J Auton Pharmacol 1995; 15: 107-13.

[30] Hagerty M, Panesar M, Wadsworth R, Kane K. Effects of diltiazem and its analogue siratiazem on contraction and 45Ca2+ uptake in sheep coronary artery rings. Gen Pharmacol 1995; 26: 1349-54.

[31] Kawakami M, Matsumura S, Shimamura T, et al. Pharmacological studies on a new antihypertensive agent, S-2150, a benzothiazepine derivative: 2. Hypotensive effects in normotensive and hypertensive rats. J Cardiovasc Pharmacol 1996; 28: 695-702.

[32] Teramoto N. Mechanisms of the inhibitory action of semotiadil fumarate, a novel Ca antagonist, on the voltage-dependent Ca current in smooth muscle cells of the rabbit portal vein. Jpn J Pharmacol 1993; 61: 18395.

[33] Hara Y, Nakaya H. SD-3212, a new class I and IV antiarrhythmic drug: a potent inhibitor of the muscarinic acetylcholine-receptor-operated potassium current in guinea-pig atrial cells. Br J Pharmacol 1995; 116: 27506.

[34] Yasui K, Palade P. Inhibitory action of SR33557 on L-type calcium current in single ventricular myocytes of rat. Br J Pharmacol 1995; 114: 468-74.

[35] Yatani A, Brown AM, Schwartz A. Bepridil block of cardiac calcium and sodium channels. J Pharmacol Exp Ther 1986; 237: 9-17.

[36] Romey G, Bois P, Lazdunski M. Effects of two chemically related new Ca2+ channel antagonists, SR33557 (fantofarone) and SR33805, on the L-type cardiac channel. Eur J Pharmacol 1994; 263: 101-5.

[37] Cohen CJ, Spires S, Van Skiver D. Block of T-type Ca channels in guinea pig atrial cells by antiarrhythmic agents and Ca channel antagonists. J Gen Physiol 1992; 100: 703-28. 
[38] Takahara A, Uneyama H, Sasaki N, et al. Effects of AH-1058, a new antiarrhythmic drug, on experimental arrhythmias and cardiac membrane currents. J Cardiovasc Pharmacol 1999; 33: 625-32.

[39] Koidl B, Miyawaki N, Tritthart HA. A novel benzothiazine Ca2+ channel antagonist, semotiadil, inhibits cardiac L-type Ca2+ currents. Eur J Pharmacol 1997; 322: 243-7.

[40] Cazorla O, Lacampagne A, Fauconnier J, Vassort G. SR33805, a Ca2+ antagonist with length-dependent $\mathrm{Ca} 2+$-sensitizing properties in cardiac myocytes. Br J Pharmacol 2003; 139: 99-108.

[41] Bril A, Faivre JF, Forest MC, et al. Electrophysiological effect of BRL-32872, a novel antiarrhythmic agent with potassium and calcium channel blocking properties, in guinea pig cardiac isolated preparations. $\mathbf{J}$ Pharmacol Exp Ther 1995; 273: 1264-72.

[42] Buljubasic N, Marijic J, Stowe DF, Gross GJ, Kampine JP, Bosnjak ZJ. Comparative cardiac effects of KT362 and verapamil in isolated heart--correlation to calcium channel current depression. J Cardiovasc Pharmacol 1991; 18: 594-604.

[43] Nagata S, Hosoki K, Karasawa T. Long-lasting antagonistic effects of monatepil on Ca2+ current in guineapig ventricular cells. Arzneimittelforschung 1995; 45: 1061-3.

[44] Fossa AA, Wisialowski T, Wolfgang E, et al. Differential effect of HERG blocking agents on cardiac electrical alternans in the guinea pig. Eur J Pharmacol 2004; 486: 209-21.

[45] Dohmoto H, Takahara A, Uneyama H, Yoshimoto R. Cardiac $\mathrm{Ca}(2+)$ channel-blocking effects of the cyproheptadine derivative AH-1058 in isolated guinea pig cardiomyocytes. J Pharmacol Sci 2003; 91: 163-6.

[46] Martin RL, Lee JH, Cribbs LL, Perez-Reyes E, Hanck DA. Mibefradil block of cloned T-type calcium channels. J Pharmacol Exp Ther 2000; 295: 302-8.

[47] De Paoli P, Cerbai E, Koidl B, Kirchengast M, Sartiani L, Mugelli A. Selectivity of different calcium antagonists on T- and L-type calcium currents in guinea-pig ventricular myocytes. Pharmacol Res 2002; 46: 491-7.

[48] Masumiya H, Kase J, Tanaka Y, Tanaka H, Shigenobu K. Effects of mibefradil, a selective T-type Ca2+ channel antagonist, on sino-atrial node and ventricular myocardia. Res Commun Mol Pathol Pharmacol 1999; 104: 321-9.

[49] Emanuel K, Mackiewicz U, Pytkowski B, Lewartowski B. Effects of mibefradil, a blocker of T-type Ca2+ channels, in single myocytes and intact muscle of guinea-pig heart. J Physiol Pharmacol 1998; 49: 577-90.

[50] Leuranguer V, Mangoni ME, Nargeot J, Richard S. Inhibition of T-type and L-type calcium channels by mibefradil: physiologic and pharmacologic bases of cardiovascular effects. J Cardiovasc Pharmacol 2001; 37: 649-61.

[51] Protas L, Robinson RB. Mibefradil, an $\mathrm{I}(\mathrm{Ca}, \mathrm{T})$ blocker, effectively blocks $\mathrm{I}(\mathrm{Ca}, \mathrm{L})$ in rabbit sinus node cells. Eur J Pharmacol 2000; 401: 27-30.

[52] Pinto JM, Sosunov EA, Gainullin RZ, Rosen MR, Boyden PA. Effects of mibefradil, a T-type calcium current antagonist, on electrophysiology of Purkinje fibers that survived in the infarcted canine heart. J Cardiovasc Electrophysiol 1999; 10: 1224-35.

[53] Fang LM, Osterrieder W. Potential-dependent inhibition of cardiac Ca2+ inward currents by Ro 40-5967 and verapamil: relation to negative inotropy. Eur J Pharmacol 1991; 196: 205-7.

[54] Freeze BS, McNulty MM, Hanck DA. State-dependent verapamil block of the cloned human Ca(v)3.1 T-type $\mathrm{Ca}(2+)$ channel. Mol Pharmacol 2006; 70: 718-26.

[55] Uchino T, Lee TS, Kaku T, Yamashita N, Noguchi T, Ono K. Voltage-dependent and frequency-independent inhibition of recombinant Cav3.2 T-type Ca2+ channel by bepridil. Pharmacology 2005; 74: 174-81.

[56] Hagiwara N, Irisawa H, Kameyama M. Contribution of two types of calcium currents to the pacemaker potentials of rabbit sino-atrial node cells. J Physiol 1988; 395: 233-53.

[57] Tikhonov DB, Zhorov BS. Molecular Modeling of Benzothiazepine Binding in the L-type Calcium Channel. J Biol Chem 2008; 283: 17594-604.

[58] Lee KS, Tsien RW. Mechanism of calcium channel blockade by verapamil, D600, diltiazem and nitredipine in single dialysed heart cells. Nature 1983; 302: 790-4.

[59] Breemen C, Hwang OK, Meisheri KD. The mechanism of inhibitory action of diltiazem on vascular smooth muscle cells contractility. J Pharmacol Exp Ther 1981; 218: 459-63.

[60] Seydl K, Kimball D, Schindler H, Romanin C. The benzazepine/benzothiazepine binding domain of the cardiac L-type $\mathrm{Ca}^{2+}$ channel is accessible only from the extracellular side. Pflügers Arch 1993; 424: 552-4.

[61] Hering S, Savchenko A, Strubing C, Lakitsch M, Striessnig J. Extracellular localization of the benzothiazepine binding domain of L-type $\mathrm{Ca}^{2+}$ channels. Mol Pharmacol 1993; 43: 820-6.

[62] Tikhonov DB, Bruhova I, Zhorov BS. Atomic determinants of state-dependent block of sodium channels by charged local anesthetics and benzocaine. FEBS Lett 2006; 580: 6027-32. 
[63] Adachi-Akahane S, Amano Y, Okuyama R, Nagao, T. Quaternary diltiazem can act from both sides of the membrane in ventricular myocytes. Jpn J Pharmacol 1993; 61: 263-6.

[64] Kimball SD, Floyd DM, Das J, et al. Benzazepinone calcium channel blockers. 4. Structure-activity overview and intracellular binding site. J Med Chem 1992; 35: 780-93.

[65] Hockerman GH, Dilmac N, Scheuer T, Catteral WA. Molecular Determinants of Diltiazem Block in Domains IIIS6 and IVS6 of L-type Ca2+ Channels. Mol Pharmacol 2000; 58: 1264-70.

[66] Kawakita S, Kinoshita M, Ishikawa H, et al. Efficacy and safety of clentiazem in patients with essential hypertension: results of an early pilot test. Clin Cardiol 1991; 14: 53-60.

[67] Zhorov BS, Ananthanarayanan VS. Docking of verapamil in a synthetic Ca2+ channel: formation of a ternary complex involving Ca2+ ions. Arch Biochem Biophys 1997; 341: 238-44.

[68] Masui M, Funakawa S, Uno O, et al. Pharmacological studies on a new antihypertensive agent, S-2150, a benzothiazepine derivative: 1 . Antinecrotic and antiarrhythmic effects in reperfused rat hearts. J Cardiovasc Pharmacol 1996; 28: 526-32.

[69] Bariwal JB, Upadhyay KD, Manvar AT, et al. 1,5-Benzothiazepine, a versatile pharmacophore: A review. Eur J Med Chem 2008; 43: 2279-90.

[70] Grove A, Tomich JM, Iwamoto T, Montal M. Design of a functional calcium channel protein: inferences about an ion channel-forming motif derived from the primary structure of voltage-gated calcium channels. Protein Sci 1993; 2: 1918-30.

[71] Murakami K, Shindo K, Ito KM, Ito K. Effects of semotiadil fumarate (SD-3211) and its enantiomer, SD3212, on the changes in cytosolic $\mathrm{Ca} 2+$ and tension caused by $\mathrm{KCl}$ and norepinephrine in isolated rat aortas. $\mathrm{J}$ Cardiovasc Pharmacol 1995; 25: 262-7.

[72] Cheng RCK, Tikhonov DB, Zhorov BS. Structural Model for Phenylalkylamine Binding to L-type Calcium Channels. J Biol Chem 2009; 284: 28332-42.

[73] Wegener JW, Nawrath H. Extracellular site of action of phenylalkylamines on L-type calcium current in rat ventricular myocytes. Naunyn Schmiedebergs Arch Pharmacol 1995; 352: 322-30.

[74] Hescheler J, Pelzer D, Trube G, Trautwein W. Does the organic calcium channel blocker D600 act from inside or outside on the cardiac cell membrane? Pflugers Arch 1982; 393: 287-91.

[75] Szentandrássy N, Nagy D, Ruzsnavszky F, et al. Powerful technique to test selectivity of agents acting on cardiac ion channels: the action potential voltage-clamp. Curr Med Chem 2011; 18: 3737-56.

[76] Dillon JS, Nayler WG. The Ca2+ -antagonist and binding properties of the phenylalkylamine, anipamil. $\mathrm{Br} \mathbf{J}$ Pharmacol 1988; 94: 253-63.

[77] Mannhold R, Holtje HD, Koke V. Importance of nitrile substitution for the Ca antagonistic action. Arch Pharm (Weinhem) 1986; 319: 990-8.

[78] Nadler G, Faivre JF, Forest MC, et al. Synthesis, electrophysiological properties and analysis of structural requirements of a novel class of antiarrhythmic agents with potassium and calcium channel blocking properties. Bioorg Med Chem 1998; 6: 1993-2011.

[79] Chatelain P, Clinet M, Polster P, Christophe B, Manning AS. In vitro characterization of a novel Ca2+ entry blocker: SR 33805. Eur J Pharmacol 1993; 246: 181-93.

[80] Clozel JP, Véniant M, Osterrieder W. The structurally novel Ca2+ channel blocker Ro 40-5967, which binds to the $[3 \mathrm{H}]$ desmethoxyverapamil receptor, is devoid of the negative inotropic effects of verapamil in normal and failing rat hearts. Cardiovasc Drugs Ther 1990; 4: 731-6.

[81] Zobrist RH, Mecca TE. [3H]TA-3090, a selective benzothiazepine-type calcium channel receptor antagonist: in vitro characterization. J Pharmacol Exp Ther 1990; 253: 461-5.

[82] Matthes J, Huber I, Haaf O, Antepohl W, Striessnig J, Herzig S. Pharmacodynamic interaction between mibefradil and other calcium channel blockers. Naunyn Schmiedebergs Arch Pharmacol 2000; 361: 578-83.

[83] Nakayama K, Nozawa Y, Fukuta Y. Allosteric interaction of semotiadil fumarate, a novel benzothiazine, with 1,4-dihydropyridines, phenylalkylamines, and 1,5-benzothiazepines at the $\mathrm{Ca}(2+)$-channel antagonist binding sites in canine skeletal muscle membranes. J Cardiovasc Pharmacol 1994; 23: 731-40.

[84] Murphy BJ, Rogers CA, Sunahara RK, Lemaire S, Tuana BS. Identification, characterization, and photoaffinity labeling of the dihydropyridine receptor associated with the L-type calcium channel from bovine adrenal medulla. Mol Pharmacol 1990; 37: 173-81.

[85] Endo M, Kurachi Y, Mishina M. Pharmacology of Ionic Channel Function: Activators and Inhibitors. Springer Verlag 2000; 121-127.

[86] Clusin WT, Buchbinder M, Harrison DC. Calcium overload, "injury" current, and early ischaemic cardiac arrhythmias--a direct connection. Lancet 1983; 1: 272-4. 
[87] Fabiato A. Two kinds of calcium-induced release of calcium from the sarcoplasmic reticulum of skinned cardiac cells. Adv Exp Med Biol 1992; 311: 245-62.

[88] Venetucci LA, Trafford AW, O'Neill SC, Eisner DA. The sarcoplasmic reticulum and arrhythmogenic calcium release. Cardiovasc Res 2008; 77: 285-92.

[89] Frommeyer G, Eckardt L, Milberg P. Calcium handling and ventricular tachyarrhythmias. Wien Med Wochenschr 2012; 162: 283-6.

[90] ter Bekke RM, Volders PG. Arrhythmogenic mechano-electric heterogeneity in the long-QT syndrome. Prog Biophys Mol Biol 2012; 110: 347-58.

[91] Ishide N. Intracellular calcium modulators for cardiac muscle in pathological conditions. Jpn Heart J 1996; 37 : $1-17$.

[92] Aiba T, Shimizu W, Inagaki M, et al. Cellular and ionic mechanism for drug-induced long QT syndrome and effectiveness of verapamil. J Am Coll Cardiol 2005; 45: 300-7.

[93] Shimizu W, Ohe T, Kurita T, et al. Effects of verapamil and propranolol on early afterdepolarizations and ventricular arrhythmias induced by epinephrine in congenital long QT syndrome. J Am Coll Cardiol 1995; 26: 1299-309.

[94] Watanabe Y, Kimura J. Blocking effect of bepridil on $\mathrm{Na}+\mathrm{Ca} 2+$ exchange current in guinea pig cardiac ventricular myocytes. Jpn J Pharmacol 2001; 85: 370-5.

[95] Chatelain P, Mouton J, Feys G, Laruel A, Manning AS. Vascular calcium overload produced by vitamin D3, in rats. Effect of treatment with SR 33805, a novel calcium entry blocker. Cardiovasc Res 1995; 30:1038-43.

[96] Liu DW, Gintant GA, Antzelevitch C. Ionic bases for electrophysiological distinctions among epicardial, midmyocardial, and endocardial myocytes from the free wall of the canine left ventricle. Circ Res 1993; 72: 671-87.

[97] Szentadrassy N, Banyasz T, Biro T, et al. Apico-basal inhomogeneity in distribution of ion channels in canine and human ventricular myocardium. Cardiovasc Res 2005; 65: 851-60.

[98] Volders PG, Sipido KR, Carmeliet E, Spätjens RL, Wellens HJ, Vos MA. Repolarizing K+ currents ITO1 and IKs are larger in right than left canine ventricular midmyocardium. Circulation 1999; 99: 206-10.

[99] Keren G, Tepper D, Butler B, Torres V, Somberg JC. The effect of bepridil, verapamil, and quinidine in the prevention of ventricular tachycardia induced by programmed electrical stimulation in the digitalized dog. Am Heart J 1984; 108: 1236-43.

[100] Jost N, Kohajda Z, Kristóf A, et al. Atrial remodeling and novel pharmacological strategies for antiarrhythmic therapy in atrial fibrillation. Curr Med Chem 2011; 18: 3675-94.

[101] Shannon TR, Bers DM. Integrated Ca2+ management in cardiac myocytes. Ann N Y Acad Sci 2004; 1015: 28-38.

[102] Dibb KM, Graham HK, Venetucci LA, Eisner DA, Trafford AW. Analysis of cellular calcium fluxes in cardiac muscle to understand calcium homeostasis in the heart. Cell Calcium 2007; 42: 503-12.

[103] Hensley J, Billman GE, Johnson JD, Hohl CM, Altschuld RA. Effects of calcium channel antagonists on Ca2+ transients in rat and canine cardiomyocytes. J Mol Cell Cardiol 1997; 29: 1037-43.

[104] Ozaki H, Zaizen H, Kiyosue T, Nasu M, Arita M. Effect of bepridil on intracellular calcium concentration and contraction in cultured rat ventricular myocytes. J Cardiovasc Pharmacol 1999; 33: 492-9.

[105] Tatsukawa Y, Arita M. Effects of KT-362, a sarcolemmal and intracellular calcium antagonist, on calcium transients of cultured neonatal rat ventricular cells: a comparison with gallopamil and ryanodine. Cardiovasc Drugs Ther 1997; 10: 667-75.

[106] Tanaka H, Ichikawa $\mathrm{T}$, Matsui $\mathrm{S}$, et al. Calcium channel antagonistic effects of AH-1058, a novel antiarrhythmic drug, on guinea-pig myocardium. Res Commun Mol Pathol Pharmacol 1999; 104: 13-21.

[107] Satoh K, Yanagisawa T, Taira N. Coronary vasodilator and cardiac effects of optical isomers of verapamil in the dog. J Cardiovasc Pharmacol 1980; 2: 309-18.

[108] Hodeige D, Chatelain P, Manning A. Fantofarone (SR33557): effects on myocardial oxygen consumption and coronary blood flow. Pharmacology 1994; 48: 49-55.

[109] Marshall RJ, Muir AW. The beneficial actions of bepridil in acute myocardial infarction in anaesthetized dogs. Br J Pharmacol 1981; 73: 471-9.

[110] Verdouw PD, Scheffer MG. Cardiovascular actions after intravenous and intracoronary administration of the slow channel blocker bepridil. Arzneimittelforschung 1984; 34: 21-5.

[111] Baczkó I, Husti Z, Lang V, Leprán I, Light PE. Sarcolemmal KATP channel modulators and cardiac arrhythmias. Curr Med Chem 2011; 18: 3640-61. 
[112] Csik V, Szekeres L, Udvary E. Comparison of two calcium antagonists, verapamil and fendiline, in an experimental model of myocardial ischaemia mimicking classical angina on effort. Br J Pharmacol 1983; 79: 37-43.

[113] Woods JP, West TC. Frequency-dependence of $\mathrm{V}_{\max }$ in $\mathrm{K}$-depolarized guinea pig ventricle: effects of nifedipine and verapamil. J Cardiovasc Pharmacol 1985; 7: 197-204.

[114] Wong SS, Myerburg RJ, Ezrin AM, Gaide MS, Bassett AL. Effects of diltiazem on the electrophysiological properties of cat ventricular muscle fibers during experimentally induced right ventricular systolic hypertension. J Cardiovasc Pharmacol 1982; 4: 986-93.

[115] Guc MO, Boachie-Ansah G, Kane KA, Wadsworth RM. Comparison of antiarrhythmic and electrophysiologic effects of diltiazem and its analogue siratiazem. J Cardiovasc Pharmacol 1993; 22: 681-6.

[116] Miyawaki N, Furuta T, Shigei T, Yamauchi H, Iso T. Electrophysiological properties of SD-3211, a novel putative $\mathrm{Ca} 2+$ antagonist, in isolated guinea pig and rabbit hearts. J Cardiovasc Pharmacol 1990; 16: 769-75.

[117] Fujiki A, Tani M, Hayashi H, et al. Electrophysiologic effects of SD-3212, a new class I antiarrhythmic drug, on canine atrial flutter and atrial action-potential characteristics. J Cardiovasc Pharmacol 1997; 29: 471-5.

[118] Kodama I, Wakabayashi S, Toyama J, Shibata S, Yamada K. Electrophysiological effects of KT-362, a new antiarrhythmic agent with vasodilating action, on isolated guinea pig ventricular muscle. J Cardiovasc Pharmacol 1988; 11:687-93.

[119] Strege PR, Bernard CE, Ou Y, Gibbons SJ, Farrugia G. Effect of mibefradil on sodium and calcium currents. Am J Physiol Gastrointest Liver Physiol 2005; 289: G249-53.

[120] Iijima K, Chinushi M, Izumi D, et al. Effect of bepridil in atrial fibrillation inducibility facilitated by vagal nerve stimulation. - Prevention of vagal nerve activation-induced shortening of the atrial action potential duration -. Circ J 2010; 74: 895-902.

[121] Ishizaka T, Takahara A, Iwasaki H, et al. Comparison of electropharmacological effects of bepridil and sotalol in halothane-anesthetized dogs. Circ J 2008; 72: 1003-11.

[122] Gao Z, Lau CP, Chiu SW, Li GR. Inhibition of ultra-rapid delayed rectifier $\mathrm{K}^{+}$current by verapamil in human atrial myocytes. J Mol Cell Cardiol 2004; 36: 257-63.

[123] Sato T, Costa AD, Saito T, et al. Bepridil, an antiarrhythmic drug, opens mitochondrial KATP channels, blocks sarcolemmal KATP channels, and confers cardioprotection. J Pharmacol Exp Ther 2006; 316: 182-8.

[124] Sakuta H, Okamoto K. Effects of $\mathrm{Ca} 2+$ channel antagonists and their isomers on glibenclamide-sensitive $\mathrm{K}+$ currents in follicle-enclosed Xenopus oocytes. Eur J Pharmacol 1994; 255: 1-7.

[125] Mocanu MM, Gadgil S, Yellon DM, Baxter GF. Mibefradil, a T-type and L-type calcium channel blocker, limits infarct size through a glibenclamide-sensitive mechanism. Cardiovasc Drugs Ther 1999; 13: 115-22.

[126] Schulz R, Post H, Jalowy A, et al. Unique cardioprotective action of the new calcium antagonist mibefradil. Circulation 1999; 99: 305-11.

[127] Mori K, Kobayashi S, Saito T, Masuda Y, Nakaya H. Inhibitory effects of class I and IV antiarrhythmic drugs on the Na+-activated $\mathrm{K}+$ channel current in guinea pig ventricular cells. Naunyn Schmiedebergs Arch Pharmacol 1998; 358: 641-8.

[128] Lacroix P, Linee P, Forest MC. Diproteverine (BRL 40015): a new type of calcium antagonist with potential antianginal properties. Eur J Pharmacol 1991; 192: 317-27.

[129] Damarowsky M, Lüllmann H. A model to check the arrhythmogenic activity of antiarrhythmic drugs. Gen Pharmacol 1991; 22: 533-7.

[130] Wu TJ, Lin SF, Weiss JN, Ting CT, Chen PS. Two types of ventricular fibrillation in isolated rabbit hearts: importance of excitability and action potential duration restitution. Circulation 2002; 106: 1859-66.

[131] Campbell RM, Woosley RL, Iansmith DH, Roden DM. Lack of triggered automaticity despite repolarization abnormalities due to bepridil and lidoflazine. Pacing Clin Electrophysiol 1990; 13: 30-6.

[132] Said TH, Wilson LD, Jeyaraj D, Fossa AA, Rosenbaum DS. Transmural Dispersion of Repolarization as a Preclinical Marker of Drug-induced Proarrhythmia. J Cardiovasc Pharmacol 2012; 60: 165-71.

[133] Pelleg A, Pardo Y, Belhassen B, Shargordsky B, Chagnac A, Laniado S. Effects of verapamil and bepridil on occlusion and reperfusion arrhythmias in the canine heart. Cardiology 1985; 72: 193-201.

[134] Perelman MS, McKenna WJ, Rowland E, Krikler DM. A comparison of bepridil with amiodarone in the treatment of established atrial fibrillation. Br Heart J 1987; 58: 339-44.

[135] Pugsley MK, Ries CR, Guppy LJ, Harvie CJ, Walker MJ. Effects of anipamil, a long acting analog of verapamil, in pigs subjected to myocardial ischemia. Life Sci 1995; 57: 1219-31.

[136] Gaudron P, Blumrich M, Ertl G. Aggravation of left ventricular dilatation and reduction of survival by a calcium channel blocker in rats with chronic myocardial infarction. Am Heart J 1993; 125: 1226-33. 
[137] Shimizu W, Aiba T, Antzelevitch C. Specific therapy based on the genotype and cellular mechanism in inherited cardiac arrhythmias. Long QT syndrome and Brugada syndrome. Curr Pharm Des 2005; 11: 156172.

[138] Chinushi M, Tagawa M, Nakamura Y, Aizawa Y. Shortening of the ventricular fibrillatory intervals after administration of verapamil in a patient with Brugada syndrome and vasospastic angina. J Electrocardiol 2006; 39: 331-5.

[139] Murakami M, Nakamura K, Kusano KF, et al. Efficacy of low-dose bepridil for prevention of ventricular fibrillation in patients with Brugada syndrome with and without SCN5A mutation. J Cardiovasc Pharmacol 2010; 56: 389-95.

[140] Antzelevitch C, Pollevick GD, Cordeiro JM, et al. Loss-of-function mutations in the cardiac calcium channel underlie a new clinical entity characterized by ST-segment elevation, short QT intervals, and sudden cardiac death. Circulation 2007; 115: 442-9.

[141] Patel C, Antzelevitch C. Pharmacological approach to the treatment of long and short QT syndromes. Pharmacol Ther 2008; 118: 138-51.

[142] Koncz I, Gurabi Z, Patocskai B, et al. Mechanisms underlying the development of the electrocardiographic and arrhythmic manifestations of early repolarization syndrome. J Mol Cell Cardiol 2014; 68:20-8.

[143] Leenhardt A, Glaser E, Burguera M, Nürnberg M, Maison-Blanche P, Coumel P. Short-coupled variant of torsade de pointes. A new electrocardiographic entity in the spectrum of idiopathic ventricular tachyarrhythmias. Circulation 1994; 89: 206-15.

[144] Waxman HL, Myerburg RJ, Appel R, Sung RJ. Verapamil for control of ventricular rate in paroxysmal supraventricular tachycardia and atrial fibrillation or flutter: a double-blind randomized cross-over study. Ann Intern Med 1981; 94: 1-6.

[145] Opie LH. Calcium channel antagonists in the treatment of coronary artery disease: fundamental pharmacological properties relevant to clinical use. Prog Cardiovasc Dis 1996; 38: 273-90.

[146] Padrini R, Barbieri E, Piovan D, et al. Plasma levels and myocardial content of verapamil, norverapamil and two N-dealkyl-metabolites in man. Eur J Clin Pharmacol 1985; 28: 653-7.

[147] Schwartz JB, Todd E, Abernethy DR, Mitchell JR. Steady state verapamil tissue distribution in the dog: differing tissue accumulation. Pharmacology 1986; 32: 307-12.

[148] Rosen MR, Ilvento JP, Gelband H, Merker C. Effects of verapamil on electrophysiologic properties of canine cardiac Purkinje fibers. J Pharmacol Exp Ther 1974; 189: 414-22.

[149] Zhang S, Sawanobori T, Hirano Y, Hiraoka M. Multiple modulations of action potential duration by different calcium channel blocking agents in guinea pig ventricular myocytes. J Cardiovasc Pharmacol 1997; 30: 48996.

[150] Chouabe C, Drici MD, Romey G, Barhanin J, Lazdunski M. HERG and KvLQT1/IsK, the cardiac K+ channels involved in long QT syndromes, are targets for calcium channel blockers. Mol Pharmacol 1998; 54: 695-703.

[151] Waldegger S, Niemeyer G, Mörike K, et al. Effect of verapamil enantiomers and metabolites on cardiac K+ channels expressed in Xenopus oocytes. Cell Physiol Biochem 1999; 9: 81-9.

[152] Harper AA, Catacuzzeno L, Trequattrini C, Petris A, Franciolini F. Verapamil block of large-conductance Caactivated K channels in rat aortic myocytes. J Membr Biol 2001; 179: 103-11.

[153] Bénardeau A, Weissenburger J, Hondeghem L, Ertel EA. Effects of the T-type $\mathrm{Ca}(2+)$ channel blocker mibefradil on repolarization of guinea pig, rabbit, dog, monkey, and human cardiac tissue. J Pharmacol Exp Ther 2000; 292: 561-75.

[154] Nakaya H, Hattori Y, Nakao Y, Kanno M. Cardiac versus vascular effects of a new dihydropyridine derivative, CV-4093. In vitro comparison with other calcium antagonists. Eur J Pharmacol 1988; 146: 35-43.

[155] Satoh H, Hashimoto K. Comparative effects of a new calcium channel antagonist, mepirodipine, on rabbit spontaneously beating sino-atrial node cells. Eur J Pharmacol 1991; 193: 9-13.

[156] Masumiya H, Tanaka H, Shigenobu K. Effects of Ca2+ channel antagonists on sinus node: prolongation of late phase 4 depolarization by efonidipine. Eur J Pharmacol 1997; 335: 15-21.

[157] Ferrara N, Longobardi G, Guerra N, et al. Efficacy and pharmacokinetics of gallopamil in patients with coronary artery disease. Pharmacol Res 1996; 34: 37-41.

[158] Ludwig C, Nawrath H. Effects of D-600 and its optical isomers on force of contraction in cat papillary muscles and guinea-pig auricles. Br J Pharmacol 1977; 59: 411-7.

[159] Galper JB, Catterall WA. Inhibition of sodium channels by D600. Mol Pharmacol 1979; 15: 174-8.

[160] Lefevre IA, Coulombe A, Coraboeuf E. The calcium antagonist D600 inhibits calcium-independent transient outward current in isolated rat ventricular myocytes. J Physiol 1991; 432: 65-80. 
[161] Eigenmann R, Blaber L, Nakamura K, Thorens S, Haeusler G. Tiapamil, a new calcium antagonist. 1. Demonstration of calcium antagonistic activity and related studies. Arzneimittelforschung 1981; 31: 1393401.

[162] Osterrieder W. Inhibition of the fast $\mathrm{Na}+$ inward current by the $\mathrm{Ca} 2+$ channel blocker tiapamil. J Cardiovasc Pharmacol 1986; 8: 1101-6.

[163] Späh F. Bioelectrical and mechanical effects of tiapamil (Ro 11-1781) on isolated guinea pig myocardium. Cardiovasc Res 1986; 20: 42-51.

[164] Raddino R, Poli E, Pasini E, Ferrari R. Effects of the novel calcium channel blocker, anipamil, on the isolated rabbit heart. Comparison with verapamil and gallopamil. Naunyn Schmiedebergs Arch Pharmacol 1992; 346: 339-44.

[165] Gao Z, Sun H, Chiu SW, Lau CP, Li GR. Effects of diltiazem and nifedipine on transient outward and ultrarapid delayed rectifier potassium currents in human atrial myocytes. Br J Pharmacol 2005; 144: 595-604.

[166] Hashimoto Y, Yabana H, Murata S. Electrophysiological effect of 1-cis-diltiazem, the stereoisomer of d-cisdiltiazem, on isolated guinea-pig left ventricular myocytes. Eur J Pharmacol 2000; 391: 217-23.

[167] Nakajima H, Hoshiyama M, Yamashita K, Kiyomoto A. Effect of diltiazem on electrical and mechanical activity of isolated cardiac ventricular muscle of guinea pig. Jpn J Pharmacol 1975; 25: 383-92.

[168] Saikawa T, Nagamoto Y, Arita M. Electrophysiologic effects of diltiazem, a new slow channel inhibitor, on canine cardiac fibers. Jpn Heart J 1977; 18: 235-45.

[169] Hirth C, Borchard U, Hafner D. Effects of the calcium antagonist diltiazem on action potentials, slow response and force of contraction in different cardiac tissues. J Mol Cell Cardiol 1983; 15: 799-809.

[170] Miyazaki K, Adaniya H, Sawanobori T, Hiraoka M. Electrophysiological effects of clentiazem, a new Ca2+ antagonist, on rabbit hearts. J Cardiovasc Pharmacol 1996; 27: 615-21.

[171] Nánási PP, Knilans TK, Varró A, et al. Active and passive electrical properties of isolated canine cardiac Purkinje fibers under conditions simulating ischaemia: effect of diltiazem. Pharmacol Toxicol 1992; 71: 52-6.

[172] Schwarzl I, Stark U, Brodmann M, Haiden U, Tritthart HA, Stark G. Efficacy of the novel calcium antagonist $\mathrm{R}(+)$-semotiadil in limiting the ventricular rate during atrial flutter in isolated guinea pig hearts. J Cardiovasc Pharmacol 2000; 35: 309-14.

[173] Verrier RL, Hagestad EL. Mechanisms involved in reperfusion arrhythmias. Eur Heart J 1986; 7: Suppl A 1322.

[174] Billman GE, Hamlin RL. The effects of mibefradil, a novel calcium channel antagonist on ventricular arrhythmias induced by myocardial ischemia and programmed electrical stimulation. J Pharmacol Exp Ther 1996; 277: 1517-26.

[175] Kobayashi M, Shimotori M, Ogiwara Y, Chiba S. Effects of calcium channel blockers on sinoatrial conduction in the isolated and blood-perfused dog atrium. Arch Int Pharmacodyn Ther 1986; 279: 72-82.

[176] Himori N, Ono H, Taira N. Simultaneous assessment of effects of coronary vasodilators on the coronary blood flow and the myocardial contractility by using the blood-perfused canine papillary muscle. Jpn J Pharmacol 1976; 26: 427-35.

[177] Leboeuf J, Lamar JC, Massingham R, Ponsonnaille J. Electrophysiological effects of bepridil and its quaternary derivative CERM 11888 in closed chest anaesthetized dogs: a comparison with verapamil and diltiazem. Br J Pharmacol 1989; 98: 1351-9.

[178] Haverkamp W, Thale J, Gülker H, Hindricks G, Bender F. Comparative investigations on the antiarrhythmic and electrophysiological effects of various calcium antagonists (diltiazem, verapamil, gallopamil, nifedipine) following acute transient coronary artery occlusion and reperfusion. Eur Heart J 1987; 8: Suppl D, 117-28.

[179] Bernasconi R, Caliari S, Latini R, Leopaldi D, Porzio S, Salimbeni A. Pharmacokinetics of diltiazem and a new analogue, LR-A/113, in the conscious rat. Eur J Drug Metab Pharmacokinet 1992; 17: 269-74.

[180] Suzuki S, Mori M, Kusano S. Analysis of the daily variation in blood pressure and pharmacokinetics after single or repeated administration of clentiazem to patients with essential hypertension. Arzneimittelforschung 1992; 42: 533-9.

[181] Valérie V, Louis D, Marc L, Denis G, Claude C, Gilles C. Relationship between the cardiovascular effects and both plasma and myocardial levels of clentiazem, a new benzothiazepine calcium antagonist, in anesthetized dogs. Cardiovasc Drugs Ther 1991; 5: 997-1003.

[182] Giasson S, Garceau D, Homsy W, Dumont L. Pharmacodynamics and pharmacokinetics of clentiazem and diltiazem in closed-chest anesthetized dogs. Cardiovasc Drugs Ther 1995; 9: 685-92.

[183] Murata S, Kikkawa K, Yabana H, Nagao T. Cardiovascular effects of a new 1,5-benzothiazepine calcium antagonist in anesthetized dogs. Arzneimittelforschung 1988; 38: 521-5. 
[184] Dumont L, Derouin M, Chartrand C, Archambeault P, Garceau D, Caillé G. Peripheral vasodilator and cardiac properties of the 1,5-benzothiazepine calcium antagonist analog, TA-3090, in dogs. Can J Physiol Pharmacol 1991; 69: 512-7.

[185] Miyawaki N, Furuta T, Shigei T, Yamazaki F, Yamauchi H. Anti-ischaemic and vasospasmolytic effects of a novel Ca2+ channel blocker, SD-3211, in vitro. Clin Exp Pharmacol Physiol 1991; 18: 579-85.

[186] Kodama I, Suzuki R, Maruyama K, Toyama J. Electrophysiological effects of SD-3212, a new antiarrhythmic agent with vasodilator action, on guinea-pig ventricular cells. Br J Pharmacol 1995; 114: 503-9.

[187] Takahashi N, Ito M, Ishida S, Fujino T, Maruyama T, Saikawa T. Electrophysiological effects of SD-3212, a novel antiarrhythmic agent, on rabbit hearts in vivo and in vitro. J Cardiovasc Pharmacol 1995; 25: 1006-11.

[188] Ieiri S, Hirano K, Nishimura J, Suita S, Kanaide H. Alteration of the $[\mathrm{Ca}(2+)](i)$-force relationship during the vasorelaxation induced by a $\mathrm{Ca}(2+)$ channel blocker SR33805 in the porcine coronary artery. Br J Pharmacol 2000; 131: 1597-606.

[189] Ait Mou Y, Toth A, Cassan C, et al. Beneficial effects of SR33805 in failing myocardium. Cardiovasc Res 2011; 91: 412-9.

[190] Faivre JF, Rouanet S, Bril A. Comparative effects of glibenclamide, tedisamil, dofetilide, E-4031, and BRL32872 on protein kinase A-activated chloride current in guinea pig ventricular myocytes. J Cardiovasc Pharmacol 1998; 31: 551-7.

[191] Shibata S, Wakabayashi S, Satake N, Hester RK, Ueda S, Tomiyama A. Mode of vasorelaxing action of 5-[3[[2-(3,4-dimethoxyphenyl)-ethyl]amino]-1-oxopropyl]-2,3,4,5- tetrahydro-1,5-benzothiazepine fumarate (KT362), a new intracellular calcium antagonist. J Pharmacol Exp Ther 1987; 240: 16-22.

[192] Eskinder H, Hillard CJ, Wilke RA, Gross GJ. Effect of KT-362, a putative intracellular calcium antagonist, on norepinephrine-induced contractions and inositol monophosphate accumulation in canine femoral artery. J Cardiovasc Pharmacol 1989; 13: 502-7.

[193] Bernink PJ, Prager G, Schelling A, Kobrin I. Antihypertensive properties of the novel calcium antagonist mibefradil (Ro 40-5967): a new generation of calcium antagonists? Mibefradil International Study Group. Hypertension 1996; 27: 426-32.

[194] Perchenet L, Clément-Chomienne O. Characterization of mibefradil block of the human heart delayed rectifier hKv1.5. J Pharmacol Exp Ther 2000; 295: 771-8.

[195] Liu JH, Bijlenga P, Occhiodoro T, Fischer-Lougheed J, Bader CR, Bernheim L. Mibefradil (Ro 40-5967) inhibits several $\mathrm{Ca} 2+$ and $\mathrm{K}+$ currents in human fusion-competent myoblasts. Br J Pharmacol 1999; 126: 245 50 .

[196] McNulty MM, Hanck DA. State-dependent mibefradil block of Na+ channels. Mol Pharmacol 2004; 66: $1652-61$

[197] Yoo HY, Zheng H, Nam JH, et al. Facilitation of Ca2+-activated K+ channels (IKCa1) by mibefradil in B lymphocytes. Pflugers Arch 2008; 456: 549-60.

[198] Hollingshead LM, Faulds D, Fitton A. Bepridil. A review of its pharmacological properties and therapeutic use in stable angina pectoris. Drugs 1992; 44: 835-57.

[199] Benet LZ. Pharmacokinetics and metabolism of bepridil. Am J Cardiol 1985; 55: 8C-13C.

[200] Duchêne-Marullaz P, Kantelip JP, Trolèse JF. Effects of bepridil, a new antianginal agent, on ambulatory electrocardiography in human volunteers. J Cardiovasc Pharmacol 1983; 5: 506-10.

[201] Solaro RJ, Bousquet P, Johnson JD. Stimulation of cardiac myofilament force, ATPase activity and troponin C Ca++ binding by bepridil. J Pharmacol Exp Ther 1986; 238: 502-7.

[202] Matlib MA. Action of bepridil, a new calcium channel blocker on oxidative phosphorylation, oligomycinsensitive adenosine triphosphatase activity, swelling, $\mathrm{Ca}++$ uptake and $\mathrm{Na}+$-induced $\mathrm{Ca}++$ release processes of rabbit heart mitochondria in vitro. J Pharmacol Exp Ther 1985; 233: 376-81.

[203] Nawada T, Tanaka Y, Hisatome I, et al. Mechanism of inhibition of the sodium current by bepridil in guineapig isolated ventricular cells. Br J Pharmacol 1995; 116: 1775-80.

[204] Kang L, Zheng MQ, Morishima M, Wang Y, Kaku T, Ono K. Bepridil up-regulates cardiac Na+ channels as a long-term effect by blunting proteasome signals through inhibition of calmodulin activity. Br $\mathrm{J}$ Pharmacol 2009; 157: 404-14.

[205] Garcia ML, Slaughter RS, King VF, Kaczorowski GJ. Inhibition of sodium-calcium exchange in cardiac sarcolemmal membrane vesicles. 2. Mechanism of inhibition by bepridil. Biochemistry 1988; 27: 2410-5.

[206] Tamura A, Ogura T, Uemura H, et al. Effects of antiarrhythmic drugs on the hyperpolarization-activated cyclic nucleotide-gated channel current. J Pharmacol Sci 2009; 110: 150-9.

[207] Kotake H, Igawa O, Miyamoto J, et al. Effect of bepridil on membrane currents of rabbit sinoatrial node cells. Arzneimittelforschung 1987; 37: 424-7. 
[208] Kobayashi S, Reien Y, Ogura T, Saito T, Masuda Y, Nakaya H. Inhibitory effect of bepridil on hKv1.5 channel current: comparison with amiodarone and E-4031. Eur J Pharmacol 2001; 430: 149-57.

[209] Suzuki S, Kurata Y, Li P, et al. Stabilization of Kv1.5 channel protein by bepridil through its action as a chemical chaperone. Eur J Pharmacol 2012; 696: 28-34.

[210] Nobe S, Aomine M, Arita M. Bepridil prolongs the action potential duration of guinea pig ventricular muscle only at rapid rates of stimulation. Gen Pharmacol 1993; 24: 1187-96.

[211] Berger F, Borchard U, Hafner D. Effects of the calcium entry blocker bepridil on repolarizing and pacemaker currents in sheep cardiac Purkinje fibres. Naunyn Schmiedebergs Arch Pharmacol 1989; 339: 638-46.

[212] Yumoto Y, Horie M, Kubota T, et al. Bepridil block of recombinant human cardiac IKs current shows a timedependent unblock. J Cardiovasc Pharmacol 2004; 43: 178-82.

[213] Wang JC, Kiyosue T, Kiriyama K, Arita M. Bepridil differentially inhibits two delayed rectifier K(+) currents, $\mathrm{I}(\mathrm{Kr})$ and $\mathrm{I}(\mathrm{Ks})$, in guinea-pig ventricular myocytes. Br J Pharmacol 1999; 128: 1733-8.

[214] Wit AL, Cranefield PF. Effect of verapamil on the sinoatrial and atrioventricular nodes of the rabbit and the mechanism by which it arrests reentrant atrioventricular nodal tachycardia. Circ Res 1974; 35: 413-25.

[215] Muller CA, Opie LH, Hamm CW, Peisach M, Pineda CA, Thandroyen FT. Verapamil and tiapamil in prevention of ventricular fibrillation in pigs with coronary ligation. Comparative effects on left ventricular function. Circulation 1988; 78: 227-32.

[216] Schamroth L, Krikler DM, Garrett C. Immediate effects of intravenous verapamil in cardiac arrhythmias. $\mathrm{Br}$ Med J, 1972; 1: 660-2.

[217] Krikler DM, Spurrell RA. Verapamil in the treatment of paroxysmal supraventricular tachycardia. Postgrad Med J 1974; 50: 447-53.

[218] Hagemeijer F. Verapamil in the management of supraventricular tachyarrhythmias occurring after a recent myocardial infarction. Circulation 1978; 57: 751-5.

[219] Härtel G, Hartikainen M. Comparison of verapamil and practolol in paroxysmal supraventricular tachycardia. Eur J Cardiol 1976; 4: 87-90.

[220] Lewis RV, McMurray J, McDevitt DG. Effects of atenolol, verapamil, and xamoterol on heart rate and exercise tolerance in digitalised patients with chronic atrial fibrillation. J Cardiovasc Pharmacol 1989; 13: 1-6.

[221] Lang R, Klein HO, Weiss E, et al. Superiority of oral verapamil therapy to digoxin in treatment of chronic atrial fibrillation. Chest 1983; 83: 491-9.

[222] Tsuneda T, Yamashita T, Fukunami M, et al. Rate control and quality of life in patients with permanent atrial fibrillation: the Quality of Life and Atrial Fibrillation (QOLAF) Study. Circ J 2006; 70: 965-70.

[223] Van Noord T, Van Gelder IC, Tieleman RG, et al. VERDICT: the Verapamil versus Digoxin Cardioversion Trial: A randomized study on the role of calcium lowering for maintenance of sinus rhythm after cardioversion of persistent atrial fibrillation. J Cardiovasc Electrophysiol 2001; 12: 766-9.

[224] DiMarco JP, Miles W, Akhtar M, et al. Adenosine for paroxysmal supraventricular tachycardia: dose ranging and comparison with verapamil. Assessment in placebo-controlled, multicenter trials. The Adenosine for PSVT Study Group. Ann Intern Med 1990; 113: 104-10.

[225] Fox DJ, Tischenko A, Krahn AD, et al. Supraventricular tachycardia: diagnosis and management. Mayo Clin Proc 2008; 83: 1400-11.

[226] Delaney B, Loy J, Kelly AM. The relative efficacy of adenosine versus verapamil for the treatment of stable paroxysmal supraventricular tachycardia in adults: a meta-analysis. Eur J Emerg Med 2011; 18: 148-52.

[227] Holdgate A, Foo A. WITHDRAWN: Adenosine versus intravenous calcium channel antagonists for the treatment of supraventricular tachycardia in adults. Cochrane Database Syst Rev 2012; 2: CD005154.

[228] Lewis RV, Irvine N, McDevitt DG. Relationships between heart rate, exercise tolerance and cardiac output in atrial fibrillation: the effects of treatment with digoxin, verapamil and diltiazem. Eur Heart J 1988; 9: 777-81.

[229] Lundström T, Rydén L. Ventricular rate control and exercise performance in chronic atrial fibrillation: effects of diltiazem and verapamil. J Am Coll Cardiol 1990; 16: 86-90.

[230] Daoud EG, Knight BP, Weiss R, et al. Effect of verapamil and procainamide on atrial fibrillation-induced electrical remodeling in humans. Circulation 1997; 96: 1542-50.

[231] Yu WC, Chen SA, Lee SH, et al. Tachycardia-induced change of atrial refractory period in humans: rate dependency and effects of antiarrhythmic drugs. Circulation 1998; 97: 2331-7.

[232] Rowland E, McKenna WJ, Krikler DM. Electrophysiologic and antiarrhythmic actions of bepridil. Comparison with verapamil and ajmaline for atrioventricular reentrant tachycardia. Am J Cardiol 1985; 55: 1513-9.

[233] Heng MK, Singh BN, Roche AH, Norris RM, Mercer CJ. Effects of intravenous verapamil on cardiac arrhythmias and on the electrocardiogram. Am Heart J 1975; 90: 487-98. 
[234] Sung RJ, Elser B, McAllister RG. Jr. Intravenous verapamil for termination of re-entrant supraventricular tachycardias: intracardiac studies correlated with plasma verapamil concentrations. Ann Intern Med 1980; 93: 682-9.

[235] Kapur PA, Norel E, Dajee H, Cimochowski G. Verapamil treatment of intractable ventricular arrhythmias after cardiopulmonary bypass. Anesth Analg 1984; 63: 460-3.

[236] Baraka A, Usta N. Verapamil treatment of intractable reperfusion ventricular tachycardia/fibrillation. Anesth Analg 1986; 65: 102-3.

[237] Fyke FE, Vlietstra RE, Danielson GK, Beynen FM. Verapamil for refractory ventricular fibrillation during cardiac operations in patients with cardiac hypertrophy. J Thorac Cardiovasc Surg 1983; 86: 108-11.

[238] Lin FC, Finley CD, Rahimtoola SH, Wu D. Idiopathic paroxysmal ventricular tachycardia with a QRS pattern of right bundle branch block and left axis deviation: a unique clinical entity with specific properties. Am $\mathrm{J}$ Cardiol 1983; 52: 95-100.

[239] Wang JC, Lim SH, Teo WS, Anantharaman V. Calcium channel blockers as first line treatment for broad complex tachycardia with right bundle branch block: ingenuity or folly? Resuscitation 2002; 52: 175-82.

[240] Gill JS, Blaszyk K, Ward DE, Camm AJ. Verapamil for the suppression of idiopathic ventricular tachycardia of left bundle branch block-like morphology. Am Heart J 1993; 126: 1126-33.

[241] Kim RJ, Iwai S, Markowitz SM, Shah BK, Stein KM, Lerman BB. Clinical and electrophysiological spectrum of idiopathic ventricular outflow tract arrhythmias. J Am Coll Cardiol 2007; 49: 2035-43.

[242] Ohe T, Aihara N, Kamakura S, Kurita T, Shimizu W, Shimomura K. Long-term outcome of verapamilsensitive sustained left ventricular tachycardia in patients without structural heart disease. J Am Coll Cardiol 1995; $25: 54-8$.

[243] Shimizu W, Ohe T, Kurita T, Tokuda T, Shimomura K. Epinephrine-induced ventricular premature complexes due to early afterdepolarizations and effects of verapamil and propranolol in a patient with congenital long QT syndrome. J Cardiovasc Electrophysiol 1994; 5: 438-44.

[244] Swan H, Laitinen P, Kontula K, Toivonen L. Calcium channel antagonism reduces exercise-induced ventricular arrhythmias in catecholaminergic polymorphic ventricular tachycardia patients with RyR2 mutations. J Cardiovasc Electrophysiol 2005; 16: 162-6.

[245] Rosso R, Kalman JM, Rogowski O, et al. Calcium channel blockers and beta-blockers versus beta-blockers alone for preventing exercise-induced arrhythmias in catecholaminergic polymorphic ventricular tachycardia. Heart Rhythm 2007; 4: 1149-54.

[246] Kato M, Dote K, Sasaki S, Takemoto H, Habara S, Hasegawa D. Intracoronary verapamil rapidly terminates reperfusion tachyarrhythmias in acute myocardial infarction. Chest 2004 126: 702-8.

[247] Bonney WJ, Ceresnak SR, Ira S, Hordof A, Liberman L. Verapamil sensitive ventricular tachycardia associated with a cardiac hemangioma in the right ventricular outflow tract. Indian Pacing Electrophysiol J 2009; 9: 355-9.

[248] Hirao H, Muraoka Y, Yamada T, et al. Idiopathic verapamil-sensitive left ventricular tachycardia complicated by right ventricular outflow tract ventricular tachycardia and ventricular fibrillation. Intern Med 1999; 38 : 359-64.

[249] Griffith MJ, Garratt CJ, Rowland E, Ward DE, Camm AJ. Effects of intravenous adenosine on verapamilsensitive "idiopathic" ventricular tachycardia. Am J Cardiol 1994; 73: 759-64.

[250] Maruyama M, Tadera T, Miyamoto S, Ino T. Demonstration of the reentrant circuit of verapamil-sensitive idiopathic left ventricular tachycardia: direct evidence for macroreentry as the underlying mechanism. $\mathrm{J}$ Cardiovasc Electrophysiol 2001; 12: 968-72.

[251] Budden M, Kirchengast M, Zhang KM, Meesmann W. Effects of the calcium antagonist gallopamil on the increase of myocardial extracellular potassium activity during LAD occlusion in dogs. Basic Res Cardiol 1987; 82: 279-89.

[252] Kirchengast M, Hergenröder S. Reperfusion arrhythmias in closed-chest rats: the effect of myocardial noradrenaline depletion and Ca2(+)-antagonism. Clin Exp Pharmacol Physiol 1991; 18: 217-21.

[253] Matsuzaki T, Haruno A, Hashimoto K. Effects of gallopamil, a Ca2+ channel blocker in models of ventricular arrhythmia in dogs. Eur J Pharmacol 1993; 231: 363-70.

[254] Hayashi H, Terada H, Katoh H, McDonald TF. Prevention of reoxygenation-induced arrhythmias in guinea pig papillary muscles. J Cardiovasc Pharmacol 1996; 27: 816-23.

[255] Kowey PR, O'Brien R, Wu Y, et al. Effect of gallopamil on electrophysiologic abnormalities and ventricular arrhythmias associated with left ventricular hypertrophy in the feline heart. Am Heart J 1992; 124: 898-905.

[256] El-Sherif N, Lazzara R. Reentrant ventricular arrhythmias in the late myocardial infarction period. 7. Effect of verapamil and D-600 and the role of the "slow channel". Circulation 1979; 60: 605-15. 
[257] Seipel L, Breithardt G, Abendroth RR, Wiebringhaus E. The electrophysiological effects of the Ca-antagonists gallopamil (D 600), dimeditiapramine (Ro 11-1781) and verapamil in man. Z Kardiol 1980; 69: 551-5.

[258] Beck OA, Witt E, Lehmann HU, Hochrein H. Action of the calciumantagonistic compound gallopamile on sinus node, atrioventricular and intraventricular conduction. Z Kardiol 1978; 67: 522-6.

[259] Neuss H, Horn HG, Mitrović V, Buss J, Schlepper M. Heart rate reduction in atrial fibrillation with a rapid ventricular response by Gallopamil, a Ca-antagonist. Z Kardiol 1982; 71: 334-49.

[260] Mildenberger D, Klepzig H Jr, Hopf R, Kaltenbach M. The spectrum of side effects of gallopamil in comparison with other calcium antagonists. Z Kardiol 1989; 78: Suppl 5, 25-8.

[261] Belz GG, Doering W, Munkes R, Matthews J. Interaction between digoxin and calcium antagonists and antiarrhythmic drugs. Clin Pharmacol Ther 1983; 33: 410-7.

[262] Botto GL, Bonini W, Broffoni T. Modulation of ventricular rate in permanent atrial fibrillation: randomized, crossover study of the effects of slow-release formulations of gallopamil, diltiazem, or verapamil. Clin Cardiol 1998; 21: 837-40.

[263] Saini RK, Antonaccio MJ. Antiarrhythmic, antifibrillatory activities and reduction of infarct size after the calcium antagonist Ro 11-1781 (tiapamil) in anesthetized dogs. J Pharmacol Exp Ther 1982; 221: 29-36.

[264] Shargorodsky BM, Braun S, Belhassen B, Laniado S. Antiarrhythmic and haemodynamic effects of tiapamil, a new calcium antagonist, during coronary artery occlusion and reperfusion in dogs. Cardiovasc Res 1986; 20: 652-7.

[265] Raeder EA, Verrier RL, Lown B. Protective effect of tiapamil against ventricular fibrillation during coronary artery occlusion. Am Heart J 1986; 111: 878-82.

[266] Gerold M, Eigenmann R, Haeusler G. Cardiovascular effects of tiapamil (Ro 11-1781), a new calcium-entry blocker. J Cardiovasc Pharmacol 1982; 4: 419-29.

[267] Harada S, Sada H, Kojima M, Ban T. Negative inotropic effects of tiapamil (Ro11-1781) and verapamil in rabbit myocardium. Eur J Pharmacol 1982; 78: 7-14.

[268] Bödeker K, Bischoff KO, Menken U, Hager W. Hemodynamic and electrophysiologic effects of the new calcium antagonist Ro 11-1781. Z Kardiol 1980; 69: 790-6.

[269] Brisse B, Bender F, Bramann H, Kuhs H, Schwippe G. Management of cardiac arrhythmias with tiapamil. Cardiology 1982; 69: Suppl, 144-8.

[270] Fauchier JP, Elkik F, Cosnay P, Rouesnel P, Neel C, Quillet L. Effect of i.v. and oral tiapamil in the treatment of paroxysmal supraventricular tachycardia. Eur Heart J 1985; 6: 525-31.

[271] Gmeiner R, Ng CK. Effect of tiapamil in the Wolff-Parkinson-White syndrome. J Cardiovasc Pharmacol 1981; 3: 237-50.

[272] Steffen E, Langbehn AF, Diederich KW. Oral effectiveness of the calcium-antagonist Ro 11-1781 (Tiapamil) in supraventricular and ventricular extrasystoles. Z Kardiol 1981; 70: 172-5.

[273] Nowak FG, Cocco G, Chu D, Gasser DF. Antiarrhythmic effect of the calcium antagonist tiapamil (Ro 111781) by intravenous administration in patients with coronary heart disease. Clin Cardiol 1980; 3: 371-6.

[274] Menzel T, Kirchner P. Parenteral tiapamil treatment of arrhythmias in cardiac patients. Cardiology 1982; 69: Suppl, 192-8.

[275] Lessem J. Tiapamil in the treatment of lidocaine-resistant ventricular arrhythmias complicating acute myocardial infarction. Cardiology 1982; 69: Suppl, 199-208.

[276] Dubner S, Gimeno G, Elencwajg B, Quinteiro R, Tronge J, Bertolasi C. Antiarrhythmic effect of tiapamil in patients with acute myocardial infarction. Cardiology 1982; 69: Suppl, 172-80.

[277] Strozzi C, Sfrisi C, Leutenegger F, Padula A, Bulgarelli R. Tiapamil in the management of supraventricular arrhythmias occurring after acute myocardial infarction. Cardiology 1982; 69: Suppl, 187-91.

[278] Burkart F, Baitsch G, Braun S, Bertel O, Cocco G. Antiarrhythmic effects of tiapamil on exercise-induced arrhythmias in patients with coronary artery disease. Cardiology 1982; 69: Suppl, 165-71.

[279] List WF, Metzler H. Effect of tiapamil on perioperative cardiac arrhythmias and myocardial function. Cardiology 1982; 69: Suppl, 157-64.

[280] Curtis MJ, Walker MJ, Yuswack T. Actions of the verapamil analogues, anipamil and ronipamil, against ischaemia-induced arrhythmias in conscious rats. Br J Pharmacol 1986; 88: 355-61.

[281] Kirchengast M, Raschack M. Effects of anipamil on electrocardiogram, plasma creatine kinase, and reperfusion arrhythmias after coronary occlusion in closed-chest rats. J Cardiovasc Pharmacol 1989; 13: (Suppl 4), S73-5.

[282] MacLeod BA, Moult M, Saint KM, Walker MJ. The antiarrhythmic efficacy of intravenous anipamil against occlusion and reperfusion arrhythmias. Br J Pharmacol 1989; 98: 1165-72. 
[283] Ries C, Harvie CJ, Walker MJ, Pugsley MK. Antiarrhythmic actions of a long acting verapamil analogue, anipamil, in pigs. Proc West Pharmacol Soc 1993; 36: 95-8.

[284] Hansen BF, Mortensen A, Hansen JF, Frandsen H. (-)-anipamil retards atherosclerosis in Watanabe heritable hyperlipidemic rabbits. J Cardiovasc Pharmacol 1995; 26: 485-9.

[285] Dies R, Schneider G, Hahn KJ. Antihypertensive efficacy of anipamil in mild to moderate hypertension. J Cardiovasc Pharmacol 1989; 13: (Suppl 4), S76-8.

[286] Larsen CT, Sørum C, Rasmussen V, Fischer Hansen J. Anipamil prevents ST depression in patients with stable angina pectoris. Cardiovasc Drugs Ther 1993; 7: 915-21.

[287] Tosaki A, Szekeres L, Hearse DJ. Diltiazem and the reduction of reperfusion-induced arrhythmias in the rat: protection is secondary to modification of ischemic injury and heart rate. J Mol Cell Cardiol 1987; 19: 441-51.

[288] Baxter GF, Yellon DM. Attenuation of reperfusion-induced ventricular fibrillation in the rat isolated hypertrophied heart by preischemic diltiazem treatment. Cardiovasc Drugs Ther 1993; 7: 225-31.

[289] Fareh S, Bénardeau A, Nattel S. Differential efficacy of L- and T-type calcium channel blockers in preventing tachycardia-induced atrial remodeling in dogs. Cardiovasc Res 2001; 49: 762-70.

[290] Mitchell LB, Jutzy KR, Lewis SJ, Schroeder JS, Mason JW. Intracardiac electrophysiologic study of intravenous diltiazem and combined diltiazem-digoxin in patients. Am Heart J 1982; 103: 57-66.

[291] Ellenbogen KA, Dias VC, Cardello FP, et al. Safety and efficacy of intravenous diltiazem in atrial fibrillation or atrial flutter. Am J Cardiol 1995; 75: 45-9.

[292] Salerno DM, Dias VC, Kleiger RE, et al. Efficacy and safety of intravenous diltiazem for treatment of atrial fibrillation and atrial flutter. The Diltiazem-Atrial Fibrillation/Flutter Study Group. Am J Cardiol 1989; 63: 1046-51.

[293] Goldenberg IF, Lewis WR, Dias VC, Heywood JT, Pedersen WR. Intravenous diltiazem for the treatment of patients with atrial fibrillation or flutter and moderate to severe congestive heart failure. Am J Cardiol 1994; 74: 884-9.

[294] Schreck DM, Rivera AR, Tricarico VJ. Emergency management of atrial fibrillation and flutter: intravenous diltiazem versus intravenous digoxin. Ann Emerg Med 1997; 29: 135-40.

[295] Lee J, Kim K, Lee CC, et al. Low-dose diltiazem in atrial fibrillation with rapid ventricular response. Am J Emerg Med 2011; 29: 849-54.

[296] Theisen K, Haufe M, Peters J, Theisen F, Jahrmärker H. Effect of the calcium antagonist diltiazem on atrioventricular conduction in chronic atrial fibrillation. Am J Cardiol 1985; 55: 98-102.

[297] Atwood JE, Myers JN, Sullivan MJ, Forbes SM, Pewen WF, Froelicher VF. Diltiazem and exercise performance in patients with chronic atrial fibrillation. Chest 1988; 93: 20-5.

[298] Farshi R, Kistner D, Sarma JS, Longmate JA, Singh BN. Ventricular rate control in chronic atrial fibrillation during daily activity and programmed exercise: a crossover open-label study of five drug regimens. J Am Coll Cardiol 1999; 33: 304-10.

[299] Roth A, Harrison E, Mitani G, Cohen J, Rahimtoola SH, Elkayam U. Efficacy and safety of medium- and high-dose diltiazem alone and in combination with digoxin for control of heart rate at rest and during exercise in patients with chronic atrial fibrillation. Circulation 1986; 73: 316-24.

[300] Steinberg JS, Katz RJ, Bren GB, Buff LA, Varghese PJ. Efficacy of oral diltiazem to control ventricular response in chronic atrial fibrillation at rest and during exercise. J Am Coll Cardiol 1987; 9: 405-11.

[301] Maragno I, Santostasi G, Gaion RM, et al. Low- and medium-dose diltiazem in chronic atrial fibrillation: comparison with digoxin and correlation with drug plasma levels. Am Heart J 1988; 116: 385-92.

[302] Betriu A, Chaitman BR, Bourassa MG, et al. Beneficial effect of intravenous diltiazem in the acute management of paroxysmal supraventricular tachyarrhythmias. Circulation 1983; 67: 88-94.

[303] Huycke EC, Sung RJ, Dias VC, Milstein S, Hariman RJ, Platia EV. Intravenous diltiazem for termination of reentrant supraventricular tachycardia: a placebo-controlled, randomized, double-blind, multicenter study. J Am Coll Cardiol 1989; 13: 538-44.

[304] Dougherty AH, Jackman WM, Naccarelli GV, Friday KJ, Dias VC. Acute conversion of paroxysmal supraventricular tachycardia with intravenous diltiazem. IV Diltiazem Study Group. Am J Cardiol 1992; 70 : $587-92$.

[305] Mikroulis D, Didilis V, Konstantinou F, Tsakiridis K, Vretzakis G, Bougioukas G. Diltiazem versus amiodarone to prevent atrial fibrillation in coronary surgery. Asian Cardiovasc Thorac Ann 2005; 13: 47-52.

[306] Wijeysundera DN, Beattie WS. Calcium channel blockers for reducing cardiac morbidity after noncardiac surgery: a meta-analysis. Anesth Analg 2003; 97: 634-41.

[307] Stella L, de Novellis V, Vacca C, et al. Antiarrhythmic effects of LR-A/113 a new calcium antagonistic drug. Res Commun Mol Pathol Pharmacol 1996; 93: 235-48. 
[308] Rousseau G, Provost P, Latour JG. Sustained myocardial protection by clentiazem (TA-3090) after a 90minute coronary occlusion and 72 hours of reperfusion in dogs with collateral flow. J Cardiovasc Pharmacol 1993; 22: 264-72.

[309] Tanguay M, Jasmin G, Blaise G, Dumont L. Coronary and cardiac sensitivity to the vasoselective benzothiazepine-like calcium antagonist, clentiazem, in experimental heart failure. Cardiovasc Drugs Ther 1997; 11: 71-9.

[310] Tanno K, Kobayashi Y, Miyata A, et al. Electrophysiologic effect of a new Ca(2+)-antagonist, TA-3090 on supraventricular tachycardia and conduction system. Kokyu To Junkan 1992; 40: 897-902.

[311] Waters D, Garceau D. A dose-response study of clentiazem, a chloro-derivative of diltiazem, in patients with stable angina. CAMCAT Study Group. J Am Coll Cardiol 1993; 21: 964-70.

[312] Kimoto S, Haruna M, Matsuura E, et al. Pharmacological studies on a new antihypertensive agent, S-2150, a benzothiazepine derivative: 3. Hypotensive and antimyocardial-stunning effects in dogs. J Cardiovasc Pharmacol 1997; 29: 180-7.

[313] Mori T, Ishigai Y, Fukuzawa A, Chiba K, Shibano T. Pharmacological profile of semotiadil fumarate, a novel calcium antagonist, in rat experimental angina model. Br J Pharmacol 1995; 116: 1668-72.

[314] Takada T, Miyawaki N, Nishimura K, et al. Cardiohemodynamic effect of a novel calcium antagonist, SD3211, in the dog. Arch Int Pharmacodyn Ther 1991; 309: 75-87.

[315] Fukuchi M, Uematsu T, Nagashima S, Nakashima M. Antiarrhythmic effects of a benzothiazine derivative (SD-3211) and its stereoisomer (SA3212) in anaesthetized rats and isolated perfused rat hearts compared with bepridil. Naunyn Schmiedebergs Arch Pharmacol 1990; 341: 557-64.

[316] Nagashima S, Uematsu T, Araki S, et al. Antiarrhythmic and electrophysiological effects of SD-3212, a novel $\mathrm{Na}+$ and $\mathrm{Ca}++$ channel blocker, in anaesthetized dogs with myocardial infarction in comparison with its stereoisomer (SD-3211) and bepridil. Naunyn Schmiedebergs Arch Pharmacol 1992; 345: 688-95.

[317] Hirasawa A, Haruno A, Matsuzaki T, Hashimoto K. Effects of a new antiarrhythmic drug, SD-3212, on canine ventricular arrhythmia models. Jpn Heart J 1992; 33: 851-61.

[318] Adamson PB, Vanoli E, Shibano T, Foreman RD, Schwartz PJ. Combined sodium and calcium channel blockade in prevention of lethal arrhythmias. J Cardiovasc Pharmacol 2003; 41: 665-70.

[319] Polster P, Christophe B, Van Damme M, Houlliche A, Chatelain P. SR 33557, a novel calcium entry blocker. I. In vitro isolated tissue studies. J Pharmacol Exp Ther 1990; 255: 593-9.

[320] Manning A, Mouton J, Chatelain P. Fantofarone (SR 33557): effect on post-ischaemic functional recovery in perfused rat hearts. Eur J Pharmacol 1992; 220: 249-58.

[321] Vander Elst L, Chatelain P, Manning AS, Laruel R, Van Haverbeke Y, Muller RN. 31P nuclear magnetic resonance study of the effects of the calcium ion channel antagonist fantofarone on the rat heart. Eur $\mathrm{J}$ Pharmacol 1994; 251: 163-72.

[322] Bellissant E, Giudicelli JF. Pharmacokinetic-pharmacodynamic model for fantofarone cardiac and brachial haemodynamic effects in healthy volunteers. Br J Clin Pharmacol 1999; 48: 801-10.

[323] Bellissant E, Thuillez C, Kechrid R, Duhaze P, Giudicelli JF. Non invasive study of systemic and regional haemodynamic and cardiac effects of a new calcium antagonist, SR 33557, in healthy volunteers. Eur J Clin Pharmacol 1991; 41: 329-34.

[324] Saal JP, Lellouche D, Habbal R, Sissmann J, Castaigne A, Dubois-Randé JL. Hemodynamic effects of a new calcium antagonist, SR 33557, in patients with coronary artery disease and normal left ventricular function. J Cardiovasc Pharmacol 1994; 23: 87-91.

[325] Glasser SP, Singh SN, Humen DP. Safety and efficacy of monotherapy with fantofarone, a novel calcium channel antagonist, in patients with chronic stable angina pectoris. Fantofarone Study Group. J Clin Pharmacol 1997; 37: 53-7.

[326] Kalifa J, Bernard M, Gout B, et al. Anti-arrhythmic effects of I (Na), I (Kr), and combined I (Kr)-I (CaL) blockade in an experimental model of acute stretch-related atrial fibrillation. Cardiovasc Drugs Ther 2007; 21: 47-53.

[327] Gout B, Nichols AJ, Feuerstein GZ, Bril A. Antifibrillatory effects of BRL-32872 in anesthetized Yucatan minipigs with regional myocardial ischemia. J Cardiovasc Pharmacol 1995; 26: 636-44.

[328] Bril A, Gout B, Bonhomme M, et al. Combined potassium and calcium channel blocking activities as a basis for antiarrhythmic efficacy with low proarrhythmic risk: experimental profile of BRL-32872. J Pharmacol Exp Ther 1996; 276: 637-46.

[329] Farber NE, Gross GJ. Cardioprotective effects of a new vascular intracellular calcium antagonist, KT-362, in the stunned myocardium. J Pharmacol Exp Ther 1989; 248: 39-43. 
[330] Pelc LR, Farber NE, Warltier DC, Gross GJ. Reduction of myocardial ischemia-reperfusion injury by KT-362, a new intracellular calcium antagonist in anesthetized dogs. J Cardiovasc Pharmacol 1989; 13: 586-93.

[331] Hashimoto K, Watanabe K, Mochizuki S, Tomiyama A. Effects of KT-362, a new Na and Ca influx and Ca release inhibitor, on canine ventricular arrhythmias. Jpn J Pharmacol 1989; 51: 475-82.

[332] Wakabayashi S, Mochizuki S, Tomiyama A, Shibata S. Effects of KT-362, a new calcium release blocker, on vascular selectivity and hemodynamic actions in anesthetized dogs. Jpn J Pharmacol 1990; 54: 23-32.

[333] Farber NE, Gross GJ. Collateral blood flow following acute coronary artery occlusion: comparison of a new intracellular calcium antagonist (KT-362) and diltiazem. J Cardiovasc Pharmacol 1989; 14: 66-72.

[334] Farkas A, Qureshi A, Curtis MJ. Inadequate ischaemia-selectivity limits the antiarrhythmic efficacy of mibefradil during regional ischaemia and reperfusion in the rat isolated perfused heart. Br J Pharmacol 1999; 128: 41-50.

[335] Muller CA, Opie LH, McCarthy J, Hofmann D, Pineda CA, Peisach M. Effects of mibefradil, a novel calcium channel blocking agent with T-type activity, in acute experimental myocardial ischemia: maintenance of ventricular fibrillation threshold without inotropic compromise. J Am Coll Cardiol 1998; 32: 268-74.

[336] Fareh S, Bénardeau A, Thibault B, Nattel S. The T-type $\mathrm{Ca}(2+)$ channel blocker mibefradil prevents the development of a substrate for atrial fibrillation by tachycardia-induced atrial remodeling in dogs. Circulation 1999; 100: 2191-7.

[337] Osterrieder W, Holck M. In vitro pharmacologic profile of Ro 40-5967, a novel Ca2+ channel blocker with potent vasodilator but weak inotropic action. J Cardiovasc Pharmacol 1989; 13: 754-9.

[338] Hoischen S, Brixius K, Schwinger RH. T- and L-type Ca2+-channel antagonists reduce contractility in guinea pig cardiac myocytes. J Cardiovasc Pharmacol 1998; 32: 323-30.

[339] Véniant M, Clozel JP, Hess P, Wolfgang R. Hemodynamic profile of Ro 40-5967 in conscious rats: comparison with diltiazem, verapamil, and amlodipine. J Cardiovasc Pharmacol 1991; 18: Suppl 10, S55-8.

[340] Ezzaher A, el Houda Bouanani N, Su JB, Hittinger L, Crozatier B. Increased negative inotropic effect of calcium-channel blockers in hypertrophied and failing rabbit heart. J Pharmacol Exp Ther 1991; 257: 466-71.

[341] Shimoyama H, Sabbah HN, Tanimura M, Borzak S, Goldstein S. Short-term hemodynamic effects of mibefradil in dogs with chronic heart failure: comparison with diltiazem. J Pharmacol Exp Ther 1998; 285: 746-52.

[342] Rosenquist M, Brembilla-Perrot B, Meinertz T, et al. The acute effects of intravenously administered mibefradil, a new calcium antagonist, on the electrophysiologic characteristics of the human heart. Eur J Clin Pharmacol 1997; 52: 7-12.

[343] Mádle A, Linhartová K, Koza J. Effects of the T-type calcium channel blockade with oral mibefradil on the electrophysiologic properties of the human heart. Med Sci Monit 2001; 7: 74-7.

[344] Rousseau MF, Hayashida W, van Eyll C, et al. Hemodynamic and cardiac effects of the selective T-type and L-type calcium channel blocking agent mibefradil in patients with varying degrees of left ventricular systolic dysfunction. J Am Coll Cardiol 1996; 28: 972-9.

[345] Tzivoni D, Kadr H, Braat S, Rutsch W, Ramires JA, Kobrin I. Efficacy of mibefradil compared with amlodipine in suppressing exercise-induced and daily silent ischemia: results of a multicenter, placebocontrolled trial. Circulation 1997; 96: 2557-64.

[346] Levine TB, Bernink PJ, Caspi A, et al. Effect of mibefradil, a T-type calcium channel blocker, on morbidity and mortality in moderate to severe congestive heart failure: the MACH-1 study. Mortality Assessment in Congestive Heart Failure Trial. Circulation 2000; 101: 758-64.

[347] Gläser S, Steinbach M, Opitz C, Wruck U, Kleber FX. Torsades de pointes caused by Mibefradil. Eur J Heart Fail 2001; 3: 627-30.

[348] Sanders P, Walker J, Craig RJ, Hii JT, Steele PM. Mibefradil (Posicor) induced sinus arrest. Aust N Z J Med 1998; 28: 836-7.

[349] Glasser SP. The relevance of T-type calcium antagonists: a profile of mibefradil. J Clin Pharmacol 1998; 38 : 659-69.

[350] Krayenbühl JC, Vozeh S, Kondo-Oestreicher M, Dayer P. Drug-drug interactions of new active substances: mibefradil example. Eur J Clin Pharmacol 1999; 55: 559-65.

[351] Okamura H, Fujitani B, Furukawa K, et al. Pharmacologic properties of a novel Ca2+ entry blocker, AJ-2615, in vitro. J Cardiovasc Pharmacol 1993; 22: 804-9.

[352] Sugimoto T, Hosoki K, Karasawa T. Relative contribution of alpha 1-adrenoceptor blocking activity to the hypotensive effect of the novel calcium antagonist monatepil. J Cardiovasc Pharmacol 1995; 26: 55-60.

[353] Yamamoto T, Hosoki K, Karasawa T. Anti-arrhythmic effects of a new calcium antagonist, monatepil, AJ2615, in experimental arrhythmic models. Clin Exp Pharmacol Physiol 1993; 20: 497-500. 
[354] Kataoka T, Nose I, Honda Y, et al. Effects of the new calcium antagonist monatepil on cardiac function and myocardial oxygen supply and demand in animals. Arzneimittelforschung 1993; 43: 1303-9.

[355] Ikeno A, Nose I, Fukuya F, et al. Antihypertensive effects of AJ-2615, a new calcium antagonist with alpha 1adrenergic blocking activity in experimental hypertensive animals. J Cardiovasc Pharmacol 1993; 21: 815-21.

[356] Sasaki J, Ogihara T, Yokoyama M, et al. Comparative effects of monatepil, a novel calcium antagonist with alpha 1-adrenergic-blocking activity, and nitrendipine on lipoprotein and carbohydrate metabolism in patients with hypertension. Am J Hypertens 1994; 7: 161S-6S.

[357] Ishii M, Iimura O, Yoshinaga $\mathrm{K}$, et al. The efficacy of monatepil, a new calcium antagonist, in the treatment of essential hypertension. Am J Hypertens 1994; 7: 141S-5S.

[358] Kane KA, Berdeja García GY, Sánchez-Pérez S, Pastelín G. Electrophysiological effects of lidocaine, 1chlorpheniramine, and bepridil on normal and ouabain-intoxicated canine Purkinje fibers. J Cardiovasc Pharmacol 1983; 5: 109-15.

[359] Kane KA, Winslow E. Antidysrhythmic and electrophysiological effects of a new antianginal agent, bepridil. J Cardiovasc Pharmacol 1980; 2: 193-203.

[360] Labrid C, Leinot M, Beaughard M, Basiez M, Duchene-Marullaz P. Comparative antidysrhythmic profiles of bepridil, amiodarone and disopyramide in the guinea-pig and dog. Arch Int Pharmacodyn Ther 1981; 249: 8797.

[361] Takanari H, Honjo H, Takemoto Y, et al. Bepridil facilitates early termination of spiral-wave reentry in twodimensional cardiac muscle through an increase of intercellular electrical coupling. J Pharmacol Sci 2011; 115: 15-26.

[362] Lynch JJ, Montgomery DG, Ventura A, Lucchesi BR. Antiarrhythmic and electrophysiologic effects of bepridil in chronically infarcted conscious dogs. J Pharmacol Exp Ther 1985; 234: 72-80.

[363] Winslow E, Kane KA. Supraventricular antidysrhythmic and electrophysiological effects of bepridil, a new antianginal agent. J Cardiovasc Pharmacol 1981; 3: 655-67.

[364] Nishida K, Fujiki A, Sakamoto T, et al. Bepridil reverses atrial electrical remodeling and L-type calcium channel downregulation in a canine model of persistent atrial tachycardia. J Cardiovasc Electrophysiol 2007; 18: 765-72.

[365] Brachmann J, Aidonidis I, Dembowsky K, Seller H, Kuebler W. Bepridil versus nifedipine for ventricular tachycardia induced in the late postinfarction phase in conscious dogs. Cardiology 1989; 76: 211-21.

[366] Flaim SF, Ratz PH, Swigart SC, Gleason MM. Bepridil hydrochloride alters potential-dependent and receptoroperated calcium channels in vascular smooth muscle of rabbit aorta. J Pharmacol Exp Ther 1985; 234: 63-71.

[367] Anno T, Furuta T, Itoh M, Kodama I, Toyama J, Yamada K. Electromechanical effects of bepridil on rabbit isolated hearts. Br J Pharmacol 1984; 81: 41-7.

[368] Flammang D, Waynberger M, Jansen FH, Paillet R, Coumel P. Electrophysiological profile of bepridil, a new anti-anginal drug with calcium blocking properties. Eur Heart J 1983; 4: 647-54.

[369] Levy S, Cointe R, Metge M, Faugere G, Valeix B, Gerard R. Bepridil for recurrent sustained ventricular tachycardias: assessment using electrophysiologic testing. Am J Cardiol 1984; 54: 579-81.

[370] Somberg J, Torres V, Flowers D, Miura D, Butler B, Gottlieb S. Prolongation of QT interval and antiarrhythmic action of bepridil. Am Heart J 1985; 109: 19-27.

[371] Schmitt C, Brachmann J, Hölzel C, et al. Electrophysiologic effects of bepridil in patients with refractory ventricular tachycardia assessed by programmed electrical stimulation. Clin Cardiol 1990; 13: 864-8.

[372] Brembilla-Perrot B, Aliot E, Clementy J, et al. Evaluation of bepridil efficacy by electrophysiologic testing in patients with recurrent ventricular tachycardia: comparison of two regimens. Cardiovasc Drugs Ther 1992; 6: $187-93$.

[373] Izumi D, Chinushi M, Watanabe $\mathrm{H}$, et al. Bepridil for drug-refractory ventricular tachyarrhythmias. Intern Med 2007; 46: 119-24.

[374] Sugao M, Fujiki A, Nishida K, et al. Repolarization dynamics in patients with idiopathic ventricular fibrillation: pharmacological therapy with bepridil and disopyramide. J Cardiovasc Pharmacol 2005; 45: 5459.

[375] Nestico PF, Morganroth J, Horowitz LN, Mulhern C. Bepridil hydrochloride for treatment of benign or potentially lethal ventricular arrhythmias. Am J Cardiol 1986; 58: 1001-4.

[376] Noda K, Gotoh Y, Tanioka S, et al. The relationship between the plasma concentration of bepridil and its efficacy in the treatment of atrial fibrillation in Japanese patients. Biol Pharm Bull 2012; 35: 672-6.

[377] Nakazato Y, Yasuda M, Sasaki A, et al. Conversion and maintenance of sinus rhythm by bepridil in patients with persistent atrial fibrillation. Circ J 2005; 69: 44-8. 
[378] Aoyama Y, Niwano S, Niwano H, et al. Repetitive evaluation of fibrillation cycle length predicts the efficacy of bepridil for interruption of long-lasting persistent atrial fibrillation. Int Heart J 2011; 52: 353-8.

[379] Fujiki A, Sakabe M, Nishida K, et al. Drug-induced changes in fibrillation cycle length and organization index can predict chemical cardioversion of long-lasting atrial fibrillation with bepridil alone or in combination with aprindine. Circ J 2004; 68: 1139-45.

[380] Yamase M, Nakazato Y, Daida H. Effectiveness of amiodarone versus bepridil in achieving conversion to sinus rhythm in patients with persistent atrial fibrillation: a randomised trial. Heart 2012; 98: 1067-71.

[381] Yoshida T, Niwano S, Inuo K, et al. Bepridil prevents paroxysmal atrial fibrillation by a class III antiarrhythmic drug effect. Pacing Clin Electrophysiol 2003; 26: 314-7.

[382] Fujiki A, Tsuneda T, Sakabe M, et al. Maintenance of sinus rhythm and recovery of atrial mechanical function after cardioversion with bepridil or in combination with aprindine in long-lasting persistent atrial fibrillation. Circ J 2004; 68: 834-9.

[383] Miyaji K, Tada H, Fukushima Kusano K, et al. Efficacy and safety of the additional bepridil treatment in patients with atrial fibrillation refractory to class I antiarrhythmic drugs. Circ J 2007; 71: 1250-7.

[384] Imai S, Saito F, Takase H, et al. Use of bepridil in combination with Ic antiarrhythmic agent in converting persistent atrial fibrillation to sinus rhythm. Circ J 2008; 72: 709-15.

[385] Yoshiga Y, Shimizu A, Yamagata T, et al. Beta-blocker decreases the increase in QT dispersion and transmural dispersion of repolarization induced by bepridil. Circ J 2002; 66: 1024-8.

[386] Yasuda M, Nakazato Y, Sasaki A, et al. Clinical evaluation of adverse effects during bepridil administration for atrial fibrillation and flutter. Circ J 2006; 70: 662-6.

[387] Yamashita T, Ogawa S, Sato T, et al. Dose-response effects of bepridil in patients with persistent atrial fibrillation monitored with transtelephonic electrocardiograms: a multicenter, randomized, placebo-controlled, double-blind study (J-BAF Study). Circ J 2009; 73: 1020-7.

[388] Shiga T, Suzuki A, Naganuma M, Hosaka F, Shoda M, Hagiwara N. Clinical outcome in patients with paroxysmal or persistent atrial fibrillation receiving bepridil. Circ J 2011; 75: 1334-42.

[389] Takahara A, Sugiyama A, Dohmoto H, Yoshimoto R, Hashimoto K. Antiarrhythmic and cardiohemodynamic effects of a novel $\mathrm{Ca}(2+)$ channel blocker, AH-1058, assessed in canine arrhythmia models. Eur J Pharmacol 2000; 398: 107-12.

[390] Takahara A, Hirasawa A, Dohmoto H, et al. In vivo antiarrhythmic profile of AP-792 assessed in different canine arrhythmia models. Jpn J Pharmacol 2001; 87: 21-6. 